Universidade de São Paulo

Instituto de Física

\title{
Propagação de trincas em meios desordenados submetidos à fadiga induzida por carregamento cíclico
}

\author{
Maycon de Sousa Araújo \\ Orientador: Prof. Dr. André de Pinho Vieira
}

Tese de doutorado apresentada ao Instituto de Física para a obtenção do título de Doutor em Ciências.

Banca Examinadora:

Prof. Dr. André de Pinho Vieira (IFUSP)

Profa. Dra. Carmen Pimentel Cintra do Prado (IFUSP)

Prof. Dr. Masayuki Oka Hase (EACH-USP)

Prof. Dr. Roberto Fernandes Silva Andrade (UFBA)

Prof. Dr. Claudio Lucas Nunes de Oliveira (UFC) 
FICHA CATALOGRÁFICA

Preparada pelo Serviço de Biblioteca e Informação do Instituto de Física da Universidade de São Paulo

Araújo, Maycon de Sousa

Propagação de trincas em meios desordenados submetidos a fadiga induzida por carregamento cíclico. São Paulo, 2016.

Tese (Doutorado) - Universidade de São Paulo. Instituto de Física Depto. de Física Geral.

Orientador: Prof. Dr. André de Pinho Vieira

Área de Concentração: Física

Unitermos: 1. Sistemas desordenados; 2. Propagação de trincas;

3. Fadiga; 4. Regeneração de trincas.

USP/IF/SBI-062/2016 
À minha esposa, Francisca Maria Alves Silva Araújo. Ao meu filho, Davi Luiz Silva Araújo. In memoriam, Raimundo Pereira de Araújo. 
"Toda a nossa ciência, comparada com a realidade, é primitiva e infantil, e, no entanto, é a coisa mais preciosa que temos". Albert Einstein 


\section{Agradecimentos}

A realização deste trabalho foi conseguida com a generosidade, companheirismo e boa vontade de muitos. Agradeço a todos que contribuíram para sua concretização, em especial:

Ao professor André Vieira pela orientação deste trabalho, ao qual tenho profundo respeito e admiração.

Aos professores do Departamento de Física Geral pela liderança exercida em todas as atividades do Grupo de Mecânica Estatística deste departamento.

Aos colegas de "corredor" Antônio Mário Ramos, Carlos Mário Solano, Diego Oliveira, Yuri Baranov, Eduardo Nascimento, Helder Casa Grande, Oscar Barbosa e Carolina Ferrer pelas sugestões, discussões e momentos de descontração.

Aos estudantes André Timpanaro, Jonatas César, David Rodrigues e Rone Galvão pelas importantes colaborações no desenvolvimento numérico do trabalho.

Ao Departamento de Física Geral pelas condições de trabalho.

À Fundação de Amparo à Pesquisa do Estado de São Paulo e a Universidade de São Paulo pelo apoio financeiro a este trabalho.

À minha mãe, Maria Amélia Araújo, e ao meu irmão, Benedito Silvestre Neto, pelo apoio, compreensão e incentivo em todos os momentos.

Ao meu pai, Raimundo Araújo, in memoriam.

À minha esposa, Francisca Maria Araújo, e ao meu filho, Davi Luiz Araújo, pelos momentos de ternura, sacrifícios e superação.

Aos meus amigos, em particular, a Glauco Campelo e à sra. Maria Helena aos quais tenho muito carinho e consideração. 


\section{Resumo}

Neste trabalho desenvolveremos um modelo estatístico em uma escala micrométrica de interações entre as componentes do sistema que pretende descrever a propagação de trincas em materiais submetidos a tensões cíclicas. Apesar de sua extrema simplicidade, este modelo é capaz de reproduzir um resultado experimental bastante difundido entre engenheiros e especialistas, conhecido como lei de Paris, cujo enunciado estabelece que a taxa de crescimento de uma trinca sob carregamento cíclico é proporcional a uma potência da variação em seu correspondente fator de intensidade de tensões sendo largamente utilizada em aplicações práticas. Estamos particularmente interessados em estudar a introdução de desordem em determinados parâmetros associados ao material investigando as modificações impostas por este tipo de abordagem ao comportamento estatístico do modelo. Nossos principais resultados serão obtidos numericamente a partir de uma aproximação do tipo campo efetivo que ignora a correlação existente entre as diversas trincas que podem se formar ao longo do sistema durante o processo. Simulações numéricas do modelo serão igualmente consideradas ao analisarmos situações mais gerais do processo de propagação em que efeitos associados à regeneração de trincas podem desempenhar um importante papel na descrição do comportamento mecânico de um material.

Palavras-chave: propagação de trincas, fadiga, desordem, regeneração de trincas, modelos estatísticos simples. 


\section{Abstract}

In this work we consider a statistical model in a micrometric scale of interactions between the components of the system which intends to describe the failure of materials subjected to cyclic-load fatigue. Although quite simple, this model is able to reproduce an important experimental result widespread among engineers and experts, known as Paris law, which states that the growth rate of a crack at subcritical load is proportional to a power of the change in its stress-intensity factor and it is largely used in engineering practice. We are particularly interested to study the introduction of disorder in some parameters of the material investigating the modifications caused by this kind of approach in the statistical properties of the model. Our main results will be obtained numerically assuming an effective-field like approximation which neglects the correlation between the different cracks emerging throughout the system during the breaking process. Numerical simulations of the model are also performed in order to describe more general situations of propagation where the effects of crack self-healing can play an important role in the material strength.

Keywords: crack growth, fatigue failure, disorder, crack self-healing, simple statistical models. 


\section{Zusammenfassung}

In dieser Arbeit haben wir ein Statistisches Modell in einem mikrometrischen Skala von Wechselwirkungen zwischen den Systemkomponenten was die Rissenausbreitung in Materialien unter zyklischen Belastungen beschreibt. Obwohl ganz einfach, diese Modell kann eine allgemein bekannt experimentell Ergebnis von Ingenieuren und Experten zu reproduzieren, das Paris Gesetz hieß, die besagt dass die Wachstumsrate eines Risses unter zyklischer Belastung ist proportional zu einer Änderung in den Potenz seiner Spannungsintensitätsfaktor und ist in der Praxis weit verbreitet. Wir wollen Unordnung in wenige Systemparameter einführen und so die Änderungen durch diese Art der Vorgehensweise in den statistischen Eigenschaften des Modells untersuchen. Unsere wichtigsten Ergebnisse werden numerisch erhalten durch eine effektive Felder Näherung was die Korrelationen zwischen den Rissen während des Bruchprozesses ignoriert. Numerische Simulationen des Modells werden auch in Betracht gezogen, für allgemeinere Situationen des Ausbreitungsprozess zu analysieren, in denen die Auswirkungen der Riss Selbstheilung kann eine wichtige Rolle in des mechanischen Verhaltens eines Materials spielen.

Schlüsselwörter: Rissausbreitung, Materialermüdung, Unordnung, Riss Selbstheilung, einfache statistische Modelle. 


\section{Sumário}

$\begin{array}{lr}\text { Agradecimentos } & 5\end{array}$

$\begin{array}{lr}\text { Resumo } & 6\end{array}$

$\begin{array}{ll}\text { Abstract } & 7\end{array}$

$\begin{array}{lr}\text { Zusammenfassung } & 8\end{array}$

$\begin{array}{ll}\text { Prólogo } & 12\end{array}$

1 Introdução $\quad 14$

1.1 Processos de propagação de trincas . . . . . . . . . . . . . . . . . . . . . 14

1.2 Mecânica da fratura de materiais . . . . . . . . . . . . . . . . . 15

1.2.1 A lei de Hooke . . . . . . . . . . . . . . . . . . . . 15

1.2.2 Fragilidade $\times$ Ductibilidade . . . . . . . . . . . . . . . 15

1.2 .3 O critério de Griffith . . . . . . . . . . . . . . . . . . 16

1.2.4 O fator de intensidade de tensões . . . . . . . . . . . . . . . . . . . 18

1.2 .5 Carga periódica . . . . . . . . . . . . . . . 20

1.2.6 Fadiga . . . . . . . . . . . . . . . . . . . 21

1.2.7 Medição experimental do dano acumulado por fadiga . . . . . . . . 22

1.2 .8 A regra de Miner . . . . . . . . . . . . . . . . . . . . . . . . . 22

1.2.9 A lei de Paris . . . . . . . . . . . . . . . . . . . . . 23

1.3 Escopo geral da tese . . . . . . . . . . . . . . . . . . 24

2 Propagação subcrítica de trincas sob regime de fadiga cíclica 26

2.1 Apresentando o modelo . . . . . . . . . . . . . . . . . . . 26

2.2 Formalizando o cálculo do expoente de Paris . . . . . . . . . . . . . . . . 30

2.3 Extrapolação dos resultados numéricos ao limite termodinâmico . . . . . . 34

2.4 Cálculo do expoente de Paris no limite $\gamma \rightarrow 0$. . . . . . . . . . . . . 38

2.5 Introduzindo modificações na lei de incremento de danos . . . . . . . . . . . 39

2.5.1 Cálculo do expoente de Paris no limite $\gamma \rightarrow 0$. . . . . . . . . . 41

2.6 Generalizando as alterações introduzidas na lei de incremento de dano . . . 42

2.7 Confronto entre os resultados obtidos e a prática experimental . . . . . . 45

2.7.1 Cota inferior para o expoente de Paris $(m \geq 2) \ldots . . . . . .445$

2.7.2 Comportamento típico do fator de proporcionalidade de Paris . . . 45

2.7.3 Justificando a ocorrência de leis de potência nas regras do modelo . 46 
2.7.4 Robustez dos resultados quanto a alterações nas regras do modelo . 47

2.7.5 Comparações com o modelo de feixe de fibras . . . . . . . . . . . . 47

2.7.6 Medidas da energia envolvida na formação de trincas . . . . . . . . 47

3 Cálculo do expoente de Paris na presença de desordem $\quad 50$

3.1 Apresentando o modelo . . . . . . . . . . . . . . . . . . . 50

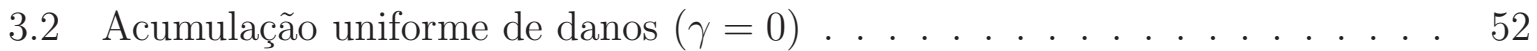

3.2.1 Esboçando o cálculo do expoente de Paris . . . . . . . . . . . . 54

3.2.2 Distribuição de probabilidades para o avanço da trinca principal . . 56

3.2.3 Determinação das distribuições marginais de avalanches $P_{L}\left(\Delta a \mid a, a_{0}\right)$

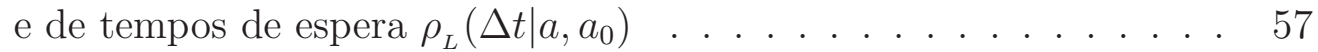

3.2.4 Formalizando o cálculo do expoente de Paris . . . . . . . . . . . . 59

3.3 Expoente de incremento de dano não nulo $(\gamma \neq 0)$. . . . . . . . . . . . . 61

3.3.1 Condições mínimas para a unicidade da trinca inicial do sistema . . 61

3.3.2 A hipótese da aproximação de trincas independentes (ATI) . . . . . 63

$\begin{array}{ll}\text { Interlúdio } & 70\end{array}$

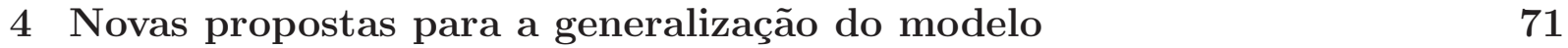

4.1 Introduzindo efeitos de regeneração de trincas nas regras do modelo . . . . 71

4.1.1 Apresentando o modelo . . . . . . . . . . . . . . . . 71

4.1.2 Cota inferior para o tempo característico de regeneração . . . . . . 73

4.1.3 Comportamento do expoente de Paris . . . . . . . . . . . . . . 74

4.2 Sistema de osciladores massa-mola como meio elástico de propagação da

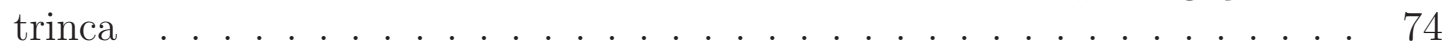

4.2.1 Apresentando o modelo. . . . . . . . . . . . . . . . 75

4.2 .2 Soluções das equações de movimento . . . . . . . . . . . . . . . . . . . . . . . . 77

4.2.3 Cálculo do expoente de Paris . . . . . . . . . . . . . . . . 81

$\begin{array}{llr}5 & \text { Conclusões } & 88\end{array}$

$\begin{array}{ll}\text { A Teoria elástica linear } & 90\end{array}$

A.1 O tensor de deformações . . . . . . . . . . . . . . . . . . . . . . . . . . . . 90

A.2 O tensor das tensões . . . . . . . . . . . . . . . . . . . . . 91

A.3 Densidade de energia livre associada a um material deformado . . . . . . . 92

A.4 As constantes elásticas . . . . . . . . . . . . . . . . . . . 93

A.4.1 Cálculo do módulo volumar de um sólido isotrópico . . . . . . . . . 94

A.4.2 Relação entre os módulos de elasticidade e as constantes de Lamé associadas a um material isotrópico . . . . . . . . . . . . . . . . 95

A.5 O tensor de rigidez $\lambda_{i j k l}$ associado a um material isotrópico . . . . . . . . . 96

A.6 Descrição do movimento no interior de um sólido isotrópico . . . . . . . . . 97

A.7 Equação de Laplace . . . . . . . . . . . . . . . . . . . . . . . . . . . . 98

$\begin{array}{ll}\text { B O modelo da rede de fusíveis } & 99\end{array}$

B.1 Equações de Maxwell aplicadas a um condutor ôhmico . . . . . . . . . . . 99

B.2 Analogia elétrico-mecânica para o modelo de propagação de trincas . . . . 101 
Referências Bibliográficas 


\section{Prólogo}

A física da matéria condensada é o ramo da física que estuda e sistematiza as propriedades macroscópicas da matéria, preocupando-se mais precisamente com uma de suas manifestações, denominada "fase condensada", que ocorre sempre quando o número de constituintes de um sistema é comparável ao número de Avogadro $\left(N_{A} \approx 10^{23}\right)$, fazendo com que as interações compartilhadas entre os mesmos fiquem cada vez mais fortes quando comparadas à interação elétron-próton no átomo de hidrogênio (forças eletrostáticas da ordem de $\left.F_{e} \approx 10^{-7} N\right)$ [1]. O exemplo clássico mais familiar de uma fase condensada é o estado sólido da matéria que se origina das interações eletromagnéticas compartilhadas

entre os átomos pertencentes a uma rede cristalina. É provavelmente a área de pesquisa mais desenvolvida da física contemporânea e tal sucesso deve-se, sobretudo, ao fato de estudar sistemas de grande interesse na indústria e tecnologias emergentes como polímeros, coloides, emulsões, membranas e cristais líquidos. Neste contexto, estruturas fragmentadas são de fundamental importância pois estão relacionadas invariavelmente a setores industriais de influência direta em nosso cotidiano [2].

Nos últimos anos, aspectos teóricos e experimentais associados à falha de materiais têm sido tema de crescente interesse em muitas áreas de estudo. Um exame detalhado da literatura nas últimas décadas revela uma quantidade razoável de pesquisa abordando o crescimento de trincas ao longo de sistemas em duas e três dimensões com uma presença marcante de leis de potência entre as grandezas envolvidas revelando claras associações a consagrados conceitos da física dos sistemas complexos como universalidades e fractalidades observados em fenômenos críticos [3].

Na realidade, o estudo da resistência dos materiais é um problema muito antigo, remontando aos primórdios da ciência moderna, e constitui a base fundamental de importantes ramos da engenharia e da física dos materiais. Diversas questões de natureza teórica, experimental e aplicada destes problemas têm atraído a atenção de cientistas em todas as áreas do conhecimento ao longo dos séculos e estão ligadas a fenômenos tradicionalmente encontrados na dinâmica de estruturas geológicas ou de subprodutos resultantes da colisão entre objetos sólidos [4]. Frequentemente, este tipo de problema é estudado numericamente através da simulação de trincas propagando-se em meios bidimensionais submetidos às mais variadas condições de carregamento e geometrias da amostra com muitos desdobramentos permanecendo ainda em aberto nesta área de pesquisa $[5,6]$.

Em geral, atribuem-se as causas da ruptura catastrófica de um material ao crescimento e propagação espontânea de trincas que são induzidas em seu interior pela aplicação sucessiva de tensões por um agente externo. Se considerarmos a aplicação de tensões cíclicas ao longo de uma amostra, o processo de formação das trincas é muitas vezes caracterizado pela acumulação progressiva de fadiga como consequência da repetitividade imposta 
pelo carregamento ao sistema. Uma alternativa para o estudo sistemático dos fatores que interferem neste processo particular de crescimento da trinca seria a aplicação da teoria elástica linear na descrição do movimento das componentes que constituem o material, apesar das grandes dificuldades introduzidas por efeitos não lineares e irreversibilidades observadas mesmo em amostras com geometrias muito simples como a do plano.

Para termos ideia dos demais complicadores que podem surgir na descrição teórica destes sistemas, consideremos a fenomenologia subjacente ao simples ato de rasgarmos uma folha de papel, por exemplo. Neste caso podemos perceber mais claramente uma série de situações extremamente interessantes: o processo é desordenado, irreversível, a entropia é elevada e o custo de energia envolvido em sua realização é relativamente baixo. Por outro lado, se tentarmos rasgar uma grande quantidade de folhas de papel simultaneamente, como em uma disposição em forma de resma, já não dispomos da mesma facilidade e baixo custo energético observados anteriormente [7], alterando radicalmente o cenário de sua descrição.

Nesta tese estamos interessados em investigar efeitos de desordem naturalmente presentes na propagação de trincas em meios elásticos submetidos à fadiga induzida por tensões cíclicas externas. Tomando por base a recente trabalho de André Vieira (orientador desta tese) e seus colaboradores [6] partiremos de uma abordagem micrométrica com o objetivo de estabelecer uma conexão objetiva entre uma regra de acumulação de danos assumida ad hoc para o material e um resultado experimental bastante conhecido para a velocidade de propagação de trincas crescendo em seu interior, conhecido como lei de Paris. As evidências experimentais que motivam o estabelecimento da regra de acumulação de danos escolhida consistem na observação da invariância de escala das distribuições de defeitos associados à acumulação de fadiga nas imediações da trinca.

Desta forma, pretendemos estabelecer conexões entre as técnicas normalmente empregadas pela física da matéria condensada e o estudo da resistência de materiais a partir deste modelo, ao estudar a lei de Paris como uma consequência de hipóteses estatísticas muito simples acerca das interações compartilhadas entre as componentes do material em uma escala mesoscópica. A introdução de desordem nos parâmetros que caracterizam a interação entre as componentes do sistema implicará maior realismo ao modelo, apesar de ameaçar seriamente qualquer descrição analítica razoável que possa ser desenvolvida, salvo situações limite particularmente simples. A abordagem utilizada em nosso trabalho nestas circunstâncias será predominantemente numérica, combinada com cálculos analíticos para casos bastante específicos que podemos atribuir aos parâmetros que controlam a acumulação de fadiga ao longo do sistema. Finalmente, o confronto entre nossos resultados e uma razoável quantidade de resultados experimentais associados a materiais heterogêneos será estabelecido, apresentando boa concordância qualitativa na comparação e fornecendo evidências importantes para a validação de toda a teoria proposta. 


\section{Capítulo 1}

\section{Introdução}

Neste capítulo pretendemos estabelecer os princípios básicos da teoria subjacente aos processos de propagação de trincas em materiais submetidos a tensões cíclicas, buscando sempre enfatizar as ideias e interpretações físicas dos conceitos envolvidos que sejam mais relevantes aos desenvolvimentos posteriores desta tese. Dentre os principais temas abordados, destacamos a definição de um processo subcrítico para o crescimento de trincas, a definição de fadiga cíclica e a apresentação da lei fenomenológica de Paris com base em trabalhos pioneiros de cientistas notáveis nesta área de pesquisa, como A. A. Griffith, P. C. Paris, F. Erdogan e M. A. Miner.

\subsection{Processos de propagação de trincas}

Processos de ruptura e fragmentação de sólidos correspondem a uma classe de fenômenos físicos praticamente onipresentes na Natureza, que desempenham um papel fundamental nas mais variadas situações de interesse prático e tecnológico [4,8,9]. São fenômenos altamente não triviais da física clássica que têm despertado bastante interesse da comunidade científica ao longo da História [10-12], da mesma forma que outros problemas mais tradicionais como a dinâmica de fluidos e o empacotamento de corpos rígidos [7,13]. Para termos uma ideia da importância destes fenômenos, estima-se que só os prejuízos causados por desastres em setores como a construção civil brasileira são da ordem de bilhões de reais por ano (5\% do PIB nacional), sem mencionarmos o custo incomensurável de muitas vidas e incapacitações envolvidas nos acidentes [14,15].

Apesar dos inúmeros avanços obtidos pela física dos materiais e pelas engenharias ao longo das últimas décadas, a descrição das causas associadas à falha de materiais ainda representa um grande desafio teórico para cientistas e especialistas [16]. Entretanto, muitos fatos estão bem estabelecidos na literatura especializada, como, por exemplo, o papel desempenhado por trincas no interior da amostra, que podem amplificar o efeito das tensões externas aplicadas ao ponto de induzir rupturas catastróficas mesmo quando a intensidade das tensões envolvidas é muito inferior àquela estimadas para romper as ligações atômicas em uma rede cristalina [4,16,17].

Argumentos de escala desenvolvidos por Griffith [18] mostram que o crescimento de uma trinca específica no interior da amostra pode ser estimulado por um balanço energético favorável a ocorrer de forma espontânea uma vez alcançado um determinado valor crítico 
para o seu comprimento, provocando até mesmo a ruptura catastrófica do material (maiores detalhes na seção 1.2.3). Abaixo deste comprimento crítico, outros tipos de mecanismos em escalas de tempo relativamente mais lentas para sua ocorrência devem controlar o processo de propagação, definindo as circunstâncias relacionadas a um regime subcrítico para o crescimento da trinca [4]. Dentre estes mecanismos, estamos particularmente interessados em estudar a ocorrência de fadiga provocada pela acumulação progressiva de danos ao submetermos o material analisado a tensões cíclicas $[4,16]$.

Nas próximas seções pretendemos formalizar as bases teóricas que fundamentam o estudo da ruptura de materiais induzidas pela acumulação de fadiga no interior do material. A aplicação da teoria elástica linear em meios materiais submetidos a uma carga periódica permitirá uma descrição satisfatória do processo de crescimento de trincas no interior do material, que contribuem de forma significativa no processo de acumulação de fadiga, culminando na eventual ruptura catastrófica do sistema.

\subsection{Mecânica da fratura de materiais}

Nesta seção apresentaremos uma breve discussão a respeito dos principais aspectos da teoria elástica linear que podem ser aplicados na descrição do processo de propagação de trincas, destacando os temas de maior interesse a serem abordados ao longo de toda a tese (maiores detalhes no apêndice A).

\subsubsection{A lei de Hooke}

Após uma grande quantidade de evidências experimentais, o cientista inglês Robert Hooke, em 1678, constatou que uma ampla variedade de materiais, quando submetidos à ação de tensões axiais sofre deformações que alteram suas dimensões iniciais, bem como sua área de seção transversal, de acordo com:

$$
\sigma=Y \epsilon
$$

onde $\sigma=F / A$ é a tensão submetida à amostra, definida como a razão entra a força aplicada e a área da superfície que recebe a aplicação; $\epsilon=\Delta L / L$ é a deformação sofrida pelo material, definida como a variação percentual no comprimento da amostra e $Y$ é uma constante de proporcionalidade denominada módulo de elasticidade ou módulo de Young do material (ver figura 1.1).

As deformações transversais também são descritas por uma relação de proporcionalidade semelhante, que define a constante denominada razão de Poisson, $\nu$, de acordo com:

$$
\epsilon_{t}=-\nu \epsilon
$$

onde $\epsilon_{t}$ é a deformação na direção transversal de aplicação das forças.

\subsubsection{Fragilidade $\times$ Ductibilidade}

Entendemos por ductibilidade a propriedade apresentada por diversos materiais submetidos a tensões externas (como, por exemplo, em ensaios de tração) de suportarem 


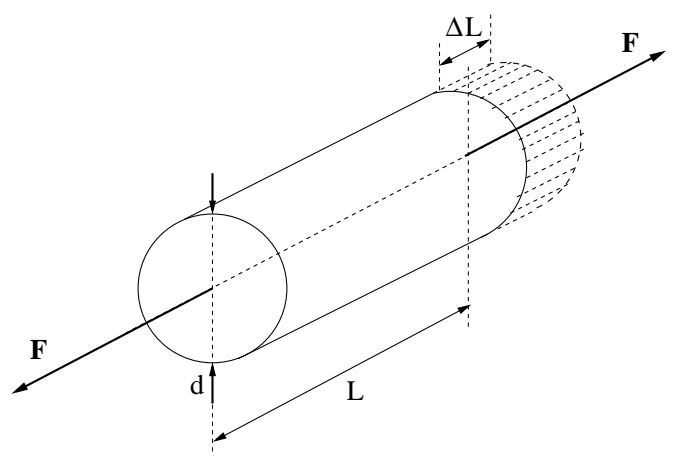

Figura 1.1: Representação típica de uma amostra de material elástico em um ensaio de tração: uma força axial $\mathbf{F}$ atua sobre a superfície de seção transversal de uma amostra com comprimento $L$, provocando uma variação de comprimento $\Delta L$ na direção de atuação das forças.

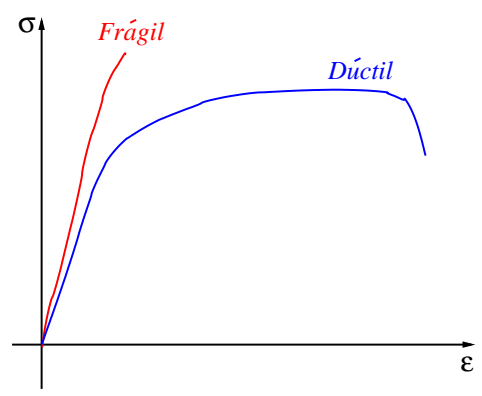

Figura 1.2: Curva característica diferenciando o comportamento típico em que os materiais submetidos a tensões externas podem ser classificados: materiais dúcteis (curva em azul) e materiais frágeis (em vermelho) [4].

deformações relativamente elevadas antes de sofrerem uma ruptura catastrófica [4]. Em oposição, podemos identificar uma outra classe de materiais que se contrapõem a esta propriedade, denominados materiais frágeis. Metais e ligas metálicas em geral são exemplos típicos de materiais que apresentam alta ductibilidade, enquanto que materiais como o vidro e a cerâmica apresentam características associadas a materiais frágeis [4].

A seguir, apresentamos na figura 1.2 curvas características tensão-deformação típicas associadas a estes diferentes tipos de materiais, enfatizando suas principais diferenças e peculiaridades.

\subsubsection{O critério de Griffith}

Nesta subseção apresentaremos uma estimativa capaz de determinar o tamanho típico que uma determinada trinca deve alcançar para que comece a se propagar espontaneamente no interior de um material, a partir de um argumento proposto por A. Griffith [18] semelhante à teoria de campo médio de Flory para polímeros [19].

Para isto, definiremos $U_{\text {tot }}$ como sendo a energia total de uma configuração associada a um meio elástico linear com uma única trinca cilíndrica circular cujo raio da base mede $a$ em seu interior (ver figura 1.3). Podemos caracterizá-la, essencialmente, através de dois tipos de interações que podem ocorrer ao longo do sistema, a saber [18-20]: 


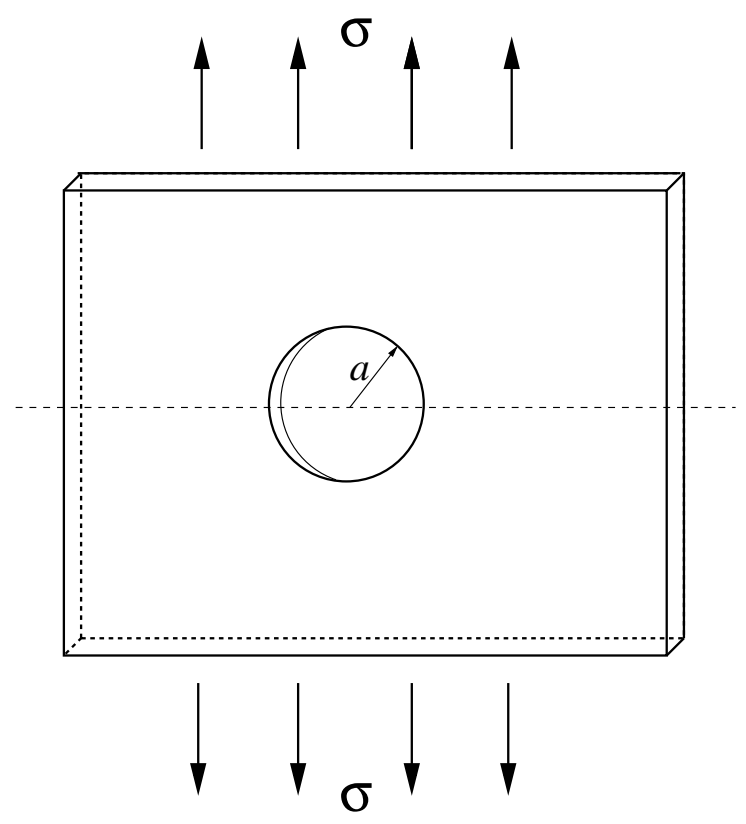

Figura 1.3: Configuração associada a uma amostra quase-bidimensional de um meio elástico linear com uma única fenda em formato cilíndrico e $a$ como medida do raio de sua base.

(i) Uma primeira contribuição assume uma forma parabólica em termos do raio a da seção transversal da superfície e pode ser calculada como segue:

$$
\begin{aligned}
& u=\int \sigma d \epsilon ; \\
& \sigma=-Y \epsilon ;
\end{aligned}
$$

$\therefore$

$$
\begin{gathered}
u=-\frac{\sigma^{2}}{2 Y} ; \\
\Delta U^{(e l)}=-\frac{\sigma^{2}}{2 Y}\left(\pi a^{2}\right) \Delta d ; \\
\frac{\Delta U^{(e l)}}{\Delta d} \equiv U_{e l}=-\frac{\pi \sigma^{2}}{2 Y} a^{2} ;
\end{gathered}
$$

onde $u$ é a densidade de energia do sistema ${ }^{1}, \sigma$ é a tensão externa aplicada por um agente externo, $Y$ é o módulo de Young do material, $\epsilon$ é a deformação imposta ao sistema, $\Delta d$ é a largura da amostra e $\Delta U^{(e l)}$ é a energia elástica utilizada na formação da trinca considerada. Este termo corresponde a uma distribuição de forças elásticas por unidade

\footnotetext{
${ }^{1}$ Também denominada tenacidade do material.
} 
de largura da amostra, dada por $F_{e l} / \Delta d=-\partial U_{e l} / \partial a=\left(\pi \sigma^{2} / Y\right) a$, onde as tensões no interior da amostra obedecem a lei de Hooke, $\sigma_{\text {int }}=-\sigma=Y \epsilon$ [eq. (1.4)].

(ii) Uma segunda contribuição está associada à energia absorvida pelo sistema no processo de formação da superfície envoltória da trinca, que assumiremos ser proporcional à sua correspondente área, de acordo com

$$
\Delta U^{(\text {sup })}=k(2 \pi a) \Delta d=2 \underbrace{(\pi k)}_{\equiv \gamma_{G}} a \Delta d ;
$$

$\therefore$

$$
\begin{gathered}
\Delta U^{(\text {sup })}=2 \gamma_{G} a \Delta d ; \\
\frac{\Delta U^{(\text {sup })}}{\Delta d} \equiv U_{\text {sup }}=2 \gamma_{G} a ;
\end{gathered}
$$

onde $\Delta U^{(\text {sup })}$ é a energia absorvida pela superfície da trinca em seu processo de formação, $\Delta d$ é a largura da amostra, $\operatorname{com} \gamma_{G}$ e $k$ sendo constantes características do material quanto à absorção superficial de energia pelo sistema. Este termo corresponde a uma força constante $F_{\text {sup }}=-\partial U_{\text {sup }} / \partial a=-2 \gamma_{G}$ supostamente envolvida na formação do par de superfícies semicilíndricas que constituirão a envoltória da trinca a ser gerada (ver figura 1.3) ${ }^{2}$.

Sendo assim, a condição de estabilidade do sistema permite-nos calcular um valor crítico para o comprimento da trinca como segue (ver figura 1.4):

$$
\begin{gathered}
U_{\text {tot }}=U_{e l}+U_{\text {sup }}=-\frac{\pi \sigma^{2}}{2 Y} a^{2}+2 \gamma_{G} a \\
\left.\frac{\partial U_{t o t}}{\partial a}\right|_{a=a_{c}}=-\frac{\pi \sigma_{c}^{2}}{Y} a_{c}+2 \gamma_{G}=0 ; \\
a \lesssim a_{c} \equiv \frac{2 \gamma_{G} Y}{\pi \sigma_{c}^{2}}
\end{gathered}
$$

determinando assim uma escala de tamanho $a_{c}$ para o comprimento da trinca que estaria associado a uma limitação natural em seu crescimento espontâneo. O crescimento não espontâneo do tamanho da trinca $\left(a<a_{c}\right)$, provocado por fatores como a acumulação de fadiga no interior do material, por exemplo, determina um balanço energético diferenciado ao sistema, denominado regime subcrítico de crescimento da trinca.

\subsubsection{O fator de intensidade de tensões}

Consideremos novamente a configuração associada a uma trinca no interior de uma amostra quase-bidimensional de material elástico de acordo com a figura 1.3. A solução das equações da mecânica para uma trinca em formato elíptico, no limite de raios de

\footnotetext{
${ }^{2}$ Este fato explicaria a conveniência de termos mantido explicitamente um fator 2 em (1.10).
} 


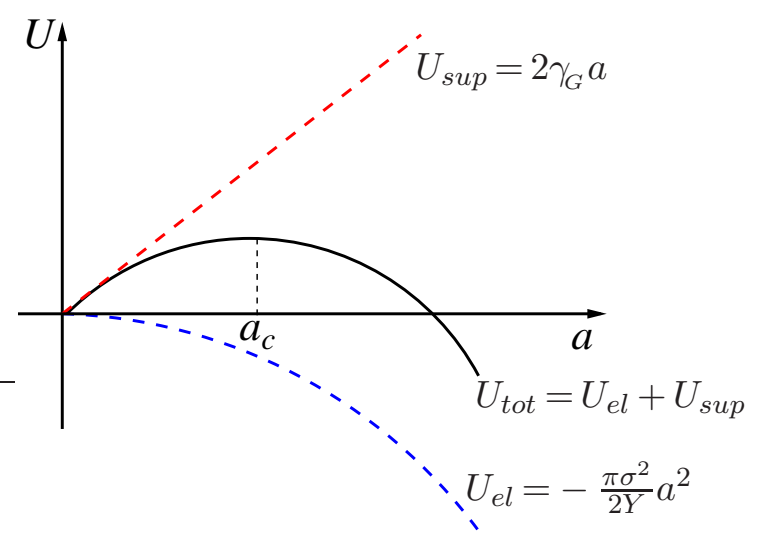

Figura 1.4: Diagrama de energias para o processo de propagação de trincas segundo os argumentos de escala associados ao critério de Griffith.

curvaturas muito pequenos para a ponta da trinca (trincas muito delgadas), permite-nos descrever a distribuição de tensões ao longo da linha mediatriz da amostra segundo uma expressão analítica dada por (ver apêndice A):

$$
\sigma(x ; a)=\frac{\sigma_{0}|x|}{\sqrt{x^{2}-a^{2}}}
$$

onde $\sigma_{0}$ é a tensão externa aplicada ao material e $x$ é a coordenada que localiza um ponto ao longo da linha mediatriz do sistema em relação a um referencial centrado no ponto médio da trinca (ver figura 1.5).

Nas proximidades da ponta da trinca, podemos escrever:

$$
\begin{gathered}
x_{p}=a+\Delta a ; \\
\Delta a \ll a ; \\
\sigma\left(x_{p} ; a\right)=\frac{\sigma_{0}(a+\Delta a)}{\sqrt{(a+\Delta a)^{2}-a^{2}}} ; \\
\sigma\left(x_{p} ; a\right) \sim \frac{\sigma_{0} a}{\sqrt{2 a \Delta a}} ; \\
\sigma(x ; a) \sim \frac{\overbrace{\sigma_{0} \sqrt{2 \pi a}}}{\sqrt{4 \pi(x-a)}}, \quad x \simeq a ;
\end{gathered}
$$

$\therefore$

$$
\sigma(x ; a) \sim \frac{K}{\sqrt{4 \pi(x-a)}}, \quad x \simeq a
$$




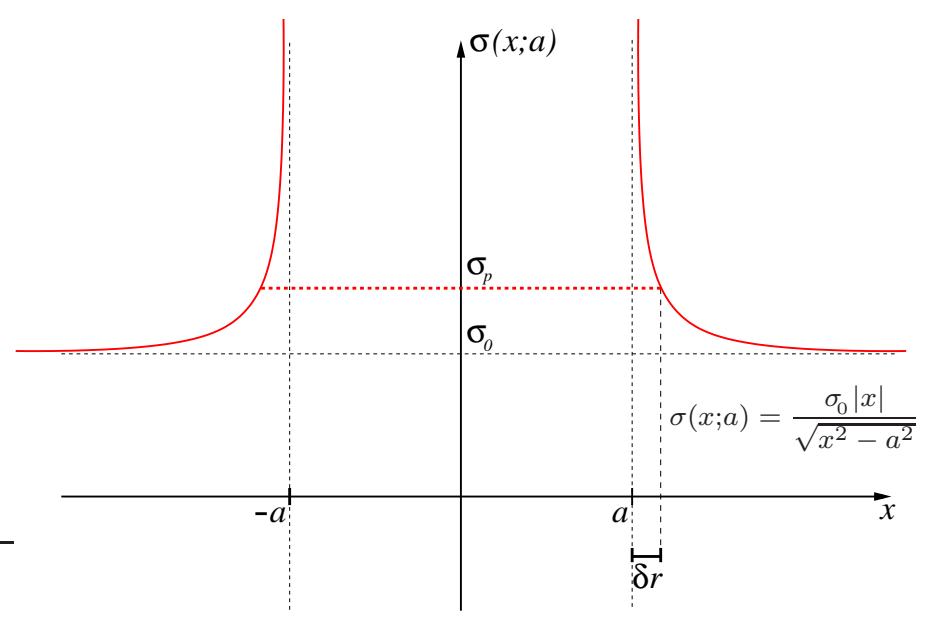

Figura 1.5: Esboço gráfico da distribuição de tensões $\sigma(x ; a)$ ao longo da linha de propagação do sistema. O valor de corte $\sigma_{p}$ representa a tensão máxima admissível que pode ser atribuída às vizinhanças da ponta da trinca dentro de um raio de alcance determinado pelo incremento no semicomprimento da trinca $\delta r$ a cada instante do processo.

onde $\Delta a$ representa um pequeno incremento na ponta da trinca e $K$ define o denominado fator de intensidade de tensão, que traduz matematicamente a amplificação de tensões proporcionada pela presença da trinca no interior do material.

A partir deste argumento, podemos calcular ainda o tamanho da zona plástica associada ao processo de crescimento da trinca, como segue:

$$
\sigma\left(x_{p} ; a\right) \equiv \sigma_{p} \sim \frac{K}{\sqrt{4 \pi r_{p}}} ;
$$

onde $\sigma_{p}$ seria a intensidade da tensão crítica que determina o limite de aplicabilidade da teoria elástica linear, e, portanto, associada a processos plásticos que podem ocorrer na ponta da trinca; e $r_{p}$ delimita o raio de alcance destes processos.

Sendo assim,

$$
r_{p} \sim \frac{K^{2}}{4 \pi \sigma_{p}^{2}}
$$

revelando que o raio da zona plástica é proporcional ao quadrado do fator de intensidade de tensão.

\subsubsection{Carga periódica}

Entendemos por carga periódica o tipo de solicitação que depende do tempo e corresponde à aplicação sucessiva de ciclos de tensões repetitivas num intervalo limitado pelos valores extremos $\sigma_{\max }$ e $\sigma_{\min }$. A figura 1.6 mostra uma modalidade de carga periódica particularmente importante, em que os valores extremos são simétricos em relação ao nível de tensão nula.

Dentre os principais parâmetros que caracterizam este tipo de carregamento que podemos submeter a uma amostra, destacamos: 


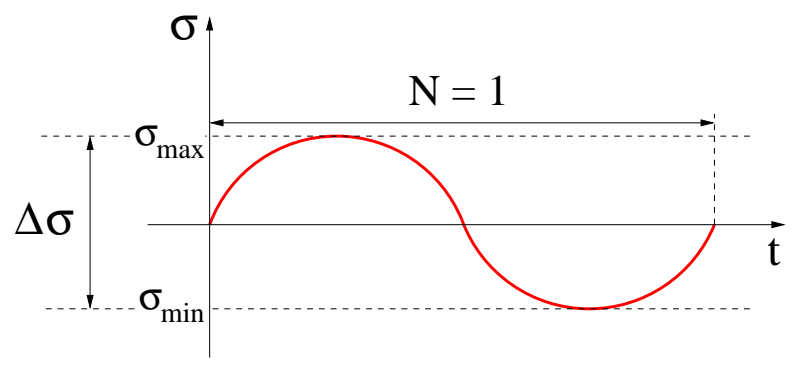

Figura 1.6: Comportamento típico da intensidade de tensões atuando em uma amostra sob a ação de uma carga periódica. A dependência temporal das tensões aplicadas é caracterizada principalmente pelos valores extremos da tensão aplicada, $\sigma_{\max }$ e $\sigma_{\min }$, e pelo número de ciclos de carregamento $N$. É importante destacar ainda que, do ponto de vista experimental, os valores instantâneos da tensão ou a frequência de carregamento cíclico particularmente imposta pelo agente externo não caracterizam de forma determinante o processo de crescimento de trincas, destacando-se, em contrapartida, apenas os valores médios associados a essas grandezas.

1. Tensão média - definida como a média entre as tensões máxima e mínima do ciclo, isto é,

$$
\sigma_{m}=\frac{\sigma_{\max }+\sigma_{\min }}{2}
$$

2. Amplitude de tensão - definida como a diferença entre a tensão máxima e a tensão média, ou seja,

$$
\Delta \sigma=\sigma_{\max }-\sigma_{m}
$$

Finalmente, podemos definir ainda a razão de tensões, $R$, como a razão entre as amplitudes de tensões mínima e máxima, ou seja,

$$
R=\frac{\sigma_{\min }}{\sigma_{\max }} .
$$

Em geral, convenciona-se que tensões de tração são positivas e tensões de compressão são negativas, de maneira que um ciclo simétrico de tensões alternadas seja caracterizado pelo valor $R=-1$.

\subsubsection{Fadiga}

Fadiga é um tipo de falha que pode ocorrer em materiais sob carga periódica ainda que as solicitações impostas sejam bastante inferiores ao limite de resistência do material. É consequência de esforços alternados, que produzem trincas, em geral na superfície, devido à concentração de tensões. Um exemplo típico da acumulação de fadiga em materiais ocorre quando um arame metálico é submetido a um esforço de flexão alternado, provocando o surgimento de pequenas trincas em lados opostos ao ponto de aplicação das forças e reduzindo gradativamente sua área de seção transversal. A ruptura ocorre quando esta área se torna suficientemente pequena para não mais resistir às solicitações aplicadas, causando a falência do material. 


\subsubsection{Medição experimental do dano acumulado por fadiga}

Do ponto de vista prático podemos medir o dano acumulado por fadiga em um material submetido a tensões cíclicas através da seguinte proposta:

$$
\begin{aligned}
& \frac{N}{N_{\infty}}=\frac{F}{F_{l i m}} ; \\
& F=\frac{N}{N_{\infty}} F_{l i m} ;
\end{aligned}
$$

onde $N$ é o número de ciclos de carregamento considerado, $N_{\infty}$ é o número de ciclos do carregamento que determina a ruptura catastrófica do material, $F$ é o dano acumulado e $F_{\text {lim }}$ é o correspondente limiar de dano atribuído ao sistema. Desta maneira estamos identificando a proporção de vida útil consumida ao longo do processo $N / N_{\infty}$ com o nível de fadiga acumulada pelo material ${ }^{3}$.

\subsubsection{A regra de Miner}

A proposta para a medição de fadiga acumulada discutida anteriormente pode ser generalizada de maneira a considerar situações mais realísticas dos carregamentos aplicados a um determinado material. Um carregamento arbitrário pode ser decomposto em uma série de sucessivos carregamentos cíclicos com amplitudes de tensão $\Delta \sigma_{0 j}$ e duração $N_{j}$ de maneira que o dano acumulado passaria a ser medido da seguinte forma:

$$
F=\sum_{j=1}^{k} F_{j}=F_{\text {lim }} \sum_{j=1}^{k} \frac{N_{j}}{N_{\infty}^{(j)}}
$$

onde $F_{j}$ é o dano acumulado em cada etapa do processo, $N_{\infty}^{(j)}$ é a vida útil associada a cada amplitude de tensão considerada e $k$ é o número de aplicações cíclicas necessárias para a reprodução do carregamento original (não necessariamente cíclico, a priori). Sendo assim, estamos admitindo que o princípio de superposição linear seja válido para os danos acumulados em cada etapa particular do processo.

No caso em que o número de aplicações cíclicas intermediárias $k \equiv n$ conduz a uma ruptura catastrófica devemos satisfazer ainda

$$
\begin{gathered}
F \equiv F_{\text {lim }} ; \\
\sum_{j=1}^{n} F_{j}=F_{\text {lim }} \sum_{j=1}^{n} \frac{N_{j}}{N_{\infty}^{(j)}}=F_{\text {lim }} ; \\
\sum_{j=1}^{n} \frac{N_{j}}{N_{\infty}^{(j)}}=1 .
\end{gathered}
$$

\footnotetext{
${ }^{3}$ Se atribuirmos um valor unitário para o limiar de dano $F_{\text {lim }} \equiv 1$ podemos reconhecer o dano acumulado por fadiga como uma grandeza adimensional.
} 
Esta última equação reproduz um resultado bastante difundido pela literatura especializada conhecido como regra de Miner. Sendo assim, a acumulação de danos no interior do material apresenta um comportamento linear ("aditividade") e possui importantes implicações na descrição de fenômenos associados à resistência dos materiais ao motivar o desenvolvimento de equações diferenciais simples capazes de descrever rupturas induzidas por uma carga periódica.

\subsubsection{A lei de Paris}

Em geral, o crescimento de trincas em regime subcrítico é muito bem descrito por um resultado de natureza empírica conhecido por lei de Paris [21], cujo enunciado estabelece que sua velocidade de propagação sob tensões cíclicas depende da amplitude de variação do seu correspondente fator de intensidade de tensão segundo uma lei de potência na forma

$$
\frac{d a}{d N}=C(\Delta K)^{m} \sim a^{m / 2}
$$

onde $a$ é o semicomprimento da trinca, $N$ é o número de ciclos de carregamento aplicados (em contraposição ao que seria o tempo de carregamento $t$ ), $d a / d N$ é a velocidade de propagação da trinca, $\Delta K=\Delta \sigma_{0} \sqrt{\pi a}$ é a amplitude de variação do fator de intensidade de

tensão, sendo $\Delta \sigma_{0}=\sigma_{0}^{(\max )}-\sigma_{0}^{(\min )}$ a amplitude de tensão externa aplicada, definida como a diferença entre seus correspondentes valores extremos, $m$ é um parâmetro que depende do material, conhecido por expoente de Paris, e $C$ é apenas um fator de proporcionalidade ${ }^{4}$. Uma ampla variedade de materiais obedece esta lei em um intervalo de validade que pode chegar a três ordens de magnitude (3 décadas) para as mais variadas geometrias e condições de carregamento impostas às amostras (ver figura 1.7) [4, 16, 23-27].

Esta lei encontra grande aplicação em engenharia, principalmente por permitir estimativas razoáveis do tempo de vida útil de materiais sob carregamento quando reescrita da seguinte forma (também conhecida como lei de Basquin) [4,28]:

$$
N_{\infty} \sim(\Delta \sigma)^{-m}
$$

onde $N_{\infty}$ é o número de ciclos necessários para induzir a ruptura catastrófica do material. Atualmente esta lei incorporou-se aos fundamentos da mecânica de materiais, sendo ensinada em cursos básicos de física e engenharia, refletindo seu grande impacto nestas áreas de pesquisa $[4,29]$.

É importante ressaltar que, apesar da simplicidade e consagrada aplicabilidade, uma compreensão sistemática da lei de Paris a partir de primeiros princípios permanece em aberto, sendo que existe apenas um número reduzido de trabalhos que se dedicam à questão de determinar uma relação explícita entre o expoente de Paris $m$ e parâmetros microscópicos associados ao material. Uma contribuição nesta direção foi oferecida por André Vieira e seus colaboradores [6] ao proporem um modelo estatístico capaz de reproduzir a lei de Paris e que fornece uma relação bastante simples entre seu expoente

\footnotetext{
${ }^{4}$ Existem exceções importantes desta lei que podem apresentar um comportamento exponencial lembrando fatores de Boltzman para a dependência entre a velocidade de propagação da trinca e a amplitude do fator de intensidade de tensão [22].
} 


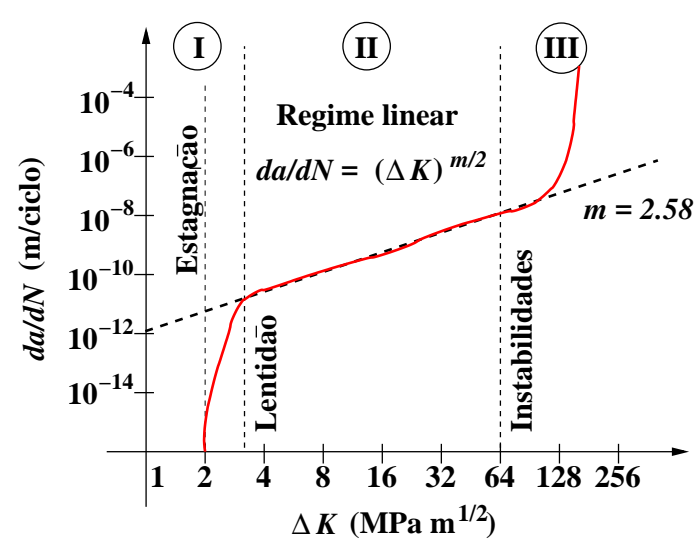

(a)

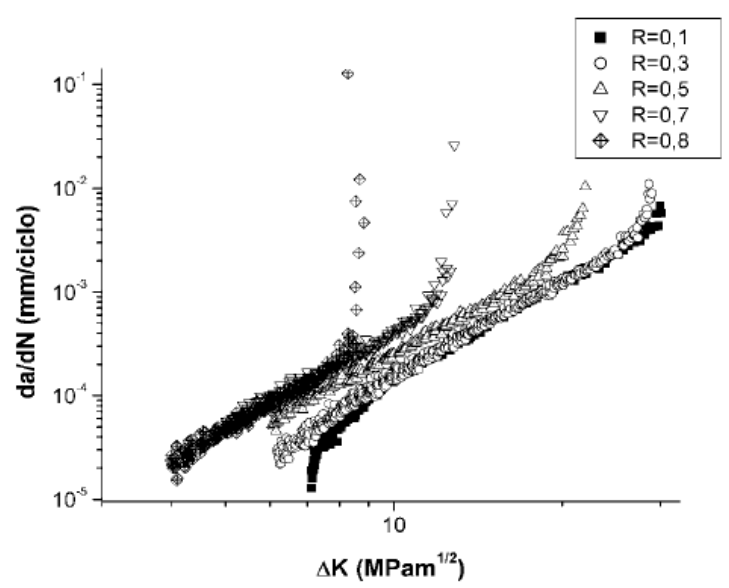

(b)

Figura 1.7: Ilustrando a lei de Paris: (a) comportamento típico da velocidade de propagação de uma trinca, $d a / d N$, em função da variação em seu respectivo fator de intensidade de tensão $\Delta K$ para materiais frágeis; (b) resultados experimentais associados à liga de alumínio SAE-AMS $7475 \mathrm{~T} 7351$ de uso frequente em engenharia aeronáutica $\left(R \equiv K_{\min } / K_{\max }, \bar{m} \approx 4\right)[30,31]$.

e parâmetros intrínsecos ao modelo em uma escala mesoscópica de interações entre as componentes do sistema considerado.

Ao longo desta tese pretendemos revisitar o modelo de Vieira e colaboradores, buscando fornecer maiores contribuições quanto a estas questões, além de esclarecer certos problemas encontrados na própria abordagem originalmente proposta. Dedicamos parte das seções seguintes presentes neste capítulo para analisarmos sob perspectivas reducionistas alguns dos resultados já estabelecidos por este modelo, de maneira a esclarecer e facilitar a compreensão de grande parte de suas propriedades em discussões futuras. Evidenciaremos ainda a capacidade do modelo em reproduzir a lei de Paris a partir de argumentações heurísticas de caráter muito geral, contextualizando-as com modelos alternativos encontrados na literatura especializada, de maneira a motivar novas abordagens a serem exploradas nos próximos capítulos.

\subsection{Escopo geral da tese}

Nossa tese está organizada em duas partes, a saber: primeiramente, nos preocupamos em retomar o modelo originalmente proposto por Vieira e colaboradores em [6], generalizando o cálculo do expoente de Paris para diferentes contextos do processo de acumulação de danos; enquanto que, em um segundo momento, estudamos a introdução de desordem do tipo quenched aos limiares de dano associados ao material [6,32], investigando as possíveis alterações que possam ocorrer nas propriedades estatísticas do sistema nesta nova abordagem.

Mais especificamente, no capítulo 2, pretendemos sistematizar uma série de modificações a serem introduzidas nas regras do modelo original, explorando os mais variados 
regimes de comportamento apresentados pelo sistema identificados através das alterações observadas no cálculo do expoente de Paris nos diferentes contextos considerados. Além disso, desenvolveremos novas contribuições para o cálculo do expoente de Paris em regimes específicos de comportamento do sistema onde o tratamento analítico encontrava-se incompleto mesmo em sua versão original. No capítulo 3, mostraremos ainda ser possível reproduzir a lei de Paris independentemente do grau de desordem introduzida, apesar dos novos regimes de comportamento apresentados pelo sistema sofrerem mudanças ainda mais radicais quando comparadas com as versões anteriormente consideradas.

No capítulo 4, pretendemos introduzir novas alterações nas regras do modelo original com o objetivo de contemplar situações mais complexas dos processos de propagação como, por exemplo, a descrição de materiais com a capacidade de se auto regenerarem à medida que a trinca cresce em seu interior. Finalmente, no capítulo 5, concluiremos nosso trabalho ao apresentarmos um panorama geral dos resultados obtidos juntamente com nossas considerações finais e eventuais perspectivas de continuidade das investigações. 


\section{Capítulo 2}

\section{Propagação subcrítica de trincas sob regime de fadiga cíclica}

Neste capítulo pretendemos rever as propriedades de um modelo unidimensional para a propagação de trincas proposto por Vieira e colaboradores em [6], desenvolvendo novas contribuições sempre que possível. Este modelo destaca-se principalmente pela capacidade de estabelecer uma conexão direta entre o dano acumulado sobre os elementos que constituem um determinado material em uma escala micrométrica de interações e a lei fenomenológica de Paris. As principais contribuições a serem incorporadas à abordagem desenvolvida anteriormente estão relacionadas ao cálculo do expoente de Paris para intervalos particulares do expoente de incremento de dano onde o tratamento analítico apresentava-se, até então, incompleto.

\subsection{Apresentando o modelo}

O modelo discutido por Vieira e colaboradores em [6] assume o seguinte conjunto de hipóteses:

1. Por simplicidade, considera-se inicialmente a existência de uma única trinca elíptica bastante delgada (excentricidade muito próxima da unidade) que se propaga na direção de seu eixo maior em uma amostra bidimensional de um material elástico linear submetido a tensões cíclicas. Desta forma, o crescimento da trinca ao longo da amostra é essencialmente unidimensional, tornando-se conveniente definir uma linha de propagação para o sistema como sendo a reta orientada $r$ que passa pelo centro da elipse e contém seu eixo maior (ver figura 2.1).

2. A linha de propagação do sistema é composta por "elementos de material"1 suficientemente pequenos compartilhando interações elásticas entre si e separados por uma distância $\delta r$ distribuída em intervalos igualmente espaçados com o objetivo de descrever os principais processos físicos que podem ocorrer no interior da amostra em uma escala micrométrica (ver figura 2.2).

\footnotetext{
${ }^{1}$ A abordagem consiste em determinar uma descrição em um nível intermediário de refinamento (coarse-grained) entre as escalas microscópica e macroscópica do sistema, sendo assim é mais apropriado nos referirmos às componentes do sistema por "elemento de material" em contraposição a "átomo" ou qualquer designação do gênero.
} 


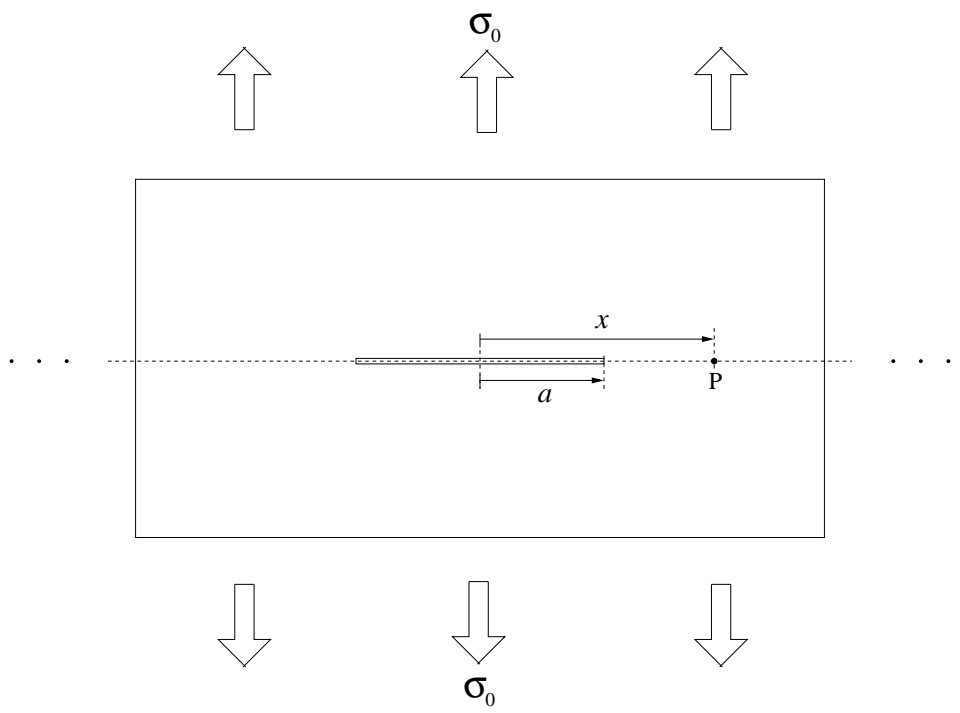

Figura 2.1: Representação esquemática de um aparato experimental tipicamente utilizado no estudo da resistência de materiais em que uma trinca elíptica quase unidimensional propaga-se ao longo da direção de seu eixo maior em uma amostra bidimensional de um material submetido a tensões cíclicas. Dentre os principais parâmetros associados ao sistema destacamos o semicomprimento da trinca, $a$, a tensão externa aplicada ao material, $\sigma_{0}$, e a coordenada $x$ que localiza um ponto $P$ ao longo do eixo de propagação em relação a um sistema de coordenadas centrado no ponto médio da trinca inicialmente presente na amostra.

3. Assumimos ainda que o tempo de relaxação do material é muito menor que o período típico de carregamento cíclico ao qual está submetido. Neste caso é aceitável considerarmos uma aproximação adiabática ${ }^{2}$ para o processo de propagação, ou seja, após o comprimento da trinca sofrer um incremento $\delta r$ o sistema entra em equilíbrio antes de ocorrer o próximo incremento (semelhantemente à aproximação de BornOppenheimer, por exemplo).

4. De acordo com a teoria elástica linear [17], a expressão analítica que determina a amplitude de tensão $\Delta \sigma(x ; a)$ ao longo da linha de propagação do sistema é dada por

$$
\Delta \sigma(x ; a)=\Delta \sigma_{0} \frac{|x|}{\sqrt{x^{2}-a^{2}}}
$$

onde $\Delta \sigma_{0}$ é a amplitude de tensão externa aplicada ao material, $x$ é a coordenada de um ponto em relação a um sistema de coordenadas na direção da linha de propagação do sistema, centrado no ponto médio de sua trinca inicial, e $a$ é o semicomprimento atual da trinca (ver figura 1.5).

5. Discretização da linha de propagação: o semicomprimento $a_{n}$ da trinca após a $n$ ésima iteração associada ao processo de propagação é dado por

$$
a_{n}=a_{0}+n \delta r
$$

\footnotetext{
${ }^{2}$ Aproximação quase-estática.
} 

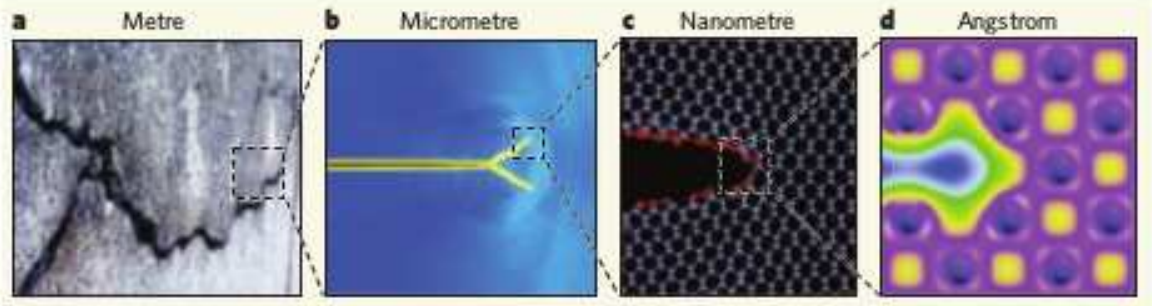

Figura 2.2: Diferentes escalas de interação associadas aos fenômenos de propagação de trincas: (a) escala macroscópica; (b) escala mesoscópica micrométrica; (c) escala nanométrica mostrando detalhes geométricos da ponta da trinca; (d) quebra de ligações químicas na escala atômica [33].

onde $a_{0}$ é o semicomprimento inicial da trinca e $\delta r$ é o incremento no semicomprimento da trinca a cada iteração.

6. Relação de recorrência - lei de acumulação de danos:

$$
F\left(x ; a_{n}\right)=F\left(x ; a_{n}-\delta r\right)+\delta F\left(x ; a_{n}\right),
$$

onde $F\left(x ; a_{n}\right)$ é o dano acumulado por fadiga sobre um elemento de material localizado pela coordenada $x$ em uma configuração do sistema cujo semicomprimento da trinca é dado por $a_{n}$ e $\delta F\left(x ; a_{n}\right)$ é o incremento de dano associado (ver figura 2.3).

7. Relação constitutiva - lei de incremento de dano:

$$
\delta F\left(x ; a_{n}\right)=f_{0} \delta t\left(a_{n}\right)\left[\Delta \sigma\left(x ; a_{n}\right)\right]^{\gamma},
$$

onde $\delta t\left(a_{n}\right)$ é o intervalo de tempo durante o qual a trinca permanece com semicomprimento $a_{n}, \Delta \sigma\left(x, a_{n}\right)$ é a amplitude de tensão à qual um elemento de material localizado em $x$ está submetido, $\gamma$ é o expoente de incremento de dano e $f_{0}$ é uma constante que determina a escala de tempo associada ao processo de propagação ${ }^{3}$.

É importante destacar que a dependência do tipo lei de potência para o incremento de dano pode ser justificada heuristicamente através de argumentos envolvendo conceitos de fractalidade e autossimilaridade observados em grande parte dos padrões espaciais de materiais fragmentados encontrados na literatura [34-51].

8. Condição de avanço da trinca:

$$
F\left(a_{n}+\delta r ; a_{n}-\delta r\right)+f_{0} \delta t\left(a_{n}\right)\left[\Delta \sigma\left(a_{n}+\delta r ; a_{n}\right)\right]^{\gamma}=F_{l i m},
$$

onde $F_{\text {lim }}$ é um determinado limiar de tensão atribuído a todas as componentes do sistema. Sendo assim, quando o dano acumulado nas vizinhanças da ponta da trinca

\footnotetext{
${ }^{3} \mathrm{~A}$ constante que determina a escala de tempo $f_{0}$ pode assumir diferentes unidades a depender do particular processo de propagação, como é típico das grandezas definidas a partir de uma lei de potência. Um exemplo semelhante que compartilha do mesmo inconveniente é a constante de equilíbrio químico para reações químicas reversíveis, por exemplo, cuja unidade depende dos coeficientes estequiométricos associados a um particular balanceamento da reação considerada.
} 


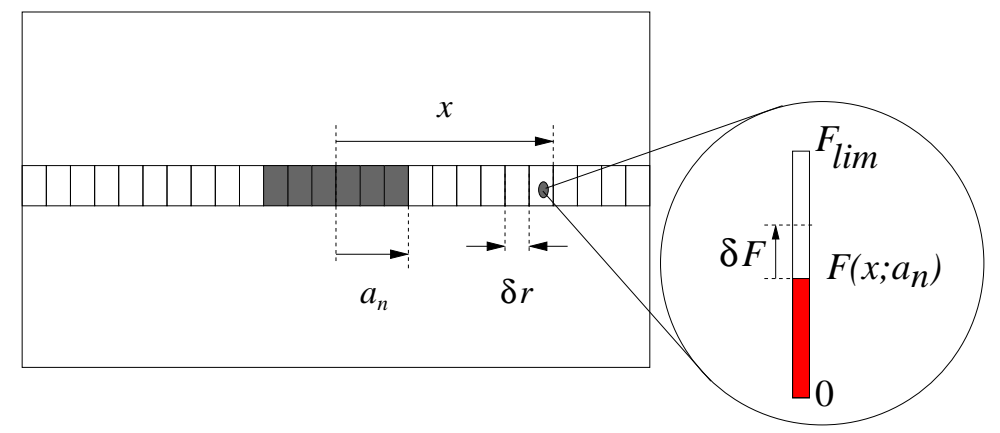

Figura 2.3: Representação esquemática do processo de acumulação de danos sobre uma das componentes do sistema localizada pela coordenada $x$ a partir do centro de uma trinca com semicomprimento $a_{n}$. O dano acumulado $F\left(x ; a_{n}\right)$ é representado por um nível hachurado em vermelho que pode sofrer um incremento $\delta F$ sendo limitado pelo limiar de tensão $F_{\text {lim }}$.

atingir seu valor máximo $F_{\text {lim }}$, o comprimento da trinca aumenta uma quantidade discreta $\delta r$ (ver figura 2.3).

Portanto, o intervalo de tempo $\delta t\left(a_{n}\right)$ em que o sistema permanece em uma determinada configuração é dado por

$$
\delta t\left(a_{n}\right)=\frac{F_{l i m}-F\left(a_{n}+\delta r ; a_{n}-\delta r\right)}{f_{0}\left[\Delta \sigma\left(a_{n}+\delta r ; a_{n}\right)\right]^{\gamma}} .
$$

Perceba que o aparecimento de singularidades nos cálculos é contornado supondo-se que o elemento de material localizado em $x=a_{n}$ experimenta amplitudes de tensões referentes à posição de seu sucessor imediato $x=a_{n}+\delta r$. Do ponto de vista físico, as divergências algébricas podem ser explicadas pelo fato da teoria elástica linear falhar nas vizinhanças imediatas da ponta da trinca onde as tensões locais tornam-se muito elevadas, caracterizando um regime não-linear de natureza plástica ${ }^{4}$.

9. Condição inicial do sistema:

$$
F\left(x ; a_{0}-\delta r\right)=0
$$

ou seja, partiremos sempre do princípio de que o dano inicial sobre todas as componentes do sistema seja nulo.

Devemos destacar ainda que as funções associadas ao dano acumulado $F\left(x ; a_{n}\right)$ e à amplitude de tensão $\Delta \sigma\left(x ; a_{n}\right)$ ao longo da linha de propagação da trinca são monotonicamente decrescentes em relação à variável de posição $x$, garantindo a unicidade da trinca inicial presente no sistema durante todo o seu processo de crescimento (ver figura 1.5).

\footnotetext{
${ }^{4}$ Uma explicação alternativa está associada ao fato de considerarmos um processo quase-unidimensional de propagação que resulta no estabelecimento de um limite de curvatura nula para a ponta da trinca. Fisicamente, singularidades algébricas deveriam se manifestar nas expressões por tratar-se de um limite incompatível com a prática experimental.
} 


\section{$2.2 \quad$ Formalizando o cálculo do expoente de Paris}

Nesta seção demonstraremos que é possível reproduzir a lei fenomenológica de Paris a partir das hipóteses associadas ao nosso modelo [6]. Pretendemos revisar o cálculo preliminar do expoente de Paris esboçado no capítulo anterior com o objetivo de formalizar os argumentos que garantem sua dependência com os demais parâmetros característicos do material, em particular, o expoente de incremento de dano.

A velocidade de propagação da trinca $d a_{n} / d t$ será definida a partir da regra que estabelece a condição de avanço da trinca $\left[\right.$ regra (8)] de acordo $\operatorname{com}^{5}$

$$
\frac{d a_{n}}{d t} \equiv \frac{\delta r}{\delta t\left(a_{n}\right)}=\frac{\delta r f_{0}\left[\Delta \sigma\left(a_{n}+\delta r ; a_{n}\right)\right]^{\gamma}}{F_{l i m}-F\left(a_{n}+\delta r ; a_{n}-\delta r\right)} \sim \frac{a_{n}^{\gamma / 2}}{1-F_{n} / F_{l i m}},
$$

onde o comportamento assintótico que determina o expoente de Paris também depende do dano acumulado nas vizinhanças da ponta da trinca, $F_{n} \equiv F\left(a_{n}+\delta r ; a_{n}-\delta r\right)$, em cada instante do processo.

A determinação do termo geral associado ao dano acumulado motiva-nos a definir uma sequência auxiliar $G_{n} \equiv F_{n} / F_{\text {lim }}$, convenientemente normalizada pelo limiar de danos do material, que pode ser calculada pelo uso recursivo das expressões eq. (2.4) e eq. (2.6) [regras (7) e (8)] em cada instante do processo, como passaremos a detalhar a seguir:

(A) SEMICOMPRIMENTO $a_{0}$ :

1. Condição inicial:

$$
F\left(x ; a_{0}-\delta r\right)=0
$$

2. Cálculo do tempo decorrido $\delta t\left(a_{0}\right)$ :

$$
\delta t\left(a_{0}\right)=\frac{F_{l i m}}{f_{0}\left[\Delta \sigma\left(a_{0}+\delta r ; a_{0}\right)\right]^{\gamma}} .
$$

3. Cálculo do dano acumulado:

$$
F\left(x ; a_{0}\right)=F_{\lim }\left[\frac{\Delta \sigma\left(x ; a_{0}\right)}{\Delta \sigma\left(a_{0}+\delta r ; a_{0}\right)}\right]^{\gamma} .
$$

Portanto, o dano acumulado na nova ponta da trinca neste instante é dado por

$$
\begin{gathered}
F_{1} \equiv F\left(a_{0}+2 \delta r ; a_{0}\right)=F_{l i m}\left[\frac{\Delta \sigma\left(a_{0}+2 \delta r ; a_{0}\right)}{\Delta \sigma\left(a_{0}+\delta r ; a_{0}\right)}\right]^{\gamma} \\
G_{1} \equiv \frac{F_{1}}{F_{l i m}}=\left[\frac{\Delta \sigma\left(a_{0}+2 \delta r ; a_{0}\right)}{\Delta \sigma\left(a_{0}+\delta r ; a_{0}\right)}\right]^{\gamma}
\end{gathered}
$$

\footnotetext{
${ }^{5}$ Perceba que os incrementos no comprimento da ponta da trinca a cada instante devem ser considerados constantes e iguais a $\delta r$, como sugere a regra de discretização da linha de propagação imposta pelo modelo [regra (5)].
} 
(B) SEMICOMPRIMENTO $a_{0}+\delta r$ :

1. Cálculo do tempo decorrido $\delta t\left(a_{0}+\delta r\right)$ :

$$
\delta t\left(a_{0}+\delta r\right)=\frac{F_{\text {lim }}-F_{l i m} G_{1}}{f_{0}\left[\Delta \sigma\left(a_{0}+2 \delta r ; a_{0}+\delta r\right)\right]^{\gamma}} .
$$

2. Cálculo do dano acumulado:

$$
F\left(x ; a_{0}+\delta r\right)=F_{\text {lim }}\left[\frac{\Delta \sigma\left(x ; a_{0}\right)}{\Delta \sigma\left(a_{0}+\delta r ; a_{0}\right)}\right]^{\gamma}+F_{\text {lim }}\left(1-G_{1}\right)\left[\frac{\Delta \sigma\left(x ; a_{0}+\delta r\right)}{\Delta \sigma\left(a_{0}+2 \delta r ; a_{0}+\delta r\right)}\right]^{\gamma} .
$$

E o dano acumulado na nova ponta da trinca neste instante é dado por

$$
\begin{gathered}
F_{2} \equiv F\left(a_{0}+3 \delta r ; a_{0}+\delta r\right)= \\
=F_{\text {lim }}\left[\frac{\Delta \sigma\left(a_{0}+3 \delta r ; a_{0}\right)}{\Delta \sigma\left(a_{0}+\delta r ; a_{0}\right)}\right]^{\gamma}+F_{\text {lim }}\left(1-G_{1}\right)\left[\frac{\Delta \sigma\left(a_{0}+3 \delta r ; a_{0}+\delta r\right)}{\Delta \sigma\left(a_{0}+2 \delta r ; a_{0}+\delta r\right)}\right]^{\gamma} ; \\
G_{2}=\left[\frac{\Delta \sigma\left(a_{0}+3 \delta r ; a_{0}\right)}{\Delta \sigma\left(a_{0}+\delta r ; a_{0}\right)}\right]^{\gamma}+\left(1-G_{1}\right)\left[\frac{\Delta \sigma\left(a_{0}+3 \delta r ; a_{0}+\delta r\right)}{\Delta \sigma\left(a_{0}+2 \delta r ; a_{0}+\delta r\right)}\right]^{\gamma} .
\end{gathered}
$$

É conveniente definirmos ainda a razão entre as amplitudes de tensão como sendo

$$
g_{n k} \equiv\left[\frac{\Delta \sigma\left(a_{0}+(n+1) \delta r ; a_{0}+(k-1) \delta r\right)}{\Delta \sigma\left(a_{0}+k \delta r ; a_{0}+(k-1) \delta r\right)}\right]^{\gamma} .
$$

Desta forma,

$$
\begin{gathered}
G_{1}=\left[\frac{\Delta \sigma\left(a_{0}+2 \delta r ; a_{0}\right)}{\Delta \sigma\left(a_{0}+\delta r ; a_{0}\right)}\right]^{\gamma}=g_{11} ; \\
G_{2}=\frac{F_{2}}{F_{l i m}}=g_{21}+g_{22}\left(1-g_{11}\right) .
\end{gathered}
$$

Continuaremos calculando os demais termos da recorrência na intenção de adquirir alguma expectativa mais concreta a respeito do termo geral. Vejamos:

(C) SEMICOMPRIMENTO $a_{0}+2 \delta r$ :

1. Cálculo do tempo decorrido $\delta t\left(a_{0}+2 \delta r\right)$ :

$$
\delta t\left(a_{0}+2 \delta r\right)=\frac{F_{l i m}-F_{l i m} G_{2}}{f_{0}\left[\Delta \sigma\left(a_{0}+3 \delta r ; a_{0}+2 \delta r\right)\right]^{\gamma}} .
$$


2. Cálculo do dano acumulado:

$$
\begin{gathered}
F\left(x ; a_{0}+2 \delta r\right)=F_{\text {lim }}\left[\frac{\Delta \sigma\left(x ; a_{0}\right)}{\Delta \sigma\left(a_{0}+\delta r ; a_{0}\right)}\right]^{\gamma}+F_{\text {lim }}\left(1-G_{1}\right)\left[\frac{\Delta \sigma\left(x ; a_{0}+\delta r\right)}{\Delta \sigma\left(a_{0}+2 \delta r ; a_{0}+\delta r\right)}\right]^{\gamma}+ \\
+F_{l i m}\left(1-G_{2}\right)\left[\frac{\Delta \sigma\left(x ; a_{0}+2 \delta r\right)}{\Delta \sigma\left(a_{0}+3 \delta r ; a_{0}+2 \delta r\right)}\right]^{\gamma} \\
G_{3}=g_{31}+g_{32}\left(1-G_{1}\right)+g_{33}\left(1-G_{2}\right) .
\end{gathered}
$$

$\therefore$

Assim, podemos esboçar uma generalização como segue [6]:

$$
\begin{aligned}
& G_{0} \equiv 0 ; \\
& G_{1}=g_{11}\left(1-G_{0}\right) ; \\
& G_{2}=g_{21}\left(1-G_{0}\right)+g_{22}\left(1-G_{1}\right) ; \\
& G_{3}=g_{31}\left(1-G_{0}\right)+g_{32}\left(1-G_{1}\right)+g_{33}\left(1-G_{2}\right) ; \\
& G_{n}=\sum_{k=1}^{n} g_{n k}\left(1-G_{k-1}\right), \quad n>0 .
\end{aligned}
$$

Percebemos agora que todo o desenvolvimento seguinte dependerá das propriedades da matriz associada à razão entre as amplitudes de tensão $g_{n k}$ correspondendo a diferentes instantes do processo. Um pouco de trabalho algébrico nos mostra que seus principais comportamentos assintóticos são dados por [6]:

$$
g_{n k} \approx\left\{\begin{array}{l}
\left(2 \delta r / a_{0}\right)^{\gamma / 2}, \quad k \delta r \ll a_{0} \ll n \delta r ; \\
(2 / k)^{\gamma / 2}, \quad a_{0} \ll k \delta r \ll n \delta r ; \\
(n-k+2)^{-\gamma / 2}, \quad a_{0} \ll k \delta r \approx n \delta r .
\end{array}\right.
$$

Na Figura 2.4 apresentamos o comportamento típico da matriz $g_{n k}$ para alguns valores particulares do expoente de incremento de dano $\gamma$.

Perceba ainda que a matriz $g_{n k}$ apresenta valores "apreciáveis" apenas quando $k \approx n$ [pelo menos para valores iniciais do tamanho da trinca suficientemente grandes $\left(a_{0} \gg \delta r\right)$ e expoentes de incremento de dano suficientemente elevados $(\gamma>2)$ ], permitindo desprezar muitos termos da soma (2.24). Sendo assim, tomaremos a liberdade de escrever

$$
\begin{gathered}
G^{*} \approx\left(1-G^{*}\right) s_{\infty} \\
s_{n}(\gamma) \equiv \sum_{k=1}^{n} g_{n k} \approx \sum_{k=1}^{n} \frac{1}{(n-k+2)^{\gamma / 2}}
\end{gathered}
$$




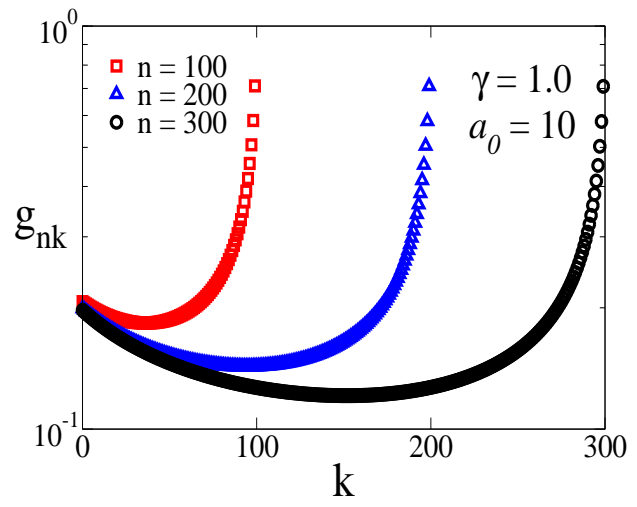

(a)

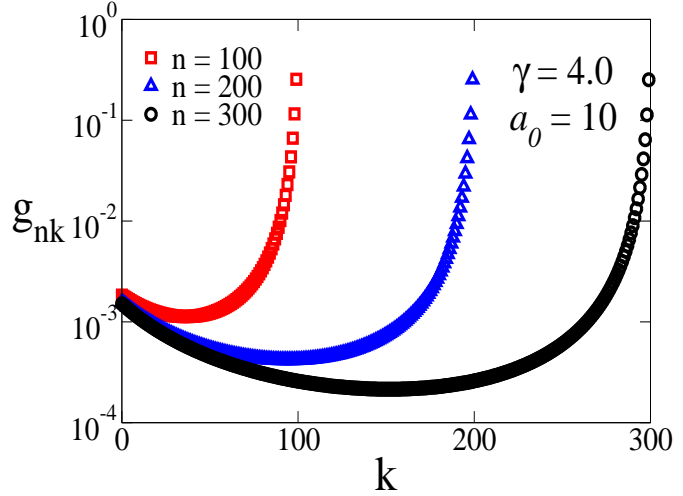

(b)

Figura 2.4: Comportamento típico da razão entre as amplitudes de tensão $g_{n k}$ para alguns valores particulares do expoente de incremento de dano $\gamma$. (a) $\gamma=1$. (b) $\gamma=4$.

$$
s_{\infty}=\lim _{n \rightarrow \infty} s_{n} \approx \sum_{j=0}^{\infty} \frac{1}{(j+2)^{\gamma / 2}}=\left\{\begin{array}{l}
\zeta\left(\frac{\gamma}{2}\right)-1, \quad \gamma>2 \\
\infty, \quad \gamma \leq 2
\end{array}\right.
$$

onde $G^{*}$ é o ponto fixo da recorrência, $s_{\infty}$ é a soma da série cujo termo geral é dado pela razão entre as amplitudes de tensão $g_{n k}$ e $\zeta(u)$ é a função zeta de Riemann.

Portanto,

$$
G^{*} \approx \frac{s_{\infty}(\gamma)}{1+s_{\infty}(\gamma)}
$$

onde o raio de convergência da série $s_{\infty}(\gamma)$ define um valor crítico para o expoente de incremento dado por $\gamma_{c}=2$ que determina o domínio de validade da aproximação $\left(\gamma>\gamma_{c}\right)^{6}$.

Apesar da divergência de $s_{\infty}(\gamma)$ quando $\gamma \leq \gamma_{c}$, um raciocínio heurístico nos mostra que, neste caso, $G_{n}$ converge para $G^{*}=1$, pois,

$$
s_{\infty}(\gamma) \gg 1 \quad\left(\gamma \leq \gamma_{c}\right) \Rightarrow G^{*} \approx \frac{1}{1+\frac{1}{s_{\infty}}} \approx 1-\frac{1}{s_{\infty}} \sim 1
$$

Finalmente, vejamos o cálculo do expoente de Paris:

$$
\begin{gathered}
\frac{d a_{n}}{d t} \sim \frac{\left[\Delta \sigma\left(a_{n+1} ; a_{n}\right)\right]^{\gamma}}{1-G_{n}} \sim a_{n}^{\gamma / 2} ; \\
m=\gamma\left(\gamma>\gamma_{c}\right)
\end{gathered}
$$

ou seja, a lei de Paris é, de fato, reproduzida sendo seu expoente $m$ exatamente igual ao expoente de incremento de dano $\gamma$.

\footnotetext{
${ }^{6}$ A designação valor crítico para o expoente de incremento de dano é oportuna haja vista a possibilidade de estabelecermos analogias consistentes entre os resultados do modelo e as classes de fenômenos críticos geralmente encontradas na física estatística.
} 


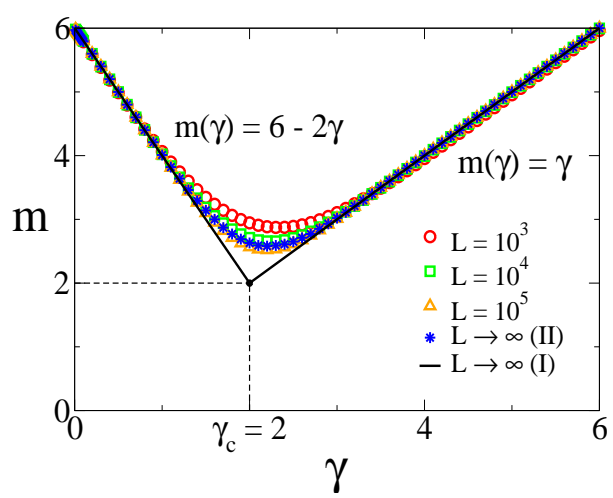

(a)

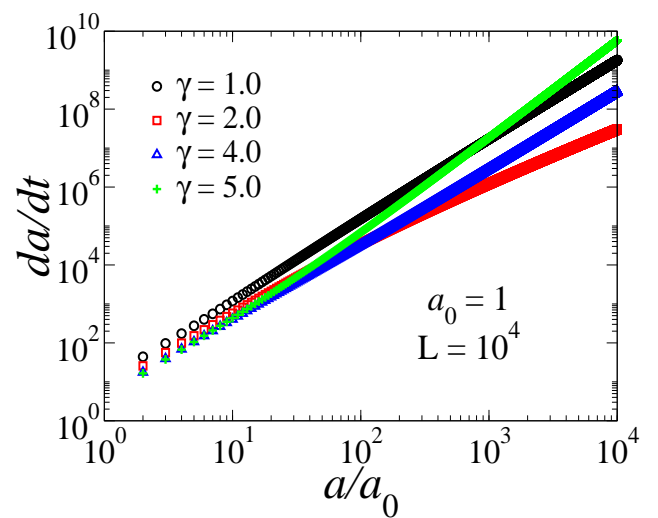

(b)

Figura 2.5: (a) Dependência entre o expoente de Paris $m$ e o expoente de incremento de dano $\gamma$ para diferentes tamanhos de amostra variando entre $L=10^{3}$ e $L=10^{5}$. A linha sólida corresponde a uma extrapolação dos resultados ao limite termodinâmico assumindo uma hipótese de escalamento de tamanho finito de acordo com a expressão Eq. (2.37) $[L \rightarrow \infty(I)]$ enquanto que os símbolos em forma de estrela correspondem a uma segunda maneira de tomarmos o limite termodinâmico que assume uma hipótese alternativa para o escalamento de tamanho finito de acordo com a expressão Eq. (2.44) $[L \rightarrow \infty(I I)]$. (b) Curva log-log típica para a velocidade de propagação da trinca $d a / d t$ em função de seu correspondente semicomprimento $a$ considerando-se alguns valores particulares do expoente de incremento de dano $\gamma$.

Os resultados analíticos apresentam excelente concordância quando confrontados com simulações numéricas do modelo, como mostra a figura 2.5. Os resultados numéricos revelam ainda maiores detalhes no comportamento do expoente de Paris em função do expoente de incremento de dano, sugerindo a expressão analítica $m(\gamma)=6-2 \gamma$ quando $\gamma<\gamma_{c}$ e no limite termodinâmico.

Apesar da grande quantidade de simulações numéricas indicando resultados bem definidos, o cálculo analítico do expoente de Paris quando $\gamma<\gamma_{c}$ permanece inviabilizado, principalmente, pelos complicadores associados à divergência da série $s_{\infty}$ neste intervalo. Nas próximas seções pretendemos retomar esta questão propondo alternativas que contornem tais dificuldades.

\subsection{Extrapolação dos resultados numéricos ao limite termodinâ- mico}

A identidade entre os expoentes de dano e de acumulação de danos obtida analiticamente nos motiva a definir uma hipótese de escalamento de tamanho finito capaz de permitir a extrapolação dos resultados numéricos ao limite termodinâmico, de acordo com 


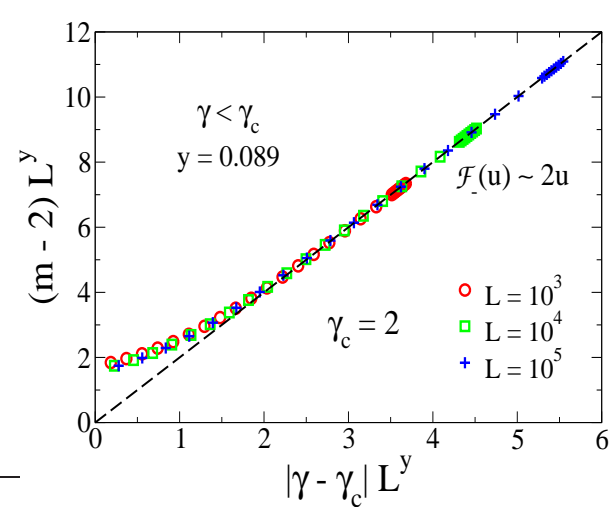

(a)

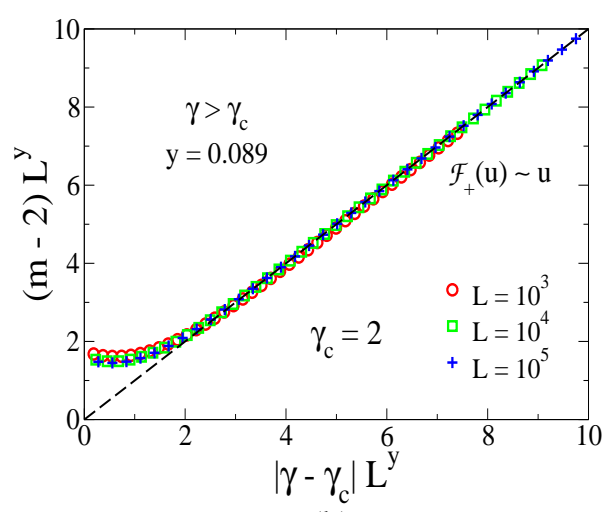

(b)

Figura 2.6: Relação de escala entre os expoentes de Paris e de incremento de dano $(m \times \gamma)$ mostrando a boa concordância entre os resultados numéricos e a expectativa analítica dos mesmos no limite termodinâmico para amostras do sistema com tamanhos variando entre $L=10^{3}$ e $L=10^{5}$. (a) $\gamma<\gamma_{c}$. (b) $\gamma>\gamma_{c}$.

o seguinte raciocínio ${ }^{7}[6]$ :

$$
\begin{gathered}
m=\gamma \\
m-\gamma_{c}=\gamma-\gamma_{c} \\
\left|m-m\left(\gamma_{c}\right)\right|=\left|\gamma-\gamma_{c}\right| \\
\left|m-m\left(\gamma_{c}\right)\right|=\frac{L^{y}}{L^{y}}\left|\gamma-\gamma_{c}\right|
\end{gathered}
$$

$\therefore$

$$
\begin{gathered}
\gamma_{c} \equiv 2 \\
m\left(\gamma_{c} ; L \rightarrow \infty\right) \equiv m\left(\gamma_{c} ; \infty\right)=\gamma_{c} ; \\
m(\gamma ; L)-m\left(\gamma_{c} ; \infty\right)= \begin{cases}L^{-y} \mathcal{F}_{-}\left(\left|\gamma-\gamma_{c}\right| L^{y}\right), & \gamma<\gamma_{c} \\
L^{-y} \mathcal{F}_{+}\left(\left|\gamma-\gamma_{c}\right| L^{y}\right), & \gamma>\gamma_{c}\end{cases}
\end{gathered}
$$

onde $L$ é o tamanho da amostra considerada, $\mathcal{F}_{ \pm}(u)$ são funções universais de escalamento associadas ao comportamento esperado do expoente de Paris no limite termodinâmico e y é um expoente arbitrário a ser determinado pelo melhor colapso obtido entre as curvas do expoente de Paris em função do expoente de incremento de dano reescaladas convenientemente pelo fator $L^{y \dagger}$.

Desta forma podemos confrontar os resultados numéricos com as expectativas analíticas da seção anterior, como mostra a figura 2.5, em que denotamos esta proposta de escalamento finito por $L \rightarrow \infty(I)$. Na figura 2.6 mostramos ainda os detalhes associados à

\footnotetext{
${ }^{7}$ Expressões válidas apenas quando $\gamma>\gamma_{c}$. O aspecto essencial desta abordagem é a hipótese de relações lineares que pode ser definida aos dois regimes associados ao modelo.

${ }^{\dagger}$ Metodologia tradicionalmente empregada neste tipo de procedimento.
} 


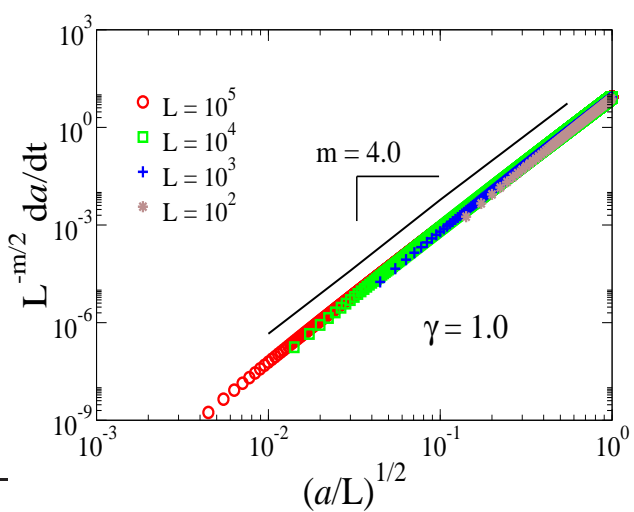

(a)

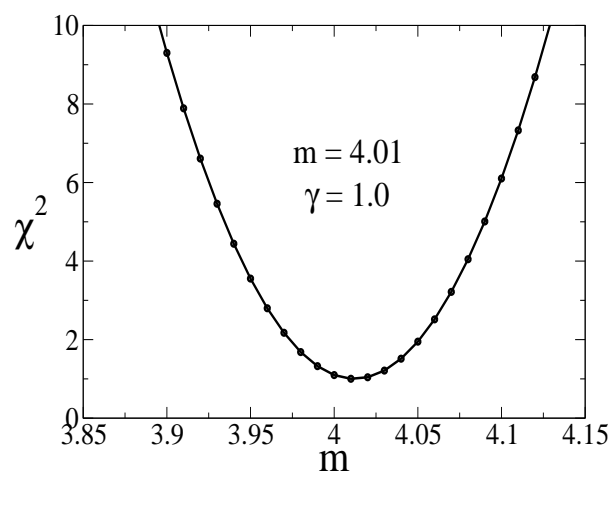

(b)

Figura 2.7: Análise de tamanho finito aplicada aos resultados de simulação numérica do modelo: (a) Relação de escala entre a velocidade de propagação da trinca e seu respectivo comprimento $(d a / d t \times a)$ para diferentes amostras do sistema com tamanhos variando entre $L=10^{2}$ e $L=10^{5}$. (b) Comportamento típico do funcional de desvio quadrático médio definido por eq. (2.47) como função do expoente de Paris indicando $m=4$ como o melhor parâmetro de escala a ser escolhido.

determinação do expoente de escala $y$ com os respectivos colapsos das curvas confirmando a boa concordância com os resultados analíticos esperados (pelo menos para o intervalo $\left.\gamma>\gamma_{c}\right)$.

Sendo assim, de um ponto de vista exclusivamente numérico, podemos admitir a capacidade do modelo em reproduzir a lei de Paris de maneira que seu respectivo expoente obedece uma função linear por partes em relação ao expoente de incremento de dano, dada por [6]:

$$
m(\gamma)=\left\{\begin{array}{l}
6-2 \gamma, \gamma \leq \gamma_{c} \\
\gamma, \gamma>\gamma_{c}
\end{array}\right.
$$

Uma metodologia alternativa que poderia reforçar ainda mais a obtenção dos resultados extrapolados ao limite termodinâmico consiste em estabelecer um confronto direto entre a velocidade de propagação da trinca, $d a / d t$, e seu comprimento relativo ao tamanho da amostra, a/L, uma vez que nossas expectativas em obedecer a lei Paris permitem escrever $[6,32]$

$$
\begin{gathered}
\frac{d a}{d t} \sim a^{m / 2} ; \\
\frac{d a}{d t} \sim L^{m / 2} \frac{a^{m / 2}}{L^{m / 2}} ; \\
L^{-m / 2} \frac{d a}{d t} \sim\left(\frac{a}{L}\right)^{m / 2}
\end{gathered}
$$


$\therefore$

$$
L^{-m / 2} \frac{d a}{d t}=\mathcal{F}\left(\frac{a}{L}\right)
$$

definindo assim um novo método de escalamento finito denotado por $L \rightarrow \infty(I I)$ na figura 2.5, em que $\mathcal{F}(u)$ é uma função universal associada ao comportamento da velocidade de propagação reescalada $L^{-m / 2} d a / d t$ no limite termodinâmico, cuja expressão assintótica esperada seria $\mathcal{F}(u \ll 1) \sim u^{m / 2}$. O expoente de escalamento da hipótese determina $\mathrm{o}$ expoente de Paris $(\equiv m / 2)$ e pode ser obtido pelo colapso das curvas de velocidade reescalada em função do comprimento relativo da trinca, $L^{-m / 2} d a / d t \times a / L$, para diferentes realizações numéricas do modelo, como mostrado na figura 2.7.

É interessante destacarmos que este método permite estimativas bastante razoáveis do expoente de Paris, independentemente de expressões analíticas conhecidas a priori. Entretanto, é necessário recorremos a um critério objetivo que garanta uma escolha confiável do expoente associado ao melhor colapso das curvas reescaladas. Podemos formalizar um procedimento capaz de estimar os erros associados a cada escolha de expoente ao definirmos um funcional de desvio quadrático médio $\chi^{2}(m)$ da seguinte forma:

$$
\begin{gathered}
z \equiv(a / L)^{1 / 2} ; \\
g_{L}(m ; z) \equiv L^{-m / 2} \frac{d a}{d t}(z) ; \\
\chi^{2}(m)=\sum_{L_{1}, L_{2}} \sum_{z}\left[\frac{g_{L_{1}}(m ; z)-g_{L_{2}}(m ; z)}{g_{L_{1}}(m ; z)+g_{L_{2}}(m ; z)}\right]^{2} ;
\end{gathered}
$$

onde $z$ está associado ao comprimento da trinca relativo ao tamanho da amostra e $g_{L}(m ; z)$ é a velocidade de propagação reescalada em termos do tamanho da amostra. O expoente $m$ capaz de minimizar o funcional em questão seria o valor mais indicado a ser atribuído como expoente de Paris do processo analisado.

Na figura 2.7 apresentamos uma estimativa numérica típica para o valor mais adequado do expoente de Paris como consequência da minimização do funcional $\chi^{2}$, levando em consideração um ensemble com $n=10^{5}$ realizações numéricas do sistema e expoente de incremento de dano $\gamma=1$.0. Perceba a boa concordância obtida entre a estimativa numérica e os resultados analíticos desenvolvidos nas seções anteriores, atestando a confiabilidade do método.

É importante mencionarmos ainda que, embora ambos os métodos de extrapolação ao limite termodinâmico propostos tenham se mostrado bastante eficazes, existe uma tendência dos mesmos a se desviarem das estimativas esperadas para o expoente de Paris em um intervalo significativo de valores do expoente de incremento de dano nas imediações de seu valor crítico $\left(\gamma \approx \gamma_{c}\right)$ (rever figura 2.5). É esperado este tipo de comportamento nas vizinhanças da criticalidade por se tratar de um intervalo de transição entre dois regimes de comportamento do expoente de Paris. Além disso, acreditamos que fatores de escala dependendo logaritmicamente do tamanho da amostra devem interferir no comportamento assintótico do modelo neste intervalo. 


\subsection{Cálculo do expoente de Paris no limite $\gamma \rightarrow 0$}

Na tentativa de obtermos o expoente de Paris pelo menos no limite $\gamma \ll \gamma_{c}$ consideremos a seguinte aproximação desde as primeiras etapas do cálculo:

$$
\left[\Delta \sigma\left(x ; a_{n}\right)\right]^{\gamma}=\exp \left\{\ln \left[\Delta \sigma\left(x ; a_{n}\right)\right]^{\gamma}\right\} \approx 1+\ln \left[\Delta \sigma\left(x ; a_{n}\right)\right]^{\gamma} .
$$

Desta forma, o termo geral para o dano acumulado normalizado $G_{n}$ pode ser simplificado como segue:

$$
G_{n} \approx 1+\ln \left(\frac{g_{n 1}}{g_{n-11}}\right), \quad n>1
$$

É importante agora determinarmos o comportamento assintótico da razão $g_{n 1} / g_{n-11}$. Semelhantemente aos cálculos da seção anterior é fácil mostrar que esse comportamento assintótico é dado simplesmente por

$$
\frac{g_{n 1}}{g_{n-11}} \approx 1-\gamma\left(\frac{a_{0}}{\delta r}\right)^{2} n^{-3}
$$

Portanto $^{8}$

$$
1-G_{n} \approx-\ln \left[1-\gamma\left(\frac{a_{0}}{\delta r}\right)^{2} n^{-3}\right] \approx \gamma\left(\frac{a_{0}}{\delta r}\right)^{2} n^{-3} \sim \gamma a_{n}^{-3} .
$$

Assim podemos concluir que

$$
\frac{d a_{n}}{d t} \sim \frac{1}{1-G_{n}} \sim \gamma^{-1} a_{n}^{3} \Rightarrow m(\gamma \rightarrow 0)=6
$$

confirmando expectativas de Vieira e colaboradores publicadas em [6].

No que se refere ao comportamento da constante de proporcionalidade da lei de Paris perceba uma dependência assintótica com o inverso do expoente de incremento de dano tal que

$$
C(\gamma) \sim \gamma^{-1} \Rightarrow \frac{d a_{n}}{d t}(\gamma \rightarrow 0) \rightarrow \infty
$$

ou seja, a velocidade de propagação da trinca diverge neste limite apesar do expoente de Paris apresentar um valor bem definido. Do ponto de vista físico podemos entender facilmente este resultado uma vez que todas as componentes do sistema devem alcançar simultaneamente seus limiares de dano, conferindo um caráter perfeitamente frágil ao material.

Na Figura 2.8 apresentamos resultados de simulações numéricas do modelo para valores do expoente de incremento de dano muito próximos de zero (valores entre $\gamma=0$ e $\gamma=0.1$ ), confirmando as expectativas analíticas desta seção.

\footnotetext{
${ }^{8}$ Perceba que $G_{n} \rightarrow 1$ quando $\gamma \rightarrow 0$, como esperado.
} 


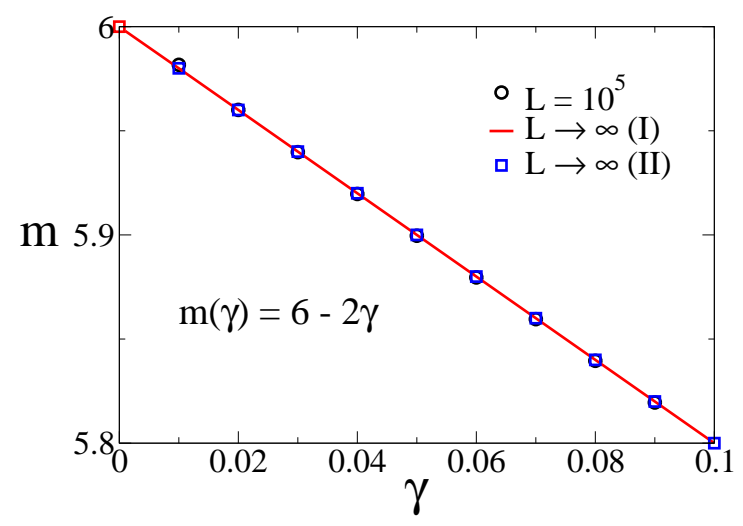

Figura 2.8: Comportamento do expoente de Paris $m$ para valores do expoente de incremento de dano $\gamma$ muito próximos de zero $\left(\gamma \ll \gamma_{c}\right)$. Perceba que $m(\gamma \rightarrow 0)=6$.

\subsection{Introduzindo modificações na lei de incremento de danos}

Nesta seção estamos interessados em explorar uma leve modificação nas regras do modelo, de maneira que a lei de incremento de dano [regra 7] passe a ser dada pela expressão

$$
\delta F\left(x ; a_{n}\right)=f_{0} \delta t\left(a_{n}\right)\left[\Delta \sigma_{0}\left(\frac{x}{\sqrt{x^{2}-a_{n}^{2}}}-1\right)\right]^{\gamma},
$$

ou seja, estamos assumindo que o dano acumulado ao longo da linha de propagação não sofre incrementos para pontos muito distantes da ponta da trinca $\left(|x| \gg a_{n}\right)$. Com esta modificação, pretendemos verificar se o modelo continua sendo capaz de reproduzir a lei de Paris e que alterações podem ocorrer na relação entre o expoente de Paris e o expoente de incremento de dano.

Semelhantemente aos cálculos das seções anteriores, o comportamento assintótico da velocidade de propagação da ponta da trinca $d a_{n} / d t$ passa a ser dado por:

$$
\begin{gathered}
\frac{d a_{n}}{d t} \sim \frac{\left[\Delta \sigma\left(a_{n+1} ; a_{n}\right)\right]^{\gamma}}{1-G_{n}} ; \\
G_{0} \equiv 0 ; \quad G_{n}=\sum_{k=1}^{n} h_{n k}\left(1-G_{k-1}\right), \quad n>0 ; \\
h_{n k} \equiv\left[\frac{\Delta \sigma\left(a_{n+1} ; a_{k-1}\right)-\Delta \sigma_{0}}{\Delta \sigma\left(a_{k} ; a_{k-1}\right)-\Delta \sigma_{0}}\right]^{\gamma} ; \\
h_{n k} \approx\left\{\begin{array}{l}
(n-k+2)^{-\gamma / 2}, \quad a_{0} \ll k \delta r \approx n \delta r \\
0, \\
\text { caso contrário. }
\end{array}\right.
\end{gathered}
$$




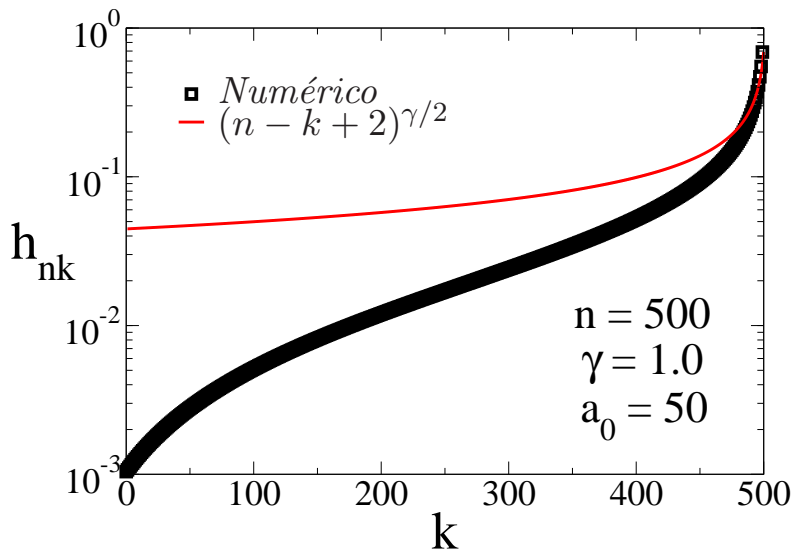

Figura 2.9: Comportamento típico da razão entre as amplitudes de tensão $h_{n k}$ para a versão modificada do modelo considerando-se um expoente de incremento de dano igual a $\gamma=1.0$.

Perceba que apenas o comportamento assintótico da razão entre as amplitudes de tensão $h_{n k}$ sofre alterações significativas em relação aos resultados obtidos anteriormente, como mostra a figura $2.9^{9}$.

Podemos ainda desprezar muitos termos da soma (2.56), resultando em

$$
\begin{gathered}
G^{*} \approx \frac{\bar{s}_{\infty}(\gamma)}{1+\bar{s}_{\infty}(\gamma)} ; \\
\bar{s}_{n}(\gamma) \equiv \sum_{k=1}^{n} h_{n k} \approx \sum_{k=1}^{n} \frac{1}{(n-k+2)^{\gamma / 2}} ; \\
\bar{s}_{\infty}(\gamma) \approx s_{\infty}(\gamma) \approx\left\{\begin{array}{l}
\zeta\left(\frac{\gamma}{2}\right)-1, \quad \gamma>2 ; \\
\infty, \quad \gamma \leq 2 .
\end{array}\right.
\end{gathered}
$$

Perceba que o comportamento assintótico de $G_{n}$ permanece inalterado, apresentando inclusive o mesmo valor crítico para o expoente de incremento de dano $\left(\gamma_{c}=2\right)$.

Sendo assim o expoente de Paris continua a ser dado por (pelo menos para $\gamma>\gamma_{c}$ )

$$
\frac{d a_{n}}{d t} \approx \frac{\left[\Delta \sigma\left(a_{n+1} ; a_{n}\right)\right]^{\gamma}}{1-G_{n}} \approx a_{n}^{\gamma / 2} \Rightarrow m=\gamma
$$

Na Figura 2.10 apresentamos a relação entre o expoente de Paris e o expoente de incremento de dano $(m \times \gamma)$ obtida numericamente para esta nova versão do modelo. É importante ressaltar que, diferentemente da versão original do modelo, os resultados numéricos revelam que o comportamento do expoente de Paris quando $\gamma<\gamma_{c}$ é dado,

\footnotetext{
${ }^{9}$ Por uma questão de clareza renomeamos a nova razão entre as amplitudes de tensão de maneira que $g_{n k} \rightarrow h_{n k}$.
} 


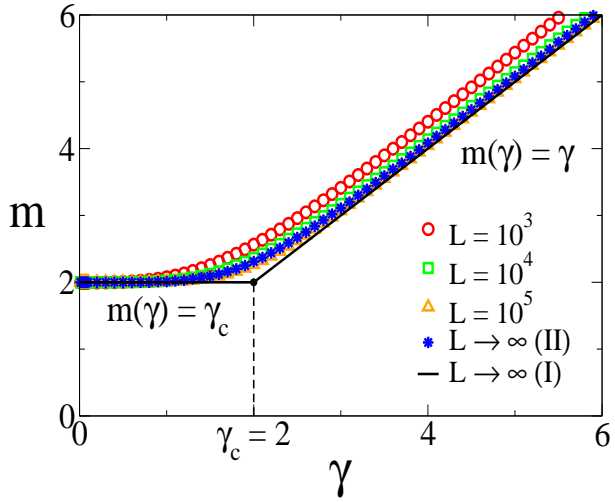

(a)

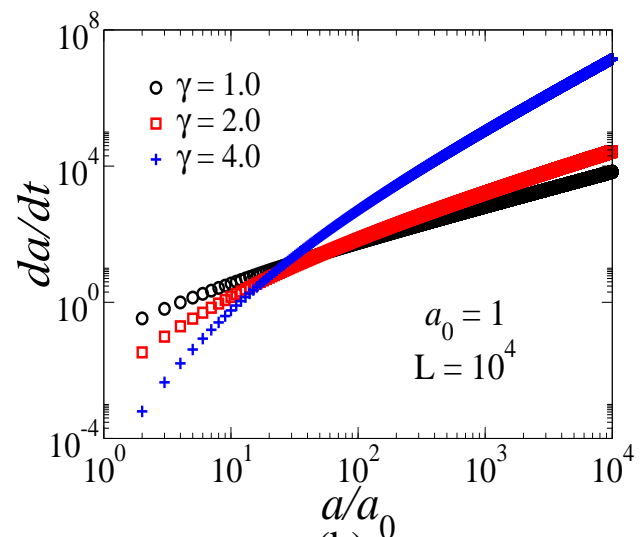

(b)

Figura 2.10: (a) Dependência do expoente de Paris $m$ em relação ao expoente de incremento de dano $\gamma$ para diferentes tamanhos de amostra variando desde $L=10^{3}$ até $L=10^{5}$. (b) Curva log-log típica para a velocidade de propagação da trinca $d a / d t$ em função de seu correspondente semicomprimento $a$, considerando-se alguns valores particulares do expoente de incremento de dano $\gamma$.

simplesmente, por um valor constante e igual a $m(\gamma)=\gamma_{c}$. Os resultados numéricos no limite termodinâmico foram novamente analisados através de diferentes hipóteses de escalamento de tamanho finito, apresentando boa concordância quando comparados com a expectativa analítica, como mostra a figura 2.11.

Nas próximas subseções pretendemos estabelecer resultados analíticos correspondentes ao intervalo $\gamma<\gamma_{c}$, com o objetivo de formalizar as diferenças observadas numericamente entre as duas versões do modelo.

\subsubsection{Cálculo do expoente de Paris no limite $\gamma \rightarrow 0$}

Nesta subseção pretendemos simplesmente calcular o expoente de Paris no limite de acumulação uniforme de danos $(\gamma \rightarrow 0)$ referente à versão modificada do modelo e verificar parte da discussão realizada anteriormente. Semelhantemente aos cálculos da Seção 2.4, o termo geral $G_{n}$ pode ser aproximado como segue:

$$
G_{n} \approx 1+\ln \left(\frac{h_{n 1}}{h_{n-11}}\right), \quad n>1
$$

onde $h_{n k}$ é a matriz associada a razão entre as amplitudes de tensão para a nova versão do modelo.

O comportamento assintótico diferenciado da matriz $h_{n k}$ implica importantes mudanças no cálculo, quando comparado com os resultados da versão original do modelo [seção (2.4)], a saber,

$$
\frac{h_{n 1}}{h_{n-11}} \approx 1-2 \gamma n^{-1} \Rightarrow 1-G_{n} \sim \gamma a_{n}^{-1}
$$




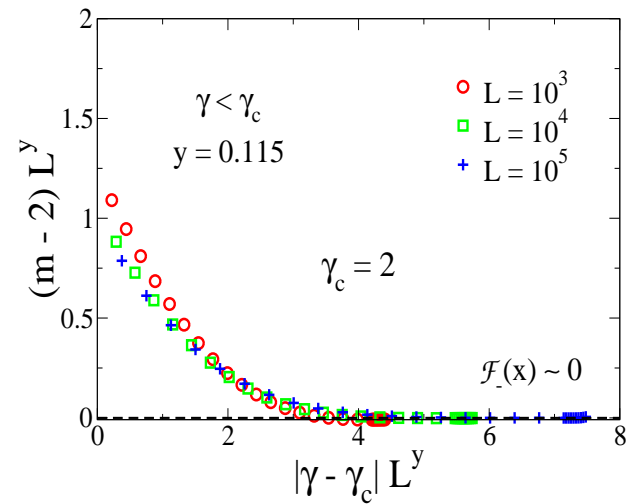

(a)

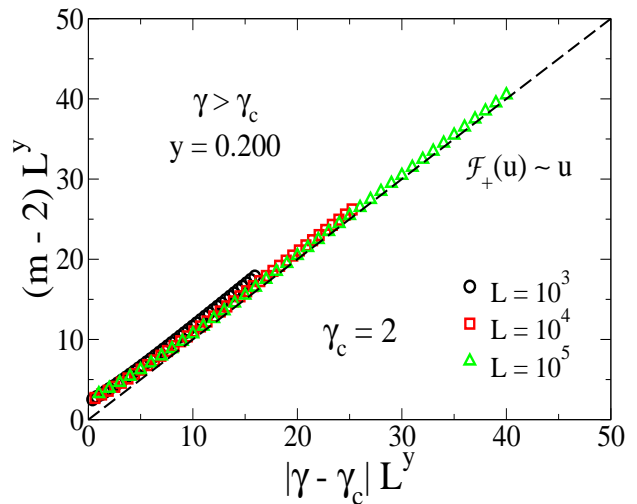

(b)

Figura 2.11: Análise de tamanho finito mostrando a boa concordância existente entre os resultados analíticos e a expectativa numérica dos mesmos no limite termodinâmico para a versão modificada do modelo. (a) $\gamma<\gamma_{c}$. (b) $\gamma>\gamma_{c}$.

Assim podemos concluir que

$$
\frac{d a_{n}}{d t} \sim \frac{1}{1-G_{n}} \sim \gamma^{-1} a_{n}^{1} \quad \Rightarrow \quad m(\gamma \rightarrow 0)=\gamma_{c}
$$

conforme as expectativas numéricas apresentadas na seção anterior. Perceba ainda que a constante da lei de Paris continua a apresentar o mesmo comportamento assintótico da versão original $\left[C(\gamma) \sim \gamma^{-1}\right]$, de maneira que a velocidade de propagação da trinca também diverge neste caso limite, como esperado.

\subsection{Generalizando as alterações introduzidas na lei de incre- mento de dano}

Baseados em modelos micromecânicos de propagação de trincas geralmente encontrados na literatura [16,23], podemos generalizar as alterações introduzidas na lei de acumulação de danos do modelo [regra 7] substituindo a amplitude de tensão externa aplicada ao material $\Delta \sigma\left(x ; a_{n}\right)$ nas expressões analíticas por um valor efetivo correspondente $\Delta \sigma_{e f}\left(x ; a_{n}\right)$, como segue:

$$
\begin{gathered}
\delta F\left(x ; a_{n}\right)=f_{0} \delta t\left(a_{n}\right)\left[\Delta \sigma_{e f}\left(x ; a_{n}\right)\right]^{\gamma} \\
\Delta \sigma_{e f}\left(x ; a_{n}\right) \equiv \Delta \sigma_{0}\left(\frac{|x|}{\sqrt{x^{2}-a_{n}^{2}}}-b\right), \quad 0 \leq b \leq 1 ;
\end{gathered}
$$

onde $b$ seria um parâmetro de tensão efetiva que limita os efeitos da acumulação de danos nas regiões da linha de propagação muito distantes da ponta da trinca $\left(|x| \gg a_{n}\right)$.

Desta forma, pretendemos investigar a influência do novo parâmetro introduzido ao assumirmos diferentes valores pertencentes ao seu intervalo de definição $(I=[0,1])$ de 
maneira a esclarecer o papel da acumulação de danos nas regiões mais afastadas da ponta da trinca. Perceba ainda que as versões anteriores do modelo podem ser recuperadas quando consideramos os casos particulares $b_{0} \equiv 0$, para o modelo original, e $b_{c} \equiv 1$, para ausência completa de acúmulo de danos no infinito (interações de curto alcance favorecidas).

Semelhante aos cálculos realizados nas seções anteriores descreveremos a propagação de trincas através do seguinte conjunto de equações:

$$
\begin{gathered}
\frac{d a_{n}}{d t} \sim \frac{\left[\Delta \sigma_{e f}\left(a_{n+1} ; a_{n}\right)\right]^{\gamma}}{1-G_{n}} ; \\
G_{0}=0 ; \quad G_{n}=\sum_{k=1}^{n} r_{n k}\left(1-G_{k-1}\right), \quad n>0 ; \\
r_{n k} \equiv\left[\begin{array}{l}
\left.\frac{\Delta \sigma\left(a_{0}+(n+1) \delta r ; a_{0}+(k-1) \delta r\right)-b \Delta \sigma_{0}}{\Delta \sigma\left(a_{0}+k \delta r ; a_{0}+(k-1) \delta r\right)-b \Delta \sigma_{0}}\right]^{\gamma} ; \\
{\left[\frac{(1-b) \sqrt{2 a_{0} \delta r}}{a_{0}-b \sqrt{2 a_{0} \delta r}}\right]^{\gamma}, \quad k \delta r \ll a_{0} \ll n \delta r ;} \\
{\left[\frac{(1-b) \sqrt{2 k}}{k-b \sqrt{2 k}}\right]^{\gamma}, \quad a_{0} \ll k \delta r \ll n \delta r ;} \\
(n-k+2)^{-\gamma / 2}, \quad a_{0} \ll k \delta r \approx n \delta r ;
\end{array}\right.
\end{gathered}
$$

onde o parâmetro de tensão efetiva $b$ desempenha um importante papel no comportamento assintótico da razão entre as amplitudes de tensão $r_{n k}$.

Continuaremos a considerar apenas os termos mais significativos da Equação (4.50) de maneira que

$$
G^{*} \approx \frac{s_{\infty}(\gamma)}{1+s_{\infty}(\gamma)} \Rightarrow \frac{d a_{n}}{d t} \sim a_{n}^{\gamma / 2}(\gamma>2)
$$

ou seja, a identidade entre o expoente de Paris e o expoente de incremento de dano é assegurada, apresentado inclusive o mesmo valor crítico $\gamma_{c}=2$, independentemente do valor assumido pelo parâmetro de tensão efetiva.

No limite de acumulação uniforme de danos $\left(\gamma \ll \gamma_{c}\right)$, as expressões analíticas também podem ser facilmente analisadas como segue:

$$
G_{n} \approx 1+\ln \left(\frac{r_{n 1}}{r_{n-11}}\right), \quad n>1
$$

Se $b \neq 1$ :

$$
\frac{r_{n 1}}{r_{n-11}} \approx 1-\gamma\left(\frac{a_{0}}{\delta r}\right)^{2} \frac{1}{(1-b)} a_{n}^{-3} \Rightarrow 1-G_{n} \sim a_{n}^{-3}
$$




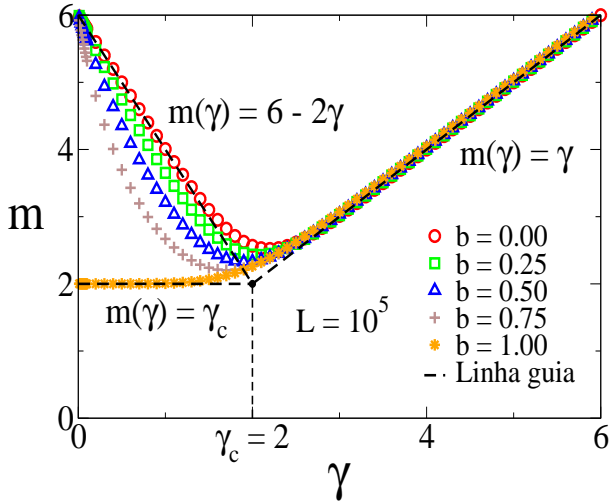

(a)

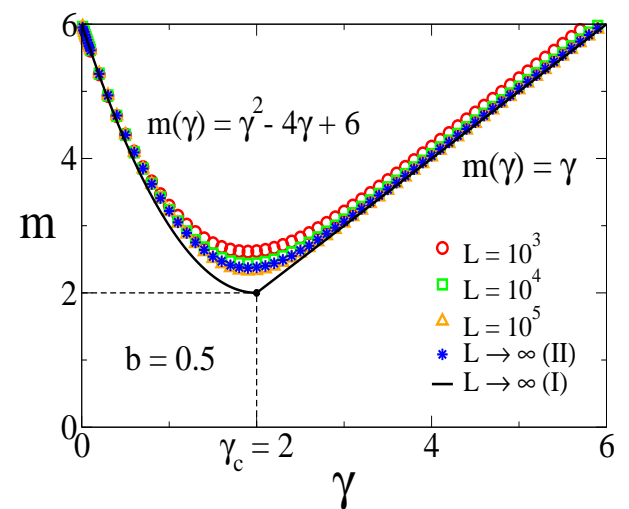

(b)

Figura 2.12: Resultados numéricos para a dependência entre o expoente de Paris $m$ e o expoente de incremento de dano $\gamma$ considerando-se a versão modificada do modelo: (a) simulações do sistema com tamanho máximo da trinca $L=10^{5}$ e diferentes valores do parâmetro de tensão efetiva $b$; (b) simulações do sistema com diferentes tamanhos máximos do sistema variando de $L=10^{3}$ a $L=10^{5}$ e $b=0.5$ como parâmetro efetivo de tensão. É importante enfatizar que a tendência a uma identidade entre os expoentes de Paris e de incremento de dano continua preservada no intervalo $\gamma>\gamma_{c}$ mas não temos mais expectativas de uma dependência linear no intervalo complementar $\gamma<\gamma_{c}$.

Se $b=1$ :

$$
\frac{r_{n 1}}{r_{n-11}} \approx 1-2 \gamma a_{n}^{-1} \Rightarrow 1-G_{n} \approx a_{n}^{-1}
$$

Portanto,

$$
\begin{gathered}
m(\gamma \rightarrow 0)= \begin{cases}6, & b \neq b_{c} \\
2, & b=b_{c}\end{cases} \\
b_{c}=1 ;
\end{gathered}
$$

onde $b=b_{c}$ é o único caso capaz de alterar significativamente o comportamento do sistema quando comparado com a versão original do modelo.

Apesar das diferenças aparentemente pontuais indicadas pelos resultados analíticos, uma grande quantidade de simulações numéricas do modelo nos revelam que o comportamento do expoente de Paris apresenta maiores contrastes quando comparados aos resultados do modelo original, como mostra a figura 2.12. Os diferentes métodos para análise de tamanho finito a que podemos submeter os resultados confirmam a identidade entre os expoentes no intervalo $\gamma>\gamma_{c}$.

Sendo assim, o comportamento do expoente de Paris no intervalo complementar $(\gamma<$ $\gamma_{c}$ ) não obedece a um padrão bem estabelecido, a ponto de desviar significativamente daquele apresentado pelo modelo original $(b=0)$. Portanto, a lei de Paris é sempre reproduzida pelo modelo generalizado embora uma relação simples entre o expoente de Paris e o expoente de incremento de danos seja observada de forma robusta apenas no intervalo $\gamma>\gamma_{c}$. 


\begin{tabular}{|c|c|c|}
\hline Liga & $\mathbf{m}$ & $\mathbf{C}$ \\
\hline Aço & 3,0 & $10^{-11}$ \\
\hline Alumínio & 3,0 & $10^{-12}$ \\
\hline Níquel & 3,3 & $4,0 \times 10^{-12}$ \\
\hline Titânio & 5,0 & $10^{-11}$ \\
\hline
\end{tabular}

Tabela 2.1: Resultados experimentais típicos para o expoente de Paris $(m)$ e para o coeficiente de Paris $(C)$ relacionados a ligas metálicas de grande aplicação prática.

\subsection{Confronto entre os resultados obtidos e a prática experimen- tal}

Nesta seção pretendemos contextualizar os resultados obtidos em nossa abordagem com uma ampla variedade de resultados experimentais e modelos fenomenológicos simples sugeridos pela literatura especializada ao longo das últimas décadas [16,20,23]. O confronto com a prática experimental permitirá a validação das principais propriedades do modelo de acordo com as próximas subseções a serem apresentadas a seguir.

\subsubsection{Cota inferior para o expoente de Paris $(m \geq 2)$}

Integrando a lei de Paris com a condição inicial $a\left(N_{0}\right)=a_{0}$ e $\Delta K=\Delta \sigma_{0} \sqrt{\pi a}$ obtemos

$$
C\left(\Delta \sigma_{0}\right)^{m}\left(N-N_{0}\right)=\left\{\begin{array}{l}
\frac{a^{1-m / 2}-a_{0}^{1-m / 2}}{1-m / 2}, \quad m \neq 2 \\
\ln \left(a / a_{0}\right), \quad m=2
\end{array}\right.
$$

onde $a_{0}$ é o comprimento inicial da trinca (identificado com um número inicial de ciclos de carregamento $N_{0}$ ) e $m_{c} \equiv 2$ define um expoente de Paris crítico.

É interessante perceber que o valor $m_{c}=2$ para o expoente de Paris já apresenta singularidades próprias, independentemente das considerações analíticas associadas à divergência da série $s_{\infty}$ anteriormente analisadas. Além disso, a prática experimental corrobora com a expectativa de nosso modelo em apresentar sempre valores acima desse valor crítico (ver tabela 2.1).

Para a grande maioria dos materiais metálicos, o expoente de Paris $m$ apresenta valores típicos entre $m=2$ e $m=4$ [23]. O valor $m=4$ é frequentemente observado para ligas de carbono sob tensão moderada [16].

\subsubsection{Comportamento típico do fator de proporcionalidade de Paris}

O fator de proporcionalidade $C$ é outro importante parâmetro que pertence a um intervalo bem definido de valores para uma ampla variedade de materiais. No caso de ligas metálicas, valores situados no intervalo entre $C=10^{-16} \mathrm{~mm}^{7} / \mathrm{N}^{4}$ e $C=10^{-12} \mathrm{~mm}^{7} / \mathrm{N}^{4}$ são geralmente associados a ligas de carbono com expoente de Paris $m=4$ (ver tabela 
$2.1)^{10}[16,23]$. Entretanto, nosso modelo sugere que o fator de proporcionalidade da lei de Paris deve divergir à medida que o expoente de incremento de dano tende a zero, uma vez que todas as ligações devem alcançar seus limiares de dano simultaneamente, ou seja,

$$
\frac{d a}{d N}(\gamma \rightarrow 0) \rightarrow \infty \quad \Rightarrow \quad C \rightarrow \infty \quad(m=6) ;
$$

embora o expoente de Paris apresente sempre um valor bem definido, a saber, $m(\gamma \rightarrow 0)=6$ (rever gráfico da figura 2.5). Este resultado é incompatível com a prática experimental sendo um importante indicativo de que esse limite não seja observável na prática.

\subsubsection{Justificando a ocorrência de leis de potência nas regras do modelo}

A lei de incremento de dano assumida de maneira ad hoc pelas regras do modelo definidas nas seções anteriores pode ser justificada através de analogias com modelos micromecânicos de crescimento de trincas tipicamente encontrados na literatura. Esses modelos são baseados em equações diferenciais simples envolvendo a evolução temporal de uma determinada variável escalar de dano, equivalente à variável $F$ de nosso modelo, de acordo com a seguinte expressão [16,30]:

$$
\frac{d F}{d N}=f[\sigma(N), F(N)]
$$

onde $f[\sigma(N), F(N)]$ é uma função não negativa geralmente descrita por uma lei de potência envolvendo a distribuição de tensão no interior do material.

Uma das representações mais simples de (2.79) é dada por [16,30]:

$$
\frac{d F}{d N}=\left\{\begin{array}{l}
\frac{1}{N_{c}}\left(\frac{\Delta \sigma-\Delta \sigma_{\text {lim }}}{r-\sigma_{\text {lim }}}\right)^{m}, \quad N>N_{0} \text { ou } \sigma>\sigma_{\text {lim }} \\
0, \quad N \leq N_{0} \text { ou } \sigma \leq \sigma_{\text {lim }} ;
\end{array}\right.
$$

onde $N_{0} \geq 0$ é o número de ciclos necessários para o início da acumulação de dano, $\sigma$ é a tensão associada a um ponto qualquer do interior do material, $\sigma_{\text {lim }}$ é o valor de tensão mínimo necessário para a ocorrência de acumulações de danos com $\Delta \sigma_{\text {lim }}$ sendo a amplitude de tensão associada, $N_{c}$ é um determinado número de ciclos característico, $m$ é o expoente de Paris e $r$ é um parâmetro associado ao material denominado tensão de resistência contra fadiga.

A solução de (2.80) correspondendo a condição inicial $F(0)=0$ (dano inicial nulo) é dada por

$$
F(N ; \Delta \sigma)=\left(\frac{N-N_{0}}{N_{c}}\right)\left(\frac{\Delta \sigma-\Delta \sigma_{l i m}}{r-\sigma_{l i m}}\right)^{m}
$$

Considerando ainda $F\left(N_{f} \mid \Delta \sigma\right)=F_{\text {lim }}$, obtemos

$$
N_{f}=N_{0}+F_{l i m} N_{c}\left(\frac{r-\sigma_{l i m}}{\Delta \sigma-\Delta \sigma_{l i m}}\right)^{m}, \quad \sigma>\sigma_{l i m} .
$$

\footnotetext{
${ }^{10}$ Em geral, $C$ e $m$ dependem ainda de outros parâmetros como, por exemplo, a razão entre os fatores de intensidade de tensão $R \equiv K_{\min } / K_{\max }[52]$.
} 
correspondendo a resultados experimentais típicos associados a curvas de fadiga (como curvas de Wöhler, por exemplo) [16,30].

Outras formas de generalizar a lei de Paris consiste em substituir $\Delta \sigma$ em (2.80) por seu valor efetivo $\Delta \sigma_{\text {ef }}$ como segue $[16,30]$ :

$$
\frac{d F}{d N}=C_{e f}\left(\Delta \sigma_{e f}\right)^{m}
$$

de acordo com as generalizações das regras do modelo exploradas nas seções anteriores.

Ainda neste mesmo espírito de generalizações, é comum encontrarmos na literatura alterações na lei de Paris com o objetivo de descrever os diferentes regimes que podemos encontrar nas curvas de velocidade de propagação. Neste caso é conveniente considerarmos expressões na forma $[16,30]$

$$
\frac{d a}{d N}=C_{1}\left(\Delta K-\Delta K_{l i m}\right)^{m_{1}}\left(K_{\max }-K_{l i m}\right)^{m_{2}}\left(K_{C}-K_{\max }\right)^{-m_{3}},
$$

onde $\Delta K_{\text {lim }}$ é o limiar de variação no fator de intensidade de tensão, $K_{\text {lim }}$ é o limiar do fator de intensidade de tensão, $K_{\max }$ é o valor máximo do fator de intensidade de tensão, $K_{C}$ é o parâmetro de tenacidade a fratura e os expoentes $m_{1}, m_{2}$ e $m_{3}$ são generalizações do expoente de Paris.

\subsubsection{Robustez dos resultados quanto a alterações nas regras do modelo}

A capacidade do modelo em reproduzir a lei de Paris aparentemente independe de alterações introduzidas na lei de acumulação de danos do modelo, entretanto, a identidade entre os expoente de Paris e de incremento de danos é observada de forma robusta apenas no intervalo $\gamma>\gamma_{c}$ sugerindo uma eventual rejeição dos resultados associados ao ramo esquerdo da curva $m \times \gamma$ obtidos numericamente (ver figura 2.5).

\subsubsection{Comparações com o modelo de feixe de fibras}

Generalizações do modelo de feixe de fibras incorporando efeitos de acumulação de danos induzidos por fadiga cíclica permitem o cálculo numérico do expoente de Paris e corroboram com a identidade $m=\gamma[5,53]$ como parte de suas propriedades.

\subsubsection{Medidas da energia envolvida na formação de trincas}

Considerando-se a estimativa de Griffith para a tamanho crítico de uma trinca que se propaga no interior de um material frágil podemos escrever:

$$
a_{c}=\frac{2 \gamma_{G} Y}{\pi \sigma_{c}^{2}}
$$

onde $a_{c}$ corresponde ao comprimento mínimo da trinca necessário para seu crescimento espontâneo, $S_{c} \equiv 2 \gamma_{G}$ é um parâmetro que especifica a capacidade de absorção energética pela superfície da trinca ${ }^{11}, Y$ é o módulo de Young do material e $\sigma_{c}$ é a correspondente intensidade crítica das tensões no interior da amostra.

\footnotetext{
${ }^{11}$ Perceba a conveniência de denominarmos a constante de absorção energética superficial com um índice $G$ (Griffith), $\gamma_{G}$, a fim de evitarmos ambiguidades com a notação utilizada para o expoente de incremento de dano.
} 

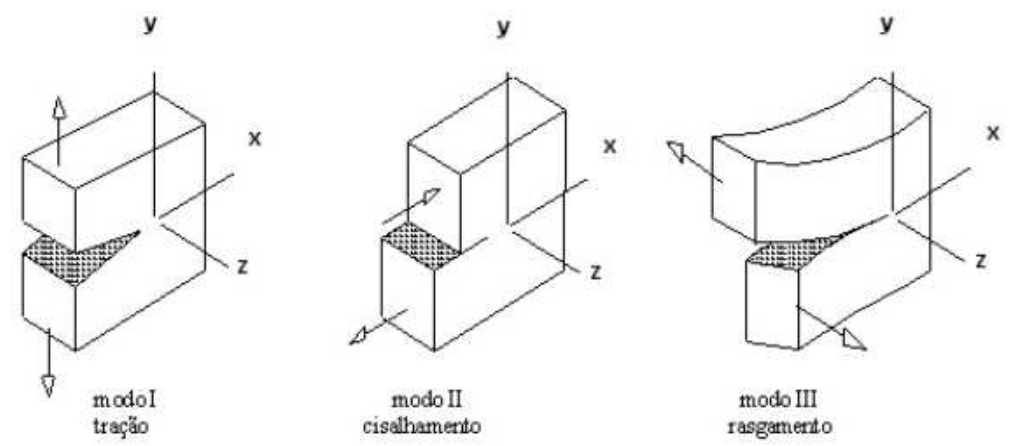

Figura 2.13: Modos típicos de carregamento que podem ser aplicados a um material por um agente externo: modo $I$ - tração, modo $I I$ - cisalhamento e modo $I I I$ - rasgamento [30].

Sendo assim, o fator de intensidade de tensão associado seria

$$
K_{c} \equiv \sigma_{c} \sqrt{\pi a_{c}}=\sqrt{S_{c} Y}
$$

estabelecendo uma conexão entre os processos que ocorrem na ponta da trinca (representados por $K_{c}$ ) e a energia liberada durante o processo (representada por $S_{c}$ ).

Em situações mais gerais do sistema, é instrutivo substituir o fator $S$ na expressão eq. (2.86) por um parâmetro generalizado de liberação de energia correspondendo a outras formas de energia que poderiam estar envolvidas no processo de crescimento da trinca (processos plásticos em materiais dúcteis, por exemplo) de maneira que [20]:

$$
\begin{aligned}
& S_{c} \rightarrow G_{I} ; \\
& K_{c} \rightarrow K_{I} ;
\end{aligned}
$$

$\therefore$

$$
G_{I}=\frac{K_{I}^{2}}{Y}
$$

onde o índice $I$ se refere a um modo particular de carregamento que pode ser submetido ao material denominado modo I ou modo de tração (ver figura 2.13) ${ }^{12}$.

A partir da relação generalizada envolvendo $G_{I}$ e $K_{I}$ [eq. (2.89)], esperamos ser capazes de contextualizar mais apropriadamente os resultados obtidos a partir de nossa formulação com conveniências experimentais relacionadas a medidas da liberação de energia tipicamente envolvidas nestes processos.

$\mathrm{Na}$ Tabela 2.2 apresentamos resultados experimentais para uma ampla variedade de materiais que confirmam nossas expectativas heurísticas de equivalência entre os parâmetros de intensificação de tensão e de liberação de energia.

\footnotetext{
${ }^{12}$ Resultados semelhantes poderiam ser obtidos a partir de expressões analíticas envolvendo a integral $J$ que descreve o trabalho realizado pelas tensões no interior do material [8].
} 


\begin{tabular}{|c|c|c|c|c|}
\hline Material & $G_{I}\left(\mathrm{~kJ} / \mathrm{m}^{2}\right)$ & $K_{I}\left(\mathrm{MNm^{2 }}\right)$ & $Y(G P a)$ & $K_{I}^{2} / Y\left(\mathrm{~kJ} / \mathrm{m}^{2}\right)$ \\
\hline Aço & 107 & 150 & 210 & 107,14 \\
\hline Aluminio & 20 & 37 & 69 & 19,84 \\
\hline Polietileno & 20 & - & 0,15 & - \\
\hline Poliestireno de alto impacto & 15,8 & - & 2,1 & - \\
\hline Borracha & 13 & - & 0,001 & - \\
\hline Aço suave & 12 & 50 & 210 & 11,90 \\
\hline Vidro de thermoset & 7 & 7 & 7 & 7 \\
\hline Borracha epoxy & 2 & 2,2 & 2,4 & 2,02 \\
\hline Acrílico & 0,5 & 1,1 & 2,5 & 0,48 \\
\hline Poliestireno & 0,4 & 1,1 & 3 & 0,40 \\
\hline Madeira & 0,12 & 0,5 & 2,1 & 0,12 \\
\hline Vidro & 0,007 & 0,7 & 70 & 0,007 \\
\hline
\end{tabular}

Tabela 2.2: Resultados experimentais caracterizando a rigidez típica dos principais materiais utilizados em aplicações práticas [20]. A taxa de liberação de energia $G_{I}$ e o fator de intensidade de tensão $K_{I}$ tabelados correspondem ao modo $I$ de carregamento (abertura) submetido às amostras analisadas. 


\section{Capítulo 3}

\section{Cálculo do expoente de Paris na presença de desordem}

Neste capítulo apresentaremos uma nova versão do modelo em que os limiares de tensão $F_{\text {lim }}$ das diferentes componentes que constituem o material não estão distribuídos uniformemente ao longo da linha de propagação do sistema, introduzindo assim desordem nas regras que o definiam originalmente. Pretendemos contornar a elevada complexidade matemática associada a este tipo de situação limitando nossa atenção, pelo menos de início, apenas ao caso particularmente simples em que o expoente de incremento de dano é considerado nulo $(\gamma=0)$, uma vez que o incremento de dano $\delta F\left(x ; a_{n}\right)$ sofrido pelas componentes do sistema não dependerá explicitamente de sua posição em relação a qualquer referencial adotado. Em um segundo momento, desenvolveremos abordagens mais abrangentes do modelo ao investigarmos o comportamento do expoente de Paris para situações em que o expoente de incremento de dano não sofre nenhum tipo de restrição de valores, ainda que sob uma perspectiva exclusivamente numérica.

\subsection{Apresentando o modelo}

Nesta seção estamos interessados em formalizar regras para o modelo que permitam descrever o crescimento de trincas no interior de materiais heterogêneos ao introduzirmos desordem nos limiares de tensão associados às diferentes componentes do sistema [32]. Neste caso, as hipóteses do modelo devem ser reconsideradas conforme um novo conjunto de regras a serem enumeradas a seguir ${ }^{1}$ :

(i) Distribuição de limiares de dano [32,54]:

$$
F_{\text {lim }}(x) ; F_{\text {min }} \leq F_{\text {lim }}(x) \leq F_{\max }
$$

onde $F_{\min }$ e $F_{\max }$ são, respectivamente, os limitantes inferior e superior para os limiares de dano das componentes.

\footnotetext{
${ }^{1}$ Utilizaremos numeração romana a fim de evitar qualquer tipo de ambiguidade em relação às versões apresentadas anteriormente.
} 
Assumiremos ainda, por simplicidade, que os limiares de dano estejam distribuídos aleatoriamente segundo uma distribuição uniforme dada por

$$
\rho\left(F_{\text {lim }}\right)=\frac{1}{\Delta F} \theta\left(F_{\text {max }}-F_{\text {lim }}\right) \theta\left(F_{\text {lim }}-F_{\text {min }}\right)
$$

onde $\theta(x)$ é a função degrau de Heaviside e $\Delta F \equiv F_{\max }-F_{\min }$ define o grau de desordem imposto ao sistema.

É importante destacar também que, neste caso, a componente a ser danificada não pertence necessariamente às vizinhanças da ponta da trinca inicial, possibilitando a existência de múltiplas trincas ao longo da linha de propagação e tornando o problema muito mais sutil do que os casos tratados anteriormente.

(ii) A configuração do sistema correspondente à n-ésima iteração das regras do modelo é representada por um conjunto de $N$ trincas ao longo de sua linha de propagação, denotado por

$$
\left\{a_{k}, \bar{x}_{k}\right\}_{n}
$$

onde $a_{k}$ é o semicomprimento de uma dada trinca centrada na posição $\bar{x}_{k}$ em relação a um sistema de referências escolhido convenientemente.

(iii) Relação de recorrência - lei de acumulação de dano:

$$
F\left(x ;\left\{a_{k}, \bar{x}_{k}\right\}_{n}\right)=F\left(x ;\left\{a_{k}, \bar{x}_{k}\right\}_{n-1}\right)+\delta F\left(x ;\left\{a_{k}, \bar{x}_{k}\right\}_{n}\right),
$$

onde $F\left(x ;\left\{a_{k}, \bar{x}_{k}\right\}_{n}\right)$ é o dano acumulado em uma componente do material localizada na posição $x$, dada uma configuração do sistema representada por $\left\{a_{k}, \bar{x}_{k}\right\}_{n}$, e $\delta F\left(x ;\left\{a_{k}, \bar{x}_{k}\right\}_{n}\right)$ é o incremento de dano associado.

(iv) Relação constitutiva - lei de incremento de dano:

$$
\delta F\left(x ;\left\{a_{k}, \bar{x}_{k}\right\}_{n}\right)=f_{0} \delta t\left(\left\{a_{k}, \bar{x}_{k}\right\}_{n}\right)\left[\Delta \sigma\left(x ;\left\{a_{k}, \bar{x}_{k}\right\}_{n}\right)\right]^{\gamma},
$$

onde $\delta t\left(\left\{a_{k}, \bar{x}_{k}\right\}_{n}\right)$ é o intervalo de tempo decorrido entre dois eventos consecutivos de ruptura e $\Delta \sigma\left(x ;\left\{a_{k}, \bar{x}_{k}\right\}_{n}\right)$ é a distribuição de tensão ao longo de sua linha de propagação.

Devemos enfatizar ainda que não podemos continuar descrevendo a distribuição de tensão $\Delta \sigma\left(x ;\left\{a_{k}, \bar{x}_{k}\right\}_{n}\right)$ através da expressão analítica eq. (2.1) determinada pela teoria elástica linear uma vez que a trinca inicial do sistema não se mantém necessariamente única ao longo de todo o seu processo de propagação (presença de múltiplas trincas ao longo do sistema). Sendo assim, é necessário que se escolha arbitrariamente uma trinca em particular dentre as várias possibilidades que podem emergir ao longo da linha de propagação, que passaremos a denominá-la por trinca principal do sistema, com a qual pretendemos determinar as propriedades estatísticas gerais do modelo ao acompanhar com exclusividade seu crescimento individual ao longo de todo o processo (ver figura 3.1). 


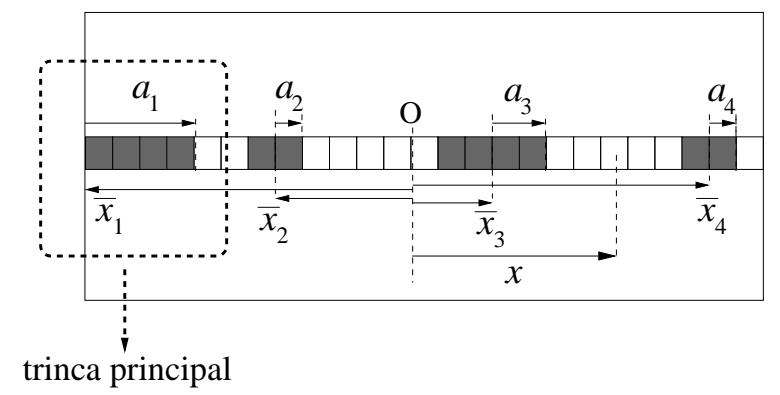

Figura 3.1: Representação esquemática de uma configuração do sistema em que a introdução de desordem nas regras do modelo é considerada destacando a presença de múltiplas trincas ao longo da linha de propagação. A trinca principal particularmente escolhida localiza-se na extremidade esquerda da amostra com centro na posição $\bar{x}_{1}$ em relação ao sistema de referências $O x$.

(v) Intervalo de tempo decorrido entre duas configurações consecutivas do sistema:

$$
\delta t\left(\left\{a_{k}, \bar{x}_{k}\right\}_{n}\right)=\min _{x}\left\{\frac{F_{l i m}(x)-F\left(x ;\left\{a_{k}, \bar{x}_{k}\right\}_{n-1}\right)}{f_{0}\left[\Delta \sigma\left(x ;\left\{a_{k}, \bar{x}_{k}\right\}_{n}\right)\right]^{\gamma}}\right\} .
$$

Neste caso, a componente a ser danificada corresponde àquela que atinge seu respectivo limiar de tensão mais precocemente, e não necessariamente uma daquelas pertencentes às vizinhanças da trinca inicial.

(vi) Condição inicial do sistema:

$$
F\left(x ;\left\{a_{k}, \bar{x}_{k}\right\}_{0}\right)=0,
$$

ou seja, partiremos sempre do princípio de que o dano inicial sobre todas as componentes do sistema seja nulo.

Sendo assim, diferentemente dos casos estudados anteriormente, devemos nos preocupar em calcular distribuições de probabilidade associadas ao crescimento da trinca principal escolhida em função do tempo [32]. A complexidade matemática associada ao cálculo das distribuições de probabilidades exigidas impõe sérias restrições ao tratamento analítico do modelo, de maneira que estamos interessados em considerar inicialmente o caso particularmente simples no qual o expoente de incremento de danos é considerado nulo, caracterizando um regime de acumulação uniforme de danos ao longo de todos os pontos da linha de propagação do sistema, que jamais poderia ser observado anteriormente pela versão original do modelo² .

\subsection{Acumulação uniforme de danos $(\gamma=0)$}

É possível simplificarmos o modelo ao ponto de permitir cálculos analíticos quando consideramos o caso particular em que o expoente de incremento de dano é nulo. Neste

\footnotetext{
${ }^{2}$ Pela ausência de divergências na velocidade de propagação da trinca principal neste caso limite.
} 
caso, as regras do modelo não exibem qualquer dependência explícita com a posição $x$ ao longo da linha de propagação, como passaremos a explicitar a seguir:

(i) Distribuição de limiares de dano:

$$
\begin{gathered}
F_{\text {lim }}(x) ; F_{\text {min }} \leq F_{\text {lim }}(x) \leq F_{\text {max }} \\
\rho\left(F_{\text {lim }}\right)=\frac{1}{\Delta F} \theta\left(F_{\text {max }}-F_{l i m}\right) \theta\left(F_{l i m}-F_{\text {min }}\right) .
\end{gathered}
$$

(ii) Configuração do sistema:

$$
\left\{a_{k}, \bar{x}_{k}\right\}_{n}
$$

(iii) Relação de recorrência - lei de acumulação de dano:

$$
F\left(x ;\left\{a_{k}, \bar{x}_{k}\right\}_{n}\right)=F\left(x ;\left\{a_{k}, \bar{x}_{k}\right\}_{n-1}\right)+\delta F\left(x ;\left\{a_{k}, \bar{x}_{k}\right\}_{n}\right) .
$$

(iv) Relação constitutiva - lei de incremento de dano:

$$
\delta F\left(x ;\left\{a_{k}, \bar{x}_{k}\right\}_{n}\right)=f_{0} \delta t\left(\left\{a_{k}, \bar{x}_{k}\right\}_{n}\right) .
$$

Neste caso, o incremento de dano depende apenas do intervalo de tempo entre configurações consecutivas do sistema. Sendo assim, a expressão para o intervalo de tempo passa a ser dada simplesmente por:

$$
\delta t\left(\left\{a_{k}, \bar{x}_{k}\right\}_{n}\right)=\frac{1}{f_{0}} \min _{x}\left[F_{l i m}(x)-F\left(x ;\left\{a_{k}, \bar{x}_{k}\right\}_{n-1}\right)\right] .
$$

(v) Condição inicial do sistema:

$$
F\left(x ;\left\{a_{k}, \bar{x}_{k}\right\}_{0}\right)=0 .
$$

As simplificações sofridas pelo modelo permitem determinar a probabilidade de encontrarmos uma componente do sistema danificada em um determinado instante $t$ do processo de propagação. Neste caso, considerando-se a distribuição de limiares de dano, podemos escrever

$$
d p=\rho\left(F_{\text {lim }}\right) d F_{\text {lim }},
$$

onde $d p$ é o diferencial de probabilidade de encontrarmos uma componente com limiar de dano entre $F_{\text {lim }}$ e $F_{\text {lim }}+d F_{\text {lim }}$.

Entretanto, pela lei de incremento de dano, temos também que

$$
d F_{\text {lim }}=f_{0} d t
$$

Sendo assim, a probabilidade de uma das componentes sofrer danos entre os instantes $t$ e $t+d t$ é dada simplesmente por

$$
d p=\frac{f_{0}}{\Delta F} d t
$$


É conveniente definirmos ainda

$$
\left\{\begin{array}{l}
f_{0} \rho=\frac{f_{0}}{\Delta F} \equiv \frac{1}{T} \\
t_{\text {min }} \equiv \frac{F_{\text {min }}}{f_{0}} \\
t_{\text {max }} \equiv \frac{F_{\max }}{f_{0}} \\
p\left(t_{\text {min }}\right)=0 ;
\end{array}\right.
$$

onde $t_{\min }$ é o instante em que a primeira componente se danifica e $t_{\max }$ é o instante em que ocorre o último rompimento.

Portanto,

$$
p(t)=\min \left\{1, \frac{t-t_{\text {min }}}{T} \theta\left(t-t_{\text {min }}\right)\right\} .
$$

Desta forma, o comportamento da probabilidade de encontrarmos uma componente danificada ao longo da linha de propagação do sistema é, essencialmente, linear com o tempo. Nas próximas seções pretendemos determinar o expoente de Paris a partir da probabilidade $p(t)$ de encontrarmos uma componente danificada através de argumentos simples envolvendo uma analogia que pode ser estabelecida entre a propagação de trincas e a percolação unidimensional.

\subsubsection{Esboçando o cálculo do expoente de Paris}

Nesta subseção estamos interessados em determinar a probabilidade de encontrarmos a trinca principal com semicomprimento $a(t)$ no instante $t$. Neste caso, é importante considerarmos ainda as seguintes hipóteses complementares:

1. Por simplicidade, é conveniente escolhermos como trinca principal a única trinca existente inicialmente no sistema, preparada na extremidade esquerda de uma amostra semi-infinita do material e cujo semicomprimento inicial seja dado por $a(0)=a_{0}$.

2. Para que a trinca principal considerada alcance um semicomprimento arbitrário $a(t)$ é necessário que, no instante correspondente, um grupo de $a-a_{0}$ componentes situadas em suas imediações já se encontrem danificadas (probabilidade $[p(t)]^{a-a_{0}}$ ) e a componente que delimitará a nova trinca permaneça intacta [probabilidade $1-p(t)]^{*}$.

Sendo assim, podemos escrever:

$$
P\left(a \mid a_{0}, t\right)=\frac{1}{Z}[p(t)]^{a-a_{0}}[1-p(t)]
$$

\footnotetext{
${ }^{*}$ A menos de um fator de normalização $1 / Z$ no limite termodinâmico.
} 
onde $P\left(a \mid a_{0}, t\right)$ representa a probabilidade de encontrarmos a trinca principal com comprimento $a(t)$ no instante $t$ a partir de uma configuração inicial em que a trinca principal encontrava-se com comprimento $a_{0}$ e $Z$ é apenas um fator de normalização.

A constante de normalização é dada por ${ }^{3}$

$$
Z=[1-p(t)] \sum_{a=a_{0}}^{\infty}[p(t)]^{a-a_{0}}=1,
$$

ou seja, a expressão já se encontra devidamente normalizada.

Portanto,

$$
P\left(a \mid a_{0}, t\right)=[p(t)]^{a-a_{0}}[1-p(t)] .
$$

Seguiremos agora calculando o comprimento médio da trinca em um dado instante da propagação, a saber,

$$
\langle a\rangle_{a_{0}, t}=\sum_{a=a_{0}}^{\infty} a P\left(a \mid a_{0}, t\right)=(1-p) \sum_{a=a_{0}}^{\infty} a p^{a-a_{0}} .
$$

A mudança de variável $\delta a=a-a_{0}$ permite-nos escrever:

$$
\langle a\rangle_{a_{0}, t}=(1-p) \sum_{\delta a=0}^{\infty}\left(\delta a+a_{0}\right) p^{\delta a}=(1-p)(\underbrace{\sum_{\delta a=0}^{\infty} \delta a p^{\delta a}}_{=\frac{p}{(1-p)^{2}}}+a_{0} \underbrace{\sum_{\delta a=0}^{\infty} p^{\delta a}}_{=\frac{1}{1-p}}) .
$$

Assim,

$$
\langle a\rangle_{a_{0}, t}=a_{0}+\frac{p(t)}{1-p(t)}
$$

Finalmente, a velocidade de propagação da trinca principal pode ser identificada com a derivada temporal de seu comprimento médio de acordo com:

$$
\langle v\rangle_{a_{0}, t}=\frac{d}{d t}\langle a\rangle_{a_{0}, t}
$$

$\therefore$

$$
\begin{gathered}
\langle v\rangle_{a_{0}, t}=\frac{d}{d t}\left(a_{0}+\frac{p}{1-p}\right)=\frac{1}{(1-p)^{2}} \underbrace{\frac{d p}{d t}}_{=\frac{1}{T}} ; \\
\langle v\rangle_{a_{0}, t}=\frac{1}{T} \frac{1}{(1-p)^{2}} .
\end{gathered}
$$

\footnotetext{
${ }^{3}$ Perceba que a soma deve ser iniciada em $a_{0}$.
} 
Reescrevendo em termos do comprimento médio da trinca $\langle a\rangle_{a_{0}, t}$, com o objetivo de explicitarmos a lei de Paris, obtemos:

$$
\langle v\rangle_{a_{0}, t}=\frac{1}{p^{2} T}\left(\langle a\rangle_{a_{0}, t}-a_{0}\right)^{2} .
$$

No limite de grandes comprimentos da trinca $\left(\langle a\rangle_{a_{0}, t} \gg a_{0}\right)$ :

$$
\langle v\rangle_{a_{0}, t} \sim\langle a\rangle_{a_{0}, t}^{2} .
$$

Portanto, o sistema continua a obedecer a lei de Paris mas com expoente médio dado por $m_{t}=4$, em contraste com os valores obtidos para a versão original do modelo no caso limite correspondente $(\gamma \rightarrow 0)$.

\subsubsection{Distribuição de probabilidades para o avanço da trinca principal}

Nesta seção pretendemos formalizar o cálculo do expoente de Paris em casos de acumulação uniforme de danos $(\gamma=0)$ ao determinarmos explicitamente a probabilidade condicional da trinca principal considerada sofrer incrementos em seu comprimento de magnitude $\Delta a$ em intervalos de tempo intercalados com duração $\Delta t$ ocorrendo conjuntamente ao longo do processo de propagação ${ }^{4}$. Admitindo-se a mesma escolha para a trinca principal do sistema considerada na seção anterior é importante destacarmos novamente um conjunto de observações adicionais como segue [32]:

1. Dado que a trinca principal encontra-se com semicomprimento $a(t)$ no instante $t$, para que ocorra uma avalanche de tamanho $\Delta a$ após um intervalo de tempo $d t$, é necessário que a componente na ponta da trinca se danifique (probabilidade $d p$ ), que outras $\Delta a-1$ componentes vizinhas já tenham alcançado seus respectivos limiares de tensão (probabilidade $p^{\Delta a-1}$ ), e que a componente correspondente à nova extremidade da trinca permaneça intacta (probabilidade $1-p$ ).

2. É necessário explicitarmos ainda a probabilidade de encontrarmos a trinca principal com semicomprimento $a(t)$ a partir da configuração inicial do sistema. Neste caso, é necessário que ocorra o rompimento de uma componente em um instante anterior da propagação dado por $t-\Delta t$ correspondendo a ocorrência da última avalanche na trinca principal (probabilidade $d p_{\Delta t}$ ) enquanto que um grupo de $a-a_{0}-1$ componentes situadas nas imediações da trinca inicial já tenham atingido seus respectivos limiares de tensão (probabilidade $[p(t-\Delta t)]^{a-a_{0}-1}$ ).

Sendo assim, a densidade de probabilidade $\rho\left(\Delta a, \Delta t, t \mid a, a_{0}\right)$ que estamos interessados em determinar é dada, simplesmente, pelo produto de cada um dos eventos independentes citados anteriormente, a saber [32]

$$
\rho_{\infty}\left(\Delta a, \Delta t, t \mid a, a_{0}\right)=\frac{1}{Z_{\infty}}[p(t-\Delta t)]^{a-a_{0}-1}[p(t)]^{\Delta a-1}[1-p(t)],
$$

onde $Z_{\infty}$ é apenas um fator de normalização para o sistema no limite termodinâmico.

\footnotetext{
${ }^{4} \mathrm{O}$ tempo de espera $\Delta t$ corresponde ao intervalo de tempo em que a trinca principal não sofre incrementos em seu comprimento. Neste caso, alguma trinca secundária é formada ou incrementa seu comprimento.
} 
Para amostras de tamanho finito $L$, é fácil perceber que a expressão anterior deve ser corrigida como segue:

$$
\rho_{L}\left(\Delta a, \Delta t, t \mid a, a_{0}\right)=\frac{1}{Z_{L}}[p(t-\Delta t)]^{a-a_{0}-1}[p(t)]^{\Delta a-1}\left\{[1-p(t)]\left(1-\delta_{\Delta a, L-a}\right)+\delta_{\Delta a, L-a}\right\},
$$

onde $\delta_{i j}$ é o símbolo delta de Kronecker e as parcelas adicionais entre chaves levam em consideração eventuais efeitos de borda.

A constante de normalização passa a ser dada por

$$
\begin{aligned}
& Z_{L}=\sum_{\Delta a=1}^{L-a} \int_{t_{\min }}^{t_{\max }} d t \int_{0}^{t-t_{\min }} d(\Delta t)[p(t-\Delta t)]^{a-a_{0}-1}[p(t)]^{\Delta a-1}\left\{[1-p(t)]\left(1-\delta_{\Delta a, L-a}\right)+\delta_{\Delta a, L-a}\right\} ; \\
& \therefore \\
& Z_{L}=\int_{t_{\min }}^{t_{\max }} d t \int_{0}^{t-t_{\min }} d(\Delta t)[p(t-\Delta t)]^{a-a_{0}-1}\{(1-p) \underbrace{\sum_{\Delta a=1}^{L-a-1} p^{\Delta a-1}}_{=\frac{1-p^{L-a-1}}{1-p}}+p^{L-a-1}\} \\
& Z_{L}=\int_{t_{\min }}^{t_{\max }} d t \underbrace{\int_{0}^{t-t_{\min }} d(\Delta t)\left[\frac{(t-\Delta t)-t_{\min }}{T}\right]^{a-a_{0}-1}}_{=\frac{T}{a-a_{0}}[p(t)]^{a-a_{0}}} ; \\
& Z_{L}=\frac{T}{a-a_{0}} \int_{t_{\min }}^{t_{\max }} d t p^{a-a_{0}}=\frac{T^{2}}{\left(a-a_{0}\right)} \underbrace{\int_{0}^{1} d p p^{a-a_{0}}}_{=\frac{1}{a-a_{0}+1}} \\
& Z_{L}=\frac{T^{2}}{\left(a-a_{0}\right)\left(a-a_{0}+1\right)}=Z_{\infty} .
\end{aligned}
$$

Portanto, em termos dos detalhes algébricos definidos na seção anterior, podemos escrever

$$
\rho_{L}\left(\Delta a, \Delta t, t \mid a, a_{0}\right)=\frac{\left(a-a_{0}\right)\left(a-a_{0}+1\right)}{T^{2}}\left(\frac{t-\Delta t-t_{\min }}{T}\right)^{a-a_{0}-1}\left(\frac{t-t_{\min }}{T}\right)^{\Delta a-1}\left[\left(\frac{t_{\max }-t}{T}\right)\left(1-\delta_{\Delta a L}\right)+\delta_{\Delta a L}\right] .
$$

\subsubsection{Determinação das distribuições marginais de avalanches $P_{L}\left(\Delta a \mid a, a_{0}\right)$ e de tempos de espera $\rho_{L}\left(\Delta t \mid a, a_{0}\right)$}

É interessante determinarmos ainda as probabilidades marginais que correspondem à distribuição de avalanches $P_{L}\left(\Delta a \mid a, a_{0}\right)$ e à distribuição de tempos de espera $\rho_{L}\left(\Delta t \mid a, a_{0}\right)$ 
associadas ao crescimento da trinca principal. Integrando sobre as variáveis de tempo $(t$ e $\Delta t$ ) obtemos a distribuição de avalanches como segue:

$$
\begin{gathered}
P_{L}\left(\Delta a \mid a, a_{0}\right)=\int_{t_{\text {min }}}^{t_{\max }} d t \int_{0}^{t-t_{\min }} d(\Delta t) \rho_{L}\left(\Delta a, \Delta t, t \mid a, a_{0}\right) ; \\
P_{L}\left(\Delta a \mid a, a_{0}\right)=\frac{1}{Z_{L}} \int_{t_{\min }}^{t_{\max }} d t p^{\Delta a-1}\left[(1-p)\left(1-\delta_{\Delta a, L-a}\right)+\delta_{\Delta a, L-a}\right] \underbrace{\int_{0}^{t-t_{\min }} d(\Delta t)[p(t-\Delta t)]^{a-a_{0}-1}}_{=\frac{T}{a-a_{0}} p^{a-a_{0}}} \\
P_{L}\left(\Delta a \mid a, a_{0}\right)=\frac{a-a_{0}+1}{T}\{\left(1-\delta_{\Delta a, L-a}\right) \underbrace{\int_{t_{\min }}^{t_{\max }} d t p^{\Delta a+a-a_{0}-1}(1-p)}_{=\frac{\left(\Delta a+a-a_{0}-1\right) ! 1 !}{\left(\Delta a+a-a_{0}+1\right) !} T}+\delta_{\Delta a, L-a}^{L \int_{t_{\min }}^{t_{\max }} d t p^{L-a_{0}-1}}\}
\end{gathered}
$$

Portanto,

$$
P_{L}\left(\Delta a \mid a, a_{0}\right)=\left(a-a_{0}+1\right)\left[\frac{1-\delta_{\Delta a, L-a}}{\left(\Delta a+a-a_{0}+1\right)\left(\Delta a+a-a_{0}\right)}+\frac{\delta_{\Delta a, L-a}}{L-a_{0}}\right] .
$$

Semelhantemente, a distribuição de tempos de espera pode ser calculada como segue:

$$
\begin{gathered}
\rho_{L}\left(\Delta t \mid a, a_{0}\right)=\sum_{\Delta a=1}^{L-a} \int_{t_{\min }+\Delta t}^{t_{\max }} d t \rho_{L}\left(\Delta a, \Delta t, t \mid a, a_{0}\right) \\
\therefore \\
\rho_{L}\left(\Delta t \mid a, a_{0}\right)=\frac{1}{Z_{L}} \int_{t_{\min }+\Delta t}^{t_{\max }} d t[p(t-\Delta t)]^{a-a_{0}-1}\{(1-p) \underbrace{\sum_{\Delta a=1}^{L-a-1}[p(t)]^{\Delta A-1}}_{=\frac{1-p^{L-a-1}}{1-p}}+p^{L-a-1}\} ; \\
\rho_{L}\left(\Delta t \mid a, a_{0}\right)=\frac{1}{Z_{L}} \underbrace{\int_{t_{\min }+\Delta t}^{t_{\max }} d t[p(t-\Delta t)]^{a-a_{0}-1}}
\end{gathered}
$$

Portanto,

$$
\rho_{L}\left(\Delta t \mid a, a_{0}\right)=\frac{\left(a-a_{0}+1\right)}{T}\left(1-\frac{\Delta t}{T}\right)^{a-a_{0}}
$$


Nas próximas seções as distribuições marginais de avalanche e de tempo de espera desempenharão um importante papel no cálculo do expoente de Paris para esta versão do modelo, ao definirmos a velocidade de propagação da trinca principal em termos de seus valores médios associados. Além disso, pretendemos confrontar os resultados analíticos desta seção com simulações numéricas do modelo a serem formalizadas na última seção deste capítulo [seção (3.3)].

\subsubsection{Formalizando o cálculo do expoente de Paris}

Para a determinação do expoente de Paris é conveniente definirmos a velocidade de propagação da trinca principal, pelo menos em média, como sendo ${ }^{5}$ [32]

$$
\langle v\rangle_{a, a_{0}, L}=\frac{\langle\Delta a\rangle_{a, a_{0}, L}}{\langle\Delta t\rangle_{a, a_{0}, L}}
$$

ou seja, a velocidade média de propagação da trinca principal pode ser interpretada como sendo a razão entre o tamanho médio de uma avalanche e o tempo médio de espera entre dois de seus avanços consecutivos conforme os cálculos a serem explicitados a seguir.

\section{Cálculo do tamanho médio das avalanches:}

$$
\begin{aligned}
& \langle\Delta a\rangle_{a, a_{0}, L}=\sum_{\Delta a=1}^{L-a} \Delta a P_{L}\left(\Delta a \mid a, a_{0}\right) \\
& \therefore \\
& \langle\Delta a\rangle_{a, a_{0}, L}=\left(a-a_{0}+1\right)\left\{\sum_{\Delta a=1}^{L-a-1} \frac{\Delta a}{\left(\Delta a+a-a_{0}+1\right)\left(\Delta a+a-a_{0}\right)}+\frac{L-a}{L-a_{0}}\right\} ; \\
& \sum_{\Delta a=1}^{L-a-1} \frac{\Delta a}{\left(\Delta a+a-a_{0}+1\right)\left(\Delta a+a-a_{0}\right)}=\left\{\begin{array}{l}
H_{L-a_{0}-1}-H_{a-a_{0}}-\frac{L-a-1}{L-a_{0}}, a \neq a_{0} \\
H_{L-a_{0}}-1, \quad a=a_{0} ;
\end{array}\right. \\
& \langle\Delta a\rangle_{a, a_{0}, L}=\left(a-a_{0}+1\right)\left[\left(H_{L-a_{0}}-H_{a-a_{0}}\right)\left(1-\delta_{a a_{0}}\right)+H_{L-a_{0}} \delta_{a a_{0}}\right],
\end{aligned}
$$

onde $H_{n}$ é o número harmônico de ordem $n$ e $\delta_{i j}$ é o símbolo delta de Kronecker (ver figura $3.2)$.

\section{Cálculo do tempo médio de espera:}

$$
\langle\Delta t\rangle_{a, a_{0}, L}=\int_{0}^{T} d(\Delta t) \Delta t \rho_{L}\left(\Delta t \mid a, a_{0}\right) ;
$$

\footnotetext{
${ }^{5}$ É importante mencionar que existem inúmeras possibilidades alternativas para a definição da velocidade média de propagação da trinca (apesar de não termos explorado explicitamente), sendo que todas elas fornecem, coerentemente, o mesmo expoente de Paris.
} 


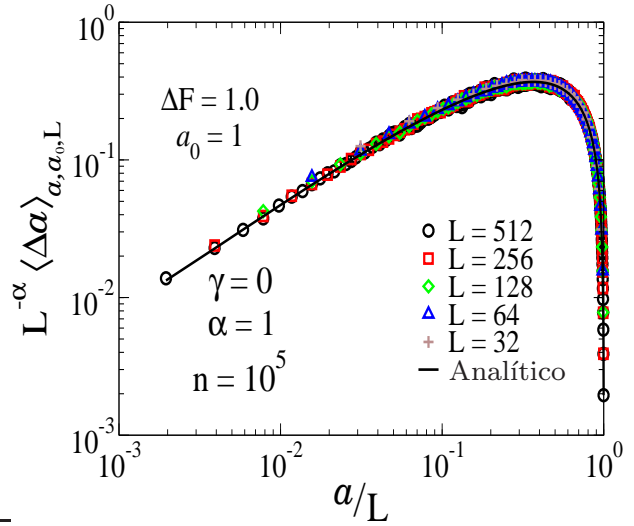

(a)

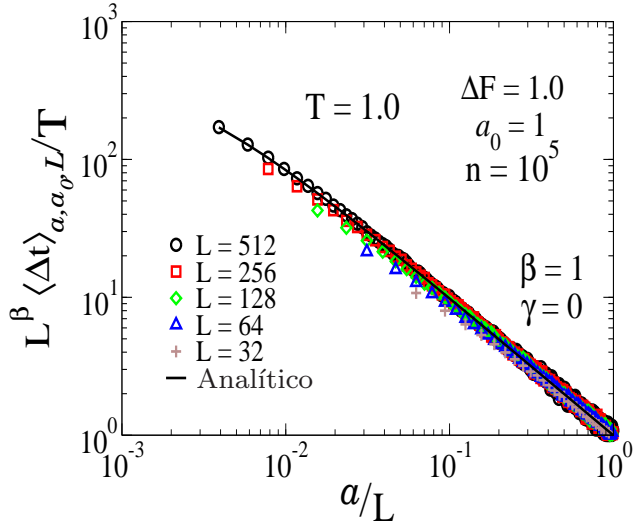

(b)

Figura 3.2: Relações de escala obtidas numericamente para o modelo na presença de desordem considerando-se o limite de acumulação uniforme de danos $(\gamma=0)$ : Valores médios para (a) avalanches e (b) tempos de espera associados à trinca principal do sistema reescalados pelo tamanho do sistema. Os resultados apresentam boa concordância com as expressões analíticas confirmando a ocorrência de leis de potências entre as grandezas médias e o comprimento da trinca principal com expoentes de escala unitários $(\alpha, \beta=1)$.

$\therefore$

$$
\begin{gathered}
\langle\Delta t\rangle_{a, a_{0}, L}=\frac{a-a_{0}+1}{T} \underbrace{\int_{0}^{T} d(\Delta t) \Delta t\left(1-\frac{\Delta t}{T}\right)^{a-a_{0}}}_{=\frac{1 !\left(a-a_{0}\right) !}{\left(a-a_{0}+2\right) !} T^{2}} ; \\
\langle\Delta t\rangle_{a, a_{0}, L}=\frac{T}{\left(a-a_{0}+2\right)} .
\end{gathered}
$$

onde o tempo médio de espera é dado simplesmente por uma fração do tempo de ruptura catastrófica $T$ apresentado pelo sistema (ver figura 3.2).

Sendo assim,

$$
\langle v\rangle_{a, a_{0}, L}=\frac{\left(a-a_{0}+2\right)\left(a-a_{0}+1\right)}{T}\left[\left(1-\delta_{a, a_{0}}\right)\left(H_{L-a_{0}}-H_{a-a_{0}}\right)+\delta_{a, a_{0}} H_{L-a_{0}}\right] .
$$

No limite de grandes comprimentos da trinca $\left(L \gg a \gg a_{0}\right)$ podemos escrever:

$$
\begin{aligned}
& H_{L} \approx \ln (L)+\gamma_{E M}+\frac{1}{2 L}+O\left(L^{-2}\right) \\
& \langle v\rangle_{a, a_{0}, L} \propto\langle v\rangle_{a, L} \approx\left[\frac{1}{T} \ln (L / a)\right] a^{2} ;
\end{aligned}
$$




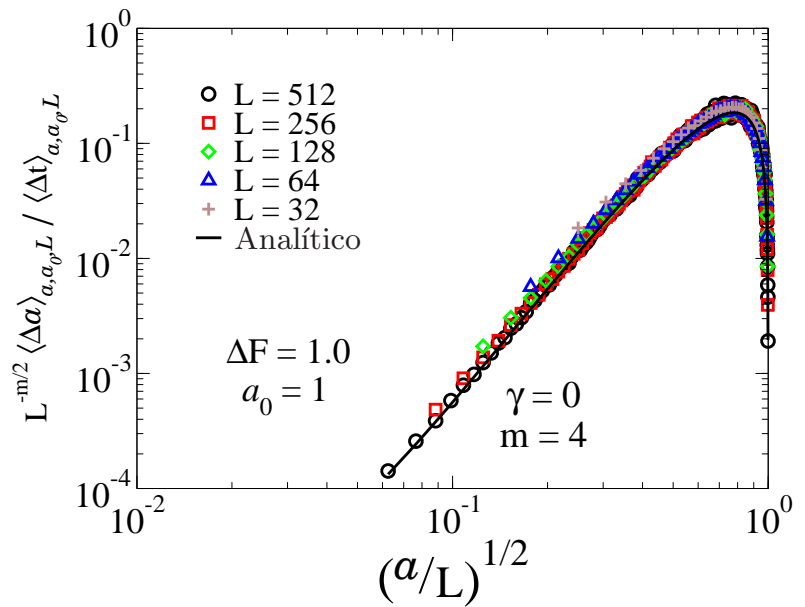

Figura 3.3: Relações de escala obtidas numericamente para a velocidade de propagação da trinca principal no limite de acumulação uniforme de danos $(\gamma=0)$. Os resultados numéricos apresentam boa concordância quando confrontados com as expressões analíticas obtidas, reproduzindo satisfatoriamente a lei de Paris e fornecendo o expoente de Paris esperado, a saber, $m=4$.

onde $\gamma_{E M}$ é a constante de Euler - Mascheroni ${ }^{6}$.

Portanto,

$$
m_{a}=4,
$$

a menos de correções logarítmicas que dependem do tamanho do sistema no fator de proporcionalidade (ver figura 3.3) ${ }^{7}$.

\subsection{Expoente de incremento de dano não nulo $(\gamma \neq 0)$}

Nesta seção pretendemos estudar as propriedades do modelo quando o expoente de incremento de dano é não nulo, caso em que as dificuldades técnicas reduzem significativamente as chances de um tratamento analítico. A abordagem a ser desenvolvida será predominantemente numérica, baseando-se em uma grande quantidade de simulações e aproximações do tipo "campo efetivo" que desprezam as interações entre as diversas trincas que podem se formar ao longo da linha de propagação da trinca.

\subsubsection{Condições mínimas para a unicidade da trinca inicial do sistema}

Nesta subseção estamos particularmente interessados em determinar as condições gerais necessárias para a garantia da ocorrência de avalanches na ponta da trinca principal do sistema. Não é difícil perceber que, para uma trinca principal suficientemente grande

\footnotetext{
${ }^{6}$ Mais uma vez, alteramos a notação tipicamente utilizada para a constante de Euler-Mascheroni através da utilização do índice $E M\left(\gamma \rightarrow \gamma_{E M}\right)$ a fim de evitarmos qualquer tipo de ambiguidade em relação à notação previamente utilizada para o expoente de incremento de dano.

${ }^{7}$ Suspeitamos que estas correções podem se tornar bastante acentuadas nas vizinhanças do valor crítico para o expoente de incremento de danos $\gamma_{c}$ como será investigado numericamente na próxima seção.
} 
$\left(a_{0} \gg \delta r\right)$, a condição mínima para a ocorrência de tais avalanches deve ser dada por [6]

$$
F_{l i m}\left(a_{n}+\delta r\right)<F\left(a_{n}+\delta r ;\left\{\bar{x}_{k}, a_{k}\right\}_{n-1}\right) \equiv F_{n-1}\left(a_{n}+\delta r\right)
$$

ou seja, na $n$-ésima iteração das regras do modelo é necessário que, pelo menos, a componente imediatamente próxima à ponta da trinca alcance seu respectivo limiar de dano.

Infelizmente, o cálculo do dano para qualquer componente nas imediações da ponta da trinca não pode ser realizado de forma determinística pelas muitas razões apontadas anteriormente. Entretanto, podemos retomar o termo geral $G_{n}$ calculado no capítulo anterior através de desigualdades majorantes que limitem os valores de tensão $F_{n-1}\left(a_{n}+\delta r\right)$ requeridos, como pretendemos evidenciar a seguir [6]:

(A) SEMICOMPRIMENTO $a_{0}$ :

$$
F\left(a_{0}+2 \delta r ;\left\{\bar{x}_{k}, a_{k}\right\}_{0}\right) \leq F_{\max } G_{1} .
$$

(B) SEMICOMPRIMENTO $a_{0}+\delta r$ :

$$
F\left(a_{0}+3 \delta r ;\left\{\bar{x}_{k}, a_{k}\right\}_{1}\right) \leq F_{\max } G_{2} .
$$

(C) SEMICOMPRIMENTO $a_{0}+n \delta r$ :

$$
F\left(a_{0}+n \delta r ;\left\{\bar{x}_{k}, a_{k}\right\}_{n-2}\right) \leq F_{\max } G_{n-1} .
$$

A generalização é imediata, como segue:

$$
F\left(a_{0}+(n+1) \delta r ;\left\{\bar{x}_{k}, a_{k}\right\}_{n-1}\right) \leq F_{\max } G_{n} \approx F_{\max }\left(\frac{s_{\infty}}{1+s_{\infty}}\right) .
$$

Portanto, para que ocorra uma avalanche devemos impor que

$$
F_{\text {min }} \leq F_{\text {lim }} \leq F\left(a_{0}+(n+1) \delta r ;\left\{\bar{x}_{k}, a_{k}\right\}_{n-1}\right) \leq F_{\max }\left(\frac{s_{\infty}}{1+s_{\infty}}\right)
$$

$\therefore$

$$
F_{\min } \leq F_{\max }\left(\frac{s_{\infty}}{1+s_{\infty}}\right)
$$

Assim, avalanches ocorrerão se

$$
\frac{F_{\min }}{F_{\max }} \leq \frac{s_{\infty}}{1+s_{\infty}}
$$

$\therefore$

$$
\frac{F_{\min }}{F_{\max }} \leq \frac{\zeta(\gamma / 2)-1}{\zeta(\gamma / 2)}, \quad \gamma>\gamma_{c}
$$


Se $\gamma<\gamma_{c}$, qualquer valor finito de desordem leva a ocorrência de avalanches pois [6]

$$
\frac{F_{\min }}{F_{\max }} \leq \frac{\zeta(\gamma / 2)-1}{\zeta(\gamma / 2)} \rightarrow 1
$$

Neste caso, é interessante perceber que o modelo apresenta um intervalo de valores para o expoente de incremento de dano onde a desordem seja "relevante" $\left(\gamma<\gamma_{c}\right)$, ou seja, as propriedades do modelo modificam-se fundamentalmente pelo simples fato da introdução de desordem ser considerada.

\subsubsection{A hipótese da aproximação de trincas independentes (ATI)}

Nesta seção estamos interessados em formalizar uma metodologia numérica capaz de descrever a lei de Paris para a situação mais geral do modelo em que o expoente de incremento de dano não seja necessariamente nulo. Nestes casos, a possibilidade de múltiplas trincas ao longo da linha de propagação inviabiliza o emprego da expressão (2.1), impossibilitando a continuidade dos cálculos analíticos, uma vez que nenhuma expressão analítica para a distribuição de tensões na presença de múltiplas trincas é conhecida exatamente.

Uma alternativa capaz de contornar tais dificuldades consiste na utilização de uma técnica associada a um modelo bastante difundido na literatura, denominado modelo da rede de fusíveis $(R F)[55,56]$ (maiores detalhes no apêndice B), que permite a obtenção numérica da distribuição de tensões requerida a partir das equações fundamentais que descrevem a mecânica dos meios elásticos envolvida neste contexto. Entretanto, a aplicabilidade prática deste método costuma apresentar graves inconvenientes associados ao elevado custo computacional dos cálculos, mesmo para sistemas de tamanhos relativamente pequenos.

Diante deste cenário, pretendemos considerar outras possibilidades para o cálculo das tensões, ainda que baseadas em severas aproximações. Estamos dispostos a admitir a hipótese mais trivial a respeito da amplitude de tensões para estes casos, supondo simplesmente uma superposição das contribuições individuais associadas a cada uma das trincas separadamente, segundo a expressão analítica previamente conhecida, desprezando assim quaisquer tipos de correlação existente entre elas.

Segundo esta aproximação, denominada aproximação de trincas independentes (ATI), a amplitude de tensões passaria a ser dada por

$$
\begin{gathered}
\Delta \sigma\left(x ;\left\{a_{k}, \bar{x}_{k}\right\}_{n}\right)=\Delta \sigma_{0}+\sum_{k=1}^{N}\left[\Delta \sigma_{k}\left(x ; a_{k}, \bar{x}_{k}\right)-\Delta \sigma_{0}\right] ; \\
x \notin \bigcup_{k=1}^{N}\left(\bar{x}_{k}-a_{k}, \bar{x}_{k}+a_{k}\right) ;
\end{gathered}
$$

onde $\Delta \sigma\left(x ;\left\{a_{k}, \bar{x}_{k}\right\}_{n}\right)$ representa a amplitude de tensão ao longo da linha de propagação associada a uma configuração do sistema apresentando $N$ trincas centradas nas posições $\bar{x}_{k}$ com respectivos semicomprimentos dados pela distribuição $\left\{a_{k}\right\}, \Delta \sigma_{0}$ é a amplitude de tensão externa aplicada e $\Delta \sigma_{k}\left(x ; a_{k}, \bar{x}_{k}\right)$ representa a distribuição de tensões que seria produzida pela $k$-ésima trinca considerando-se a ausência de todas as demais trincas do 


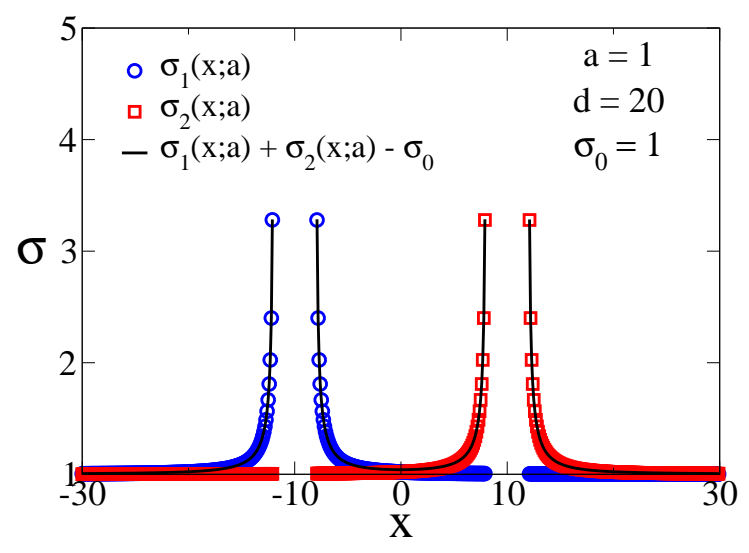

Figura 3.4: Comportamento típico da distribuição de tensão associada a duas trincas idênticas com semicomprimentos unitários $(a=1)$ e centros separados por uma distância $d=20$ considerando-se a aproximação de trincas independentes segundo a expressão analítica oriunda da teoria elástica linear. As distribuições de tensão $\sigma_{1}(x ; a)$ e $\sigma_{2}(x ; a)$ correspondem àquelas associadas a cada uma das trincas consideradas individualmente.

sistema (ver figura 3.4). Perceba que a "superposição" considerada deve receber correções apropriadas de maneira que a amplitude de tensão no infinito seja igual à amplitude de tensão externa aplicada (uma importante condição de contorno a ser satisfeita).

Esta abordagem permite-nos determinar uma boa aproximação para o comportamento de sistemas apresentando múltiplas trincas ao longo de sua linha de propagação, proporcionando o devido estudo das propriedades do modelo na presença de desordem. Na figura 3.5 confirmamos a boa concordância obtida na comparação entre a abordagem da rede de fusíveis e a aproximação de trincas independentes, considerando-se uma configuração do sistema com duas trincas de mesmo comprimento, atestando a confiabilidade de nossa abordagem aproximada.

Sendo assim, passaremos a admitir indiscriminadamente a hipótese de trincas independentes sempre que for necessário o cálculo da distribuição de tensões para um valor arbitrário do expoente de incremento de dano. Em nossas simulações sempre levamos em conta uma grande quantidade de realizações numéricas do sistema (tipicamente da ordem de $n=10^{5}$ realizações) com amostras variando de tamanho entre $L=2^{5}$ e $L=2^{9}$ para uma ampla variedade de graus de desordem $\Delta F$ introduzidas.

Nas figuras 3.6 e 3.7 apresentamos o comportamento típico do valor médio de avalanches e tempos de espera entre elas como função do semicomprimento $a$ da trinca. Os resultados mostram que ambos valores médios permanecem obedecendo leis de potências, assim como no caso de acumulação uniforme de danos $(\gamma=0)$, com expoentes característicos bem definidos e em boa concordância qualitativa com os resultados obtidos pelo modelo de fusíveis aleatórios. É importante esclarecer também que, a partir destas novas simulações com expoente de incremento de dano arbitrário, passa a ser mais conveniente escolhermos a trinca principal do sistema de maneira que seu ponto médio coincida inicialmente com o ponto médio da amostra considerada, ao contrário da escolha realizada para a obtenção dos resultados analíticos, onde a trinca principal era escolhida para iniciar seu crescimento 


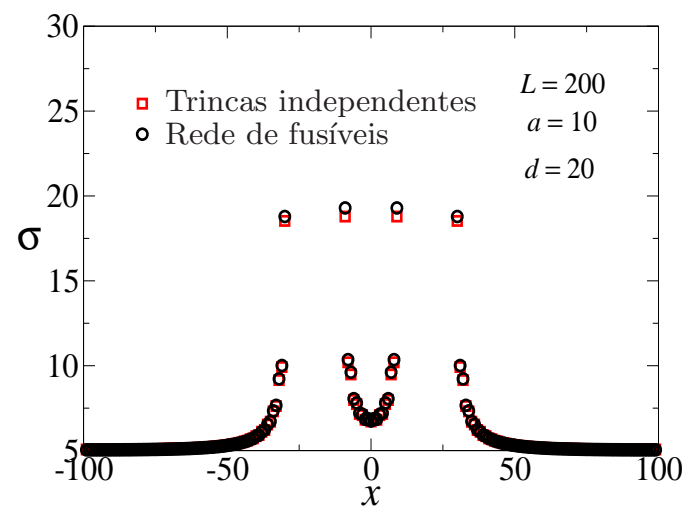

(a)

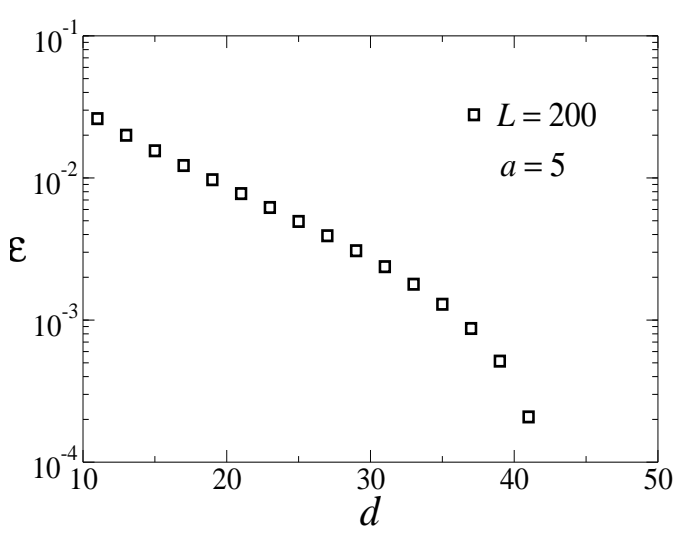

(b)

Figura 3.5: (a) Comportamento típico da tensão $\sigma\left(x ;\left\{a_{k}, \bar{x}_{k}\right\}\right)$ ao longo da linha de propagação de um sistema contendo duas trincas idênticas segundo a aproximação de trincas independentes. (b) Erro relativo entre o resultado obtido pela rede de fusíveis aleatórios e a aproximação de trincas independentes para a tensão na ponta da trinca, $\epsilon$, como função da distância $d$ de separação entre o par de trincas considerado.

a partir da extremidade esquerda da amostra.

O comportamento típico da velocidade de propagação da trinca principal para diferentes tamanhos de sistema é apresentado na figura 3.8, mostrando que o modelo é, de fato, capaz de reproduzir a lei de Paris dentro da aproximação de trincas independentes ${ }^{8}$. Os valores escolhidos para o expoente de Paris obedecem as relações de escala definidas no capítulo 2 e correspondem ao melhor colapso de curvas de velocidade reescalonadas para diferentes tamanhos da trinca principal com mesmo expoente de acumulação de danos. A dependência entre o expoente de Paris e o expoente de acumulação de dano $(m \times \gamma)$ para diferentes graus de desordem é também apresentada na figura 3.9 juntamente com os resultados do caso de acumulação uniforme para efeitos de comparação.

É interessante perceber que, em todos os casos estudados, existe uma forte tendência do expoente de Paris em apresentar um valor constante $m(\gamma)=4$ no intervalo $\gamma<\gamma_{c}$, independentemente do grau de desordem considerado. É instrutivo considerarmos ainda um cálculo simples relacionado ao comportamento do expoente de Paris em metais que atribui o crescimento da trinca aos diversos processos plásticos que podem ocorrer na ponta da trinca, de maneira que

$$
\frac{d a}{d t} \sim V_{p} \sim r_{p}^{2}
$$

onde $V_{p}$ é o volume da zona plástica correspondente à ponta da trinca principal do sistema, cujo formato seria, presumidamente, um cilindro com raio da base $r_{p}$ centrado em sua ponta $[20]$.

\footnotetext{
${ }^{8}$ Obtidas através da derivação numérica do tamanho médio da trinca como função do tempo, $d\langle a\rangle / d t$, ao invés da razão entre os valores médios de avalanche e tempos de espera entre elas.
} 
A partir da equação (1.22), podemos constatar que

$$
\frac{d a}{d t} \sim K^{4} \sim a^{2} \Rightarrow m \simeq 4
$$

como observado para sistemas que dependem fracamente da amplitude de tensões ao longo do sistema (acumulação de danos quase-uniforme; $\gamma \ll \gamma_{c}$ ). Acreditamos que, no caso dos metais, o grau de desordem poderia assumir valores típicos suficientemente altos que, eventualmente, explicaria a ocorrência da universalidade associada aos valores do expoente de incremento de danos destes materiais. 

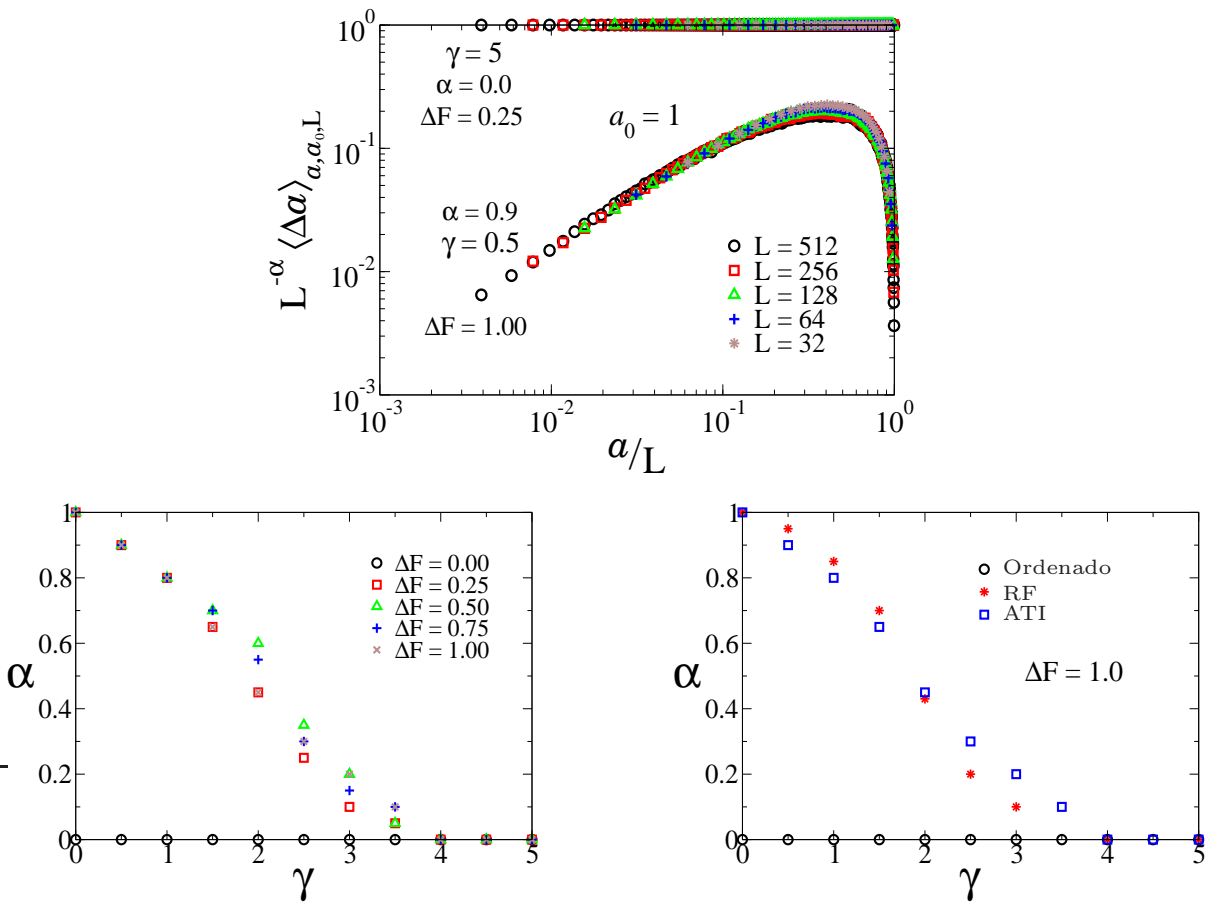

Figura 3.6: Relações de escala obtidas numericamente para o valor médio das avalanches, $\langle\Delta a\rangle_{a, a_{0}, L}$, como função do tamanho reescalado da trinca principal do sistema, $a / L$. Linha inferior de encartes: dependência do expoente $\alpha$ em relação ao expoente de incremento de dano, $\gamma$, para diferentes graus de desordem à esquerda e comparação entre os resultados obtidos pela aproximação de trincas independentes e o modelo da rede de fusíveis considerando-se um grau de desordem unitário à direita. 

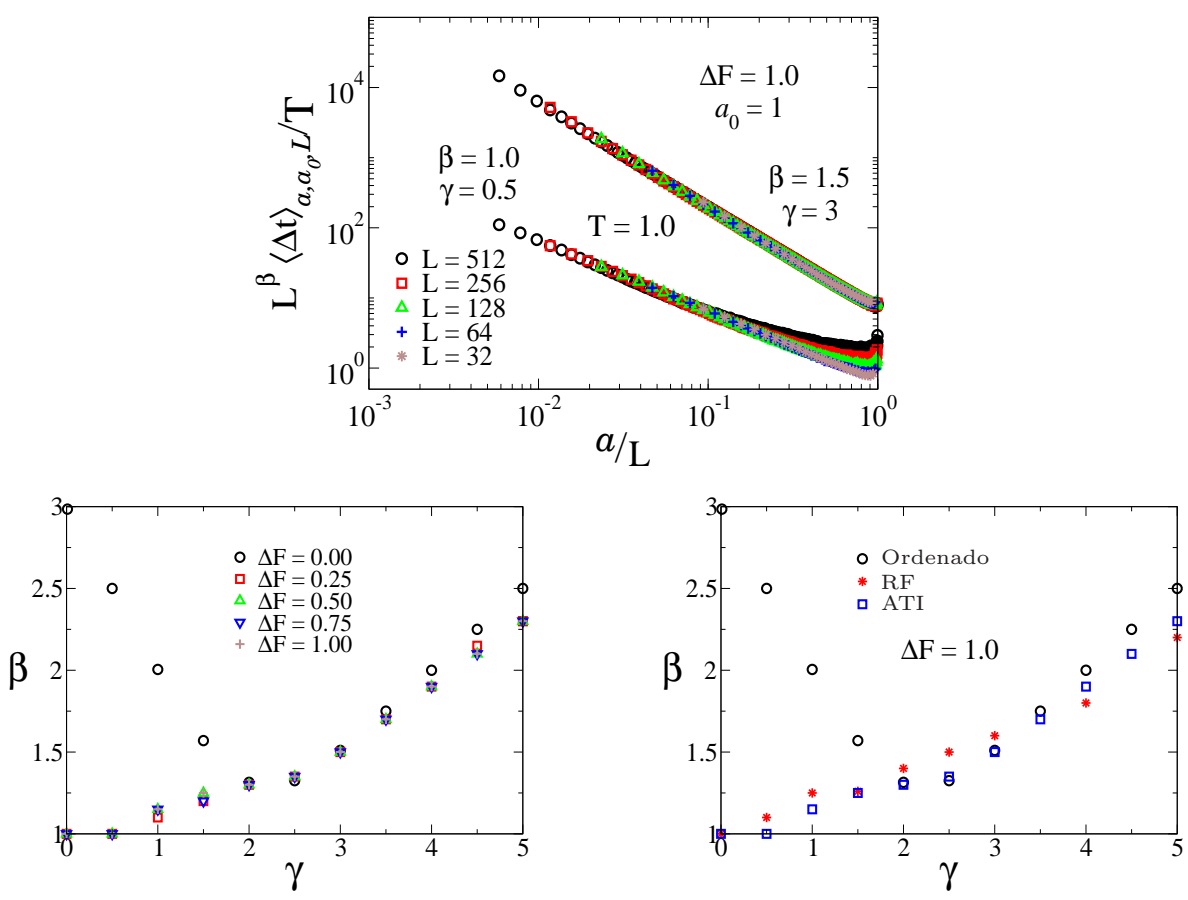

Figura 3.7: Relações de escala obtidas numericamente para o valor do tempo médio de espera entre avalanches, $\langle\Delta t\rangle_{a, a_{0}, L}$, como função do tamanho reescalado da trinca principal do sistema, $a / L$. Linha inferior de encartes: dependência do expoente de escala $\beta$ em relação ao expoente de incremento de dano, $\gamma$, para diferentes graus de desordem à esquerda e comparação entre os resultados obtidos pela aproximação de trincas independentes e o modelo da rede de fusíveis considerando-se um grau de desordem unitário à direita. 


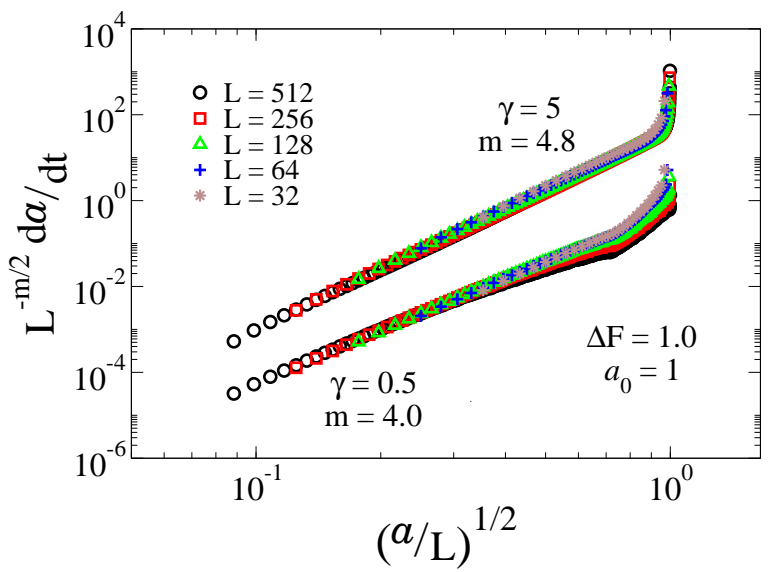

Figura 3.8: Relações de escala obtidas numericamente para a velocidade de propagação da trinca principal, $d a / d t$, como função de seu semicomprimento reescalado, $a / L$, considerando-se diferentes realizações do sistema com tamanhos variando de $L=2^{5}$ a $L=2^{9}$ e grau de desordem unitário $(\Delta F=1.0)$. Deslocamos convenientemente os resultados obtidos para $\gamma=5$ para cima por um fator de dez, garantindo uma melhor visualização. Consideramos uma definição particular para a velocidade da trinca que minimiza as flutuações estatísticas: calculamos a derivada numérica do tamanho da trinca em relação ao tempo médio em que a trinca permanece com aquele tamanho. Levamos em consideração uma grande quantidade de ensembles com $n=10^{5}$ realizações numéricas do sistema de maneira que a trinca principal sempre inicia seu crescimento com centro posicionado no ponto médio de cada amostra.

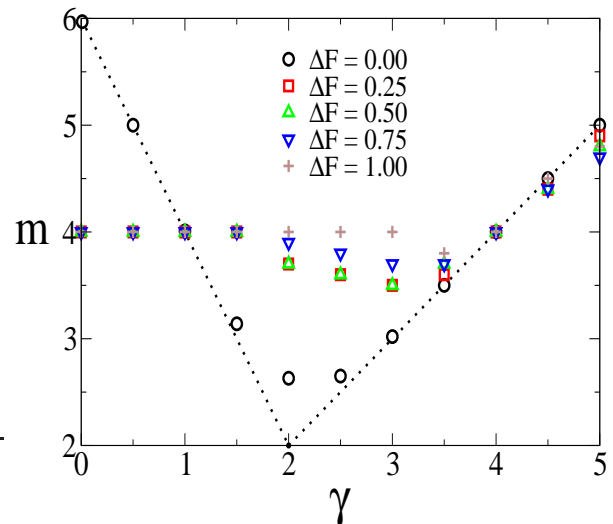

(a)

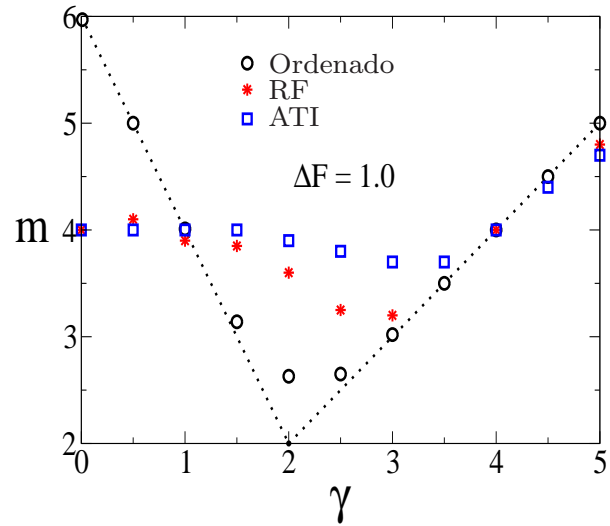

(b)

Figura 3.9: (a) Dependência entre o expoente de Paris, $m$, e o expoente de incremento de dano, $\gamma$, para o modelo na presença de desordem. (b) Comparação entre os resultados obtidos através do modelo de fusíveis aleatórios e da aproximação de trincas independentes para a mesma relação $(m \times \gamma)$ com um grau de desordem unitário $(\Delta F=1.0)$. Perceba a razoável concordância qualitativa obtida no confronto entre os resultados provenientes de ambos os métodos, indicando uma forte tendência do sistema em apresentar um expoente de Paris constante $m(\gamma)=4$ no intervalo $\gamma<\gamma_{c}$. 


\section{Interlúdio}

Estamos nos aproximando dos capítulos finais da tese e acreditamos ser conveniente fazermos uma breve pausa para enfatizarmos aspectos importantes de todo o trabalho desenvolvido até o momento. Nossos principais resultados foram divididos, essencialmente, em duas partes ao longo dos capítulos anteriores, a saber, uma correspondente ao modelo de propagação de trincas em sua versão original e outra correspondente a suas propriedades estocásticas na presença de desordem do tipo quenched. No próximo capítulo pretendemos simplesmente retomar uma série de investidas e novas tentativas de generalização do modelo em sua versão original, ainda que seus resultados não estejam plenamente formalizados. Finalmente, dedicaremos o último capítulo as conclusões e considerações finais como a tradição recomenda. 


\section{Capítulo 4}

\section{Novas propostas para a generalização do modelo}

Neste capítulo estamos interessados em explorar uma série de modificações no modelo de Vieira e colaboradores com o objetivo de contemplar situações mais gerais dos processos de propagação de trincas. No capítulo 2 mostramos que mudanças desta natureza são capazes de proporcionar significativas alterações na relação entre o expoente de Paris e o expoente de incremento de dano, diferentemente dos resultados reportados por Vieira e colaboradores em [6]. Dentre as modificações pretendidas, destacamos uma proposta baseada em um modelo massa-mola utilizado anteriormente por Marder para estudar o fenômeno conhecido como aprisionamento de trincas pela rede (lattice trapping of cracks) [57] e a introdução do efeito de regeneração de trincas na lei de acumulação de danos, cuja principal motivação está associada a resultados experimentais relacionados a materiais poliméricos $^{1}[5]$.

\subsection{Introduzindo efeitos de regeneração de trincas nas regras do modelo}

Nesta seção pretendemos incluir o efeito de regeneração de trincas na lei de acumulação de danos do modelo. Dentre as principais motivações para o estudo deste fenômeno podemos destacar a regeneração de trincas observada em polímeros, que vem despertando bastante atenção da comunidade científica desde a publicação de White e colaboradores $[3,58]$, além de diversas propostas de generalização do modelo de feixes de fibras que consideram a regeneração das fibras constituintes do sistema através de alterações convenientes em suas regras $[5,48,53,59]$.

\subsubsection{Apresentando o modelo}

Modificaremos as regras do modelo original de maneira a incorporar efeitos de regeneração de trincas ao considerarmos que apenas uma fração do incremento de dano em

\footnotetext{
${ }^{1}$ É importante destacar que as alterações que pretendemos considerar não envolverão, em nenhum momento, os casos com a presença de desordem nas regras do modelo.
} 
instantes anteriores contribui para o cálculo do dano acumulado no instante atual, como passaremos a detalhar a seguir:

1. A variável de posição $x$ continua sendo discretizada, a saber,

$$
a_{n}=a_{0}+n \delta r .
$$

onde $a_{0}$ é o semicomprimento inicial da trinca, $a_{n}$ é o semicomprimento da trinca em um instante associado a $n$-ésima iteração das regras do modelo e $\delta r$ é o incremento no semicomprimento da trinca a cada iteração.

2. Relação de recorrência - lei de acumulação de danos:

$$
F\left(x ; a_{n}\right)=F\left(x ; a_{n}-\delta r\right) e^{-\delta t\left(a_{n}\right) / \tau}+\delta F\left(x ; a_{n}\right),
$$

onde $F\left(x ; a_{n}\right)$ é o dano acumulado sobre uma componente localizada pela coordenada $x$ em uma configuração do sistema cujo semicomprimento da trinca é dado por $a_{n} \mathrm{e}$ $\delta F\left(x ; a_{n}\right)$ é o incremento de dano associado.

A forma funcional do tipo exponencial para o fator de regeneração é justificada por ajustar bem resultados experimentais relacionados diversos materiais poliméricos reportados na literatura, como o asfalto, por exemplo [5].

3. Relação constitutiva - lei de incremento de dano:

$$
\delta F\left(x ; a_{n}\right)=f_{0} \tau\left[1-e^{-\delta t\left(a_{n}\right) / \tau}\right]\left[\Delta \sigma\left(x ; a_{n}\right)\right]^{\gamma},
$$

onde $\delta t\left(a_{n}\right)$ é o intervalo de tempo durante o qual a trinca permanece com semicomprimento $a_{n}, \Delta \sigma\left(x, a_{n}\right)$ é a amplitude de tensão na qual uma componente localizada em $x$ está submetida, $\gamma$ é o expoente de incremento de dano, $f_{0}$ é uma constante que determina a escala de tempo do processo e $\tau$ é um parâmetro associado ao tempo característico de regeneração das trincas.

A motivação subjacente a esta dependência mais complexa para a lei de incremento de danos é inspirada em uma expressão no limite contínuo bastante difundida na literatura na forma [5]:

$$
F(x ; t)=f_{0} \int_{0}^{t} d t^{\prime}\left[\Delta \sigma\left(x ; t^{\prime}\right)\right]^{\gamma} e^{-\left(t-t^{\prime}\right) / \tau},
$$

onde $t$ representa um instante particular do processo de propagação e os demais parâmetros envolvidos têm o mesmo significado apresentado nas expressões anteriores.

4. Condição de avanço da trinca:

$$
F\left(a_{n} ; a_{n}-\delta r\right) e^{-\delta t\left(a_{n}\right) / \tau}+f_{0} \delta t\left(a_{n}\right)\left[\Delta \sigma\left(a_{n}+\delta r ; a_{n}\right)\right]^{\gamma}=F_{l i m},
$$

onde $F_{l i m}$ é o limiar de tensão das componentes do sistema. 
5. Condição inicial do sistema:

$$
F\left(x ; a_{0}-\delta r\right)=0,
$$

ou seja, o dano inicial sobre todas as componentes do sistema é nulo.

É instrutivo ainda analisar a ocorrência de importantes casos limites, a saber:

1. $\delta t\left(a_{n}\right) \ll \tau$ :

$$
\delta F\left(x ; a_{n}\right) \approx f_{0} \tau\left[\delta t\left(a_{n}\right) / \tau\right]\left[\Delta \sigma\left(x ; a_{n}\right)\right]^{\gamma}=f_{0} \delta t\left(a_{n}\right)\left[\Delta \sigma\left(x ; a_{n}\right)\right]^{\gamma},
$$

ou seja, recuperamos o caso original, como esperado.

2. $\delta t\left(a_{n}\right) \gg \tau$ :

$$
\delta F\left(x ; a_{n}\right) \approx f_{0} \tau\left[\Delta \sigma\left(x ; a_{n}\right)\right]^{\gamma} \approx 0,
$$

ou seja, o incremento de danos é nulo, caracterizando um regime de regeneração instantânea do material que inviabiliza o crescimento de qualquer trinca ao longo do sistema.

\subsubsection{Cota inferior para o tempo característico de regeneração}

Pela condição de avanço da trinca associada às regras do modelo podemos escrever:

$$
f_{0} \tau\left[1-e^{-\delta t\left(a_{0}\right) / \tau}\right]\left[\Delta \sigma\left(a_{0}+\delta r ; a_{0}\right)\right]^{\gamma}=F_{\text {lim }} .
$$

Consequentemente, o intervalo de tempo $\delta t\left(a_{0}\right)$ em que o sistema permanece em sua configuração inicial passa a ser dado por

$$
\delta t\left(a_{0}\right)=-\tau \ln \left\{1-\frac{F_{\text {lim }}}{f_{0} \tau\left[\Delta \sigma\left(a_{0}+\delta r ; a_{0}\right)\right]^{\gamma}}\right\} .
$$

É importante perceber que no limite de tempos característicos de regeneração muito longos $\left[\delta t\left(a_{0}\right) \ll \tau\right]$ obtemos:

$$
\delta t\left(a_{0}\right) \approx-\tau\left\{-\frac{F_{\text {lim }}}{f_{0} \tau\left[\Delta \sigma\left(a_{n}+\delta r ; a_{n}\right)\right]^{\gamma}}\right\}=\frac{F_{\text {lim }}}{f_{0}\left[\Delta \sigma\left(a_{n}+\delta r ; a_{n}\right)\right]^{\gamma}},
$$

recuperando novamente o caso original.

Perceba ainda que o tempo característico de regeneração não pode decrescer indefinidamente e possui um limitante inferior que obedece a seguinte desigualdade:

$$
\tau>\frac{F_{\text {lim }}}{f_{0}\left[\Delta \sigma\left(a_{n}+\delta r ; a_{n}\right)\right]^{\gamma}},
$$

caso contrário, o avanço da trinca seria impossibilitado.

Podemos assim identificar um valor mínimo para o parâmetro de regeneração como segue:

$$
\tau_{\min } \equiv \frac{F_{\text {lim }}}{f_{0}\left[\Delta \sigma\left(a_{0}+\delta r ; a_{0}\right)\right]^{\gamma}} .
$$

Na figura 4.1 apresentamos um esboço gráfico do comportamento apresentado pelo valor mínimo do parâmetro de regeneração em função do expoente de incremento de dano, enfatizando seu decaimento exponencial. 


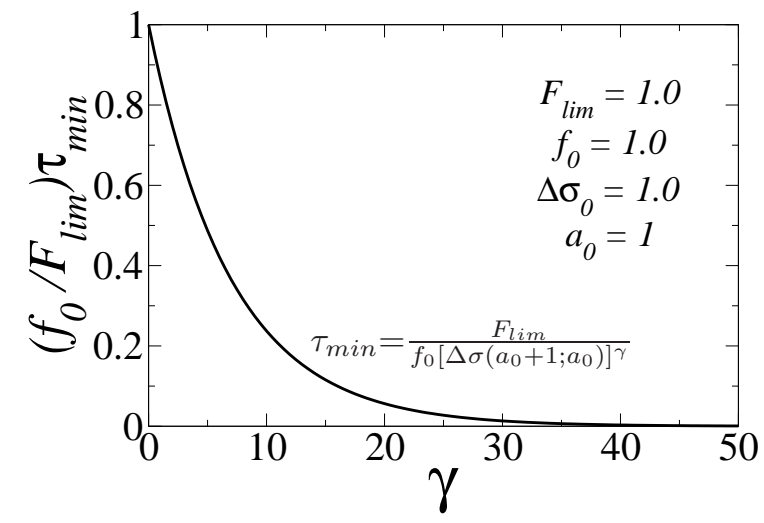

Figura 4.1: Comportamento típico do valor mínimo associado ao tempo característico de regeneração $\tau_{\min }$ como função do expoente de incremento de dano $\gamma$ considerando-se a versão do modelo com a presença de regeneração de trincas nas regras do modelo.

\subsubsection{Comportamento do expoente de Paris}

Nesta seção investigaremos numericamente o comportamento do modelo através das regras do modelo definidas anteriormente, enfatizando a dependência que o expoente de Paris pode apresentar em relação aos parâmetros de acumulação de danos, $\gamma$, e de regeneração de trincas, $\tau$.

O sistema continua a apresentar os dois regimes observados na versão original do modelo $(\tau \rightarrow \infty)$ mas o expoente de Paris passa a ser bastante sensível quanto a alterações do parâmetro $\tau$ no intervalo $\gamma<\gamma_{c}$. Neste último regime, a expressão linear $m(\gamma)=6-2 \gamma$ sofre grandes alterações, de maneira a aproximar-se do valor constante $m(\gamma)=\gamma_{c}$ à medida que o parâmetro de regeneração se aproxima de se valor mínimo $\left(\tau \rightarrow \tau_{\text {min }}\right.$ ) (ver figura 4.2). Na figura 4.3 apresentamos o comportamento típico do expoente de Paris em função do parâmetro de regeneração de trincas para valores selecionados do expoente de acumulação de danos. Na mesma figura, apresentamos também a dependência entre o tempo necessário para a ocorrência da ruptura catastrófica de uma amostra $\left(t_{\text {rup }}\right)$ e o parâmetro de regeneração.

\subsection{Sistema de osciladores massa-mola como meio elástico de propagação da trinca}

Nesta seção apresentaremos uma forma diferenciada de generalizar as propriedades do modelo, onde, ao invés de modificarmos determinada regra em particular, iremos fornecer uma nova interpretação do que seria o meio material em que a trinca se desenvolve, com o emprego de um modelo massa-mola para as partículas constituintes do modelo, de acordo com importantes trabalhos de Marder e colaboradores em [57]. A trinca será identificada por uma região do sistema em que as ligações elásticas entre os osciladores estejam quebradas enquanto que o processo de crescimento e propagação será representado 


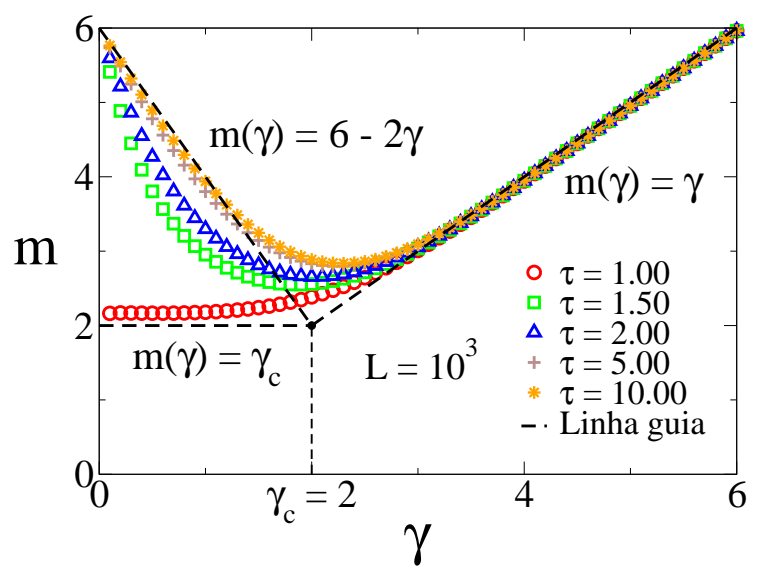

Figura 4.2: Resultados numéricos para a dependência entre o expoente de Paris, $m$, e o expoente de incremento de dano, $\gamma$, considerando-se a versão do modelo envolvendo a regeneração de trincas com valores selecionados para o parâmetro de regeneração $\tau$. É importante enfatizar que a tendência a uma identidade entre os expoentes de Paris e de incremento de dano continua preservada no intervalo $\gamma>\gamma_{c}$ mas a expectativa de uma dependência linear no intervalo complementar $\gamma<\gamma_{c}$ é observada apenas para valores suficientemente elevados do parâmetro de regeneração $\left(\tau \gg \tau_{\min }\right)$.

por uma sucessão de quebras das demais ligações existentes, através de algum processo de fadiga subjacente, levando o sistema a assumir diferentes configurações intermediárias de equilíbrio (aproximação quase-estática).

\subsubsection{Apresentando o modelo}

Nesta versão do modelo, um par de segmentos de reta paralelos compartilham interações elásticas representadas por molas ideais de constante elástica $k$ e delimitam uma região retangular do material cuja mediatriz $r$ define a linha de propagação da trinca (ver figura 4.4 (a)). Especificamente, cada segmento contém $L$ osciladores de massa $\mu$ que interagem elasticamente com seus primeiros vizinhos, com o oscilador equidistante em relação à linha mediatriz que pertence ao outro segmento, além de compartilhar uma "interação efetiva" com as partículas localizadas no interior do material ("bulk") através de uma mola ideal de constante elástica $k / N$, representando uma associação em paralelo entre $N$ molas de mesma constante elástica supostamente existentes entre a posição da partícula em questão e o limiar de posições que podem ser alcançadas pelas partículas do sistema ${ }^{2}$, estimado a uma distância $\delta$ da linha de propagação (ver figura 4.4 (b)).

Quanto ao processo de crescimento da trinca, as simplificações impostas às interações entre as partículas requerem que o identifiquemos exclusivamente através da quebra sucessiva das ligações equidistantes em relação à linha mediatriz ("ligações centrais") ${ }^{3}$, determinando diferentes configurações de equilíbrio que definem o seu perfil em cada instante

\footnotetext{
${ }^{2}$ Pode ser a posição máxima se considerarmos o segmento superior do perfil da trinca ou a posição mínima se considerarmos o segmento inferior.

${ }^{3}$ Todas as demais ligações do sistema (molas) estão proibidas de quebrar.
} 


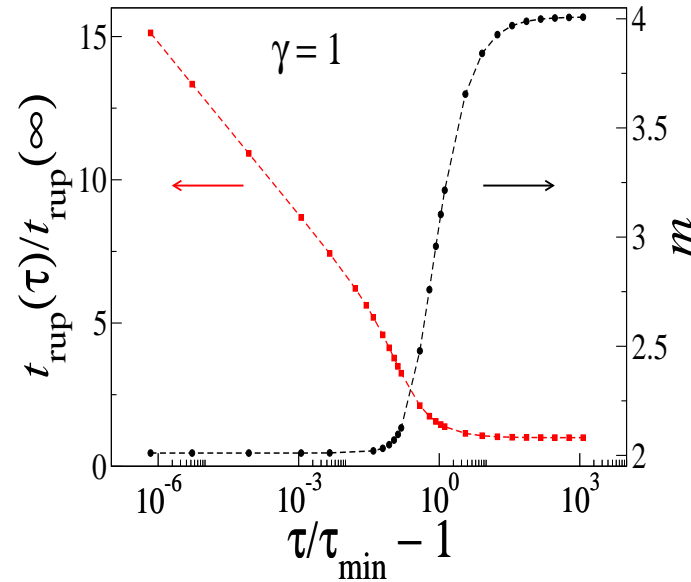

(a)

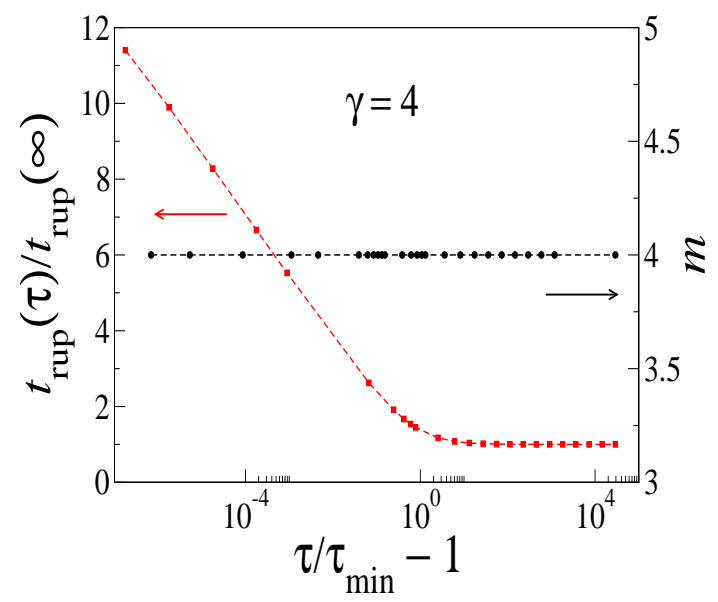

(b)

Figura 4.3: Comportamento típico do tempo de ruptura, $t_{r u p}$, (curva em vermelho) e do expoente de Paris, $m$, (curva em preto) em função do parâmetro de regeneração de trincas, $\tau$, para valores selecionados do expoente de acumulação de danos: (a) $\gamma=1$. (b) $\gamma=4$.

da propagação (ver figura 4.4 (b)). Desta forma, é importante destacar que classificamos o modelo como quase-unidimensional por considerar apenas os processos que ocorrem ao longo da linha de propagação da trinca, ignorando o fato das partículas pertencerem rigorosamente a um sistema bidimensional.

De acordo com as hipóteses do modelo e adotando um sistema de referências $O x y$ que contém a direção de propagação $r$ no eixo das abscissas, o sistema de equações diferenciais que descreve o movimento de cada oscilador pertencente ao segmento superior do perfil da trinca em um particular instante da propagação é dado por [57]

$$
\frac{\mu}{k} \ddot{u}_{j}= \begin{cases}u_{j+1}-2 u_{j}+u_{j-1} & \text { (Interação entre vizinhos); } \\ +\frac{1}{N}\left(\delta-u_{j}\right) & \text { (Interação com o interior do material); } \\ -\left(u_{j,+}-u_{j,-}\right) \theta\left(2 d-\left(u_{j,+}-u_{j,-}\right)\right) & \text { (Interação com o segmento inferior); }\end{cases}
$$

onde $u_{j}$ é a altura da partícula $j$ em relação à linha de propagação da trinca, $\ddot{u}_{j}$ é a componente da aceleração na direção $O y$ do sistema de referências, $\delta$ é o limitante superior das posições que podem ser alcançadas pelas partículas, $2 d$ é o alcance das ligações compartilhadas entre elas ${ }^{4}$ e $\theta(x)$ é a função degrau de Heaviside (ver figura 4.4). Ressaltamos ainda que a notação $u_{j, \pm}$ pretende distinguir partículas que se encontram na mesma abscissa $j$ do sistema de referências, porém, pertencentes a segmentos opostos do perfil da trinca: $(+)$ para o segmento superior e $(-)$ para o segmento inferior.

Nas próximas subseções pretendemos resolver este sistema de equações e determinar analiticamente as soluções que descrevem o perfil da trinca em um dado instante de sua

\footnotetext{
${ }^{4}$ Ao atingirem uma distância acima deste valor as partículas deixam de interagir permanentemente, sendo representado pela ruptura irreversível da mola.
} 


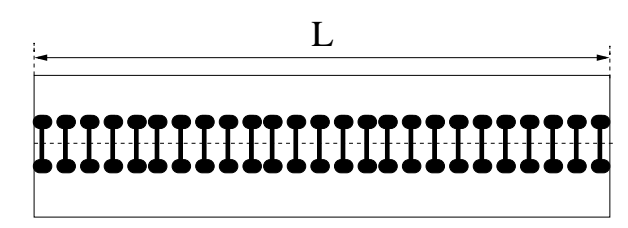

(a)

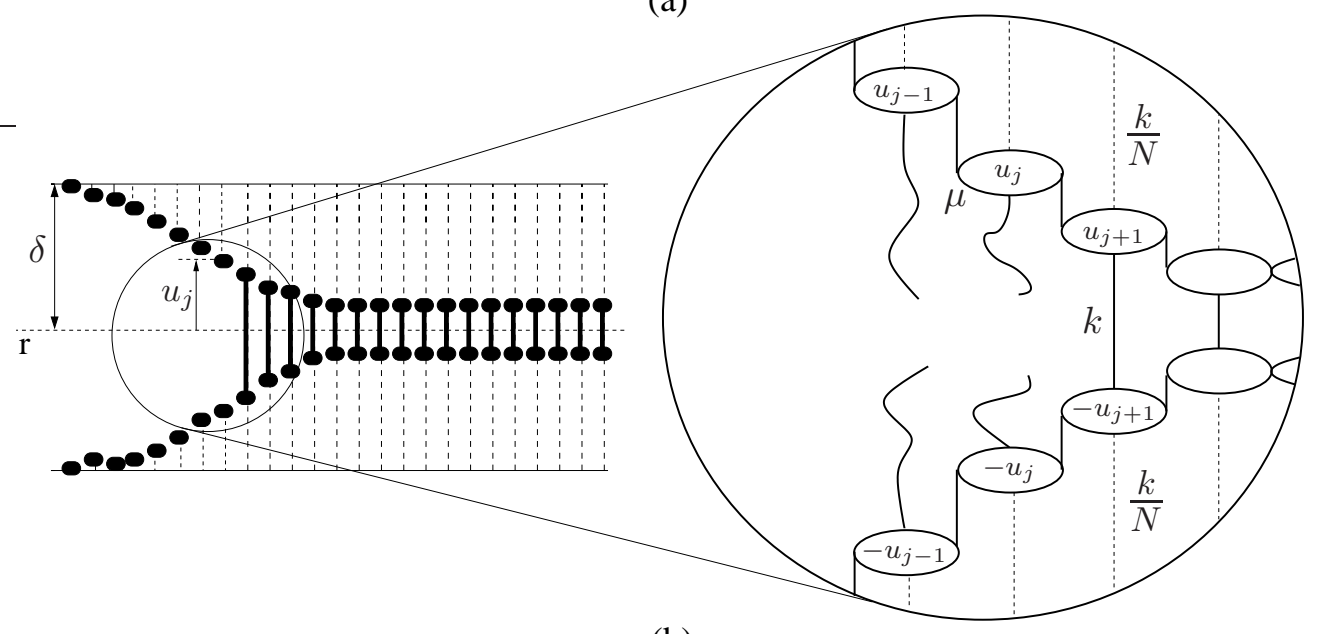

(b)

Figura 4.4: Modelo massa-mola quase-unidimensional representando a propagação de uma trinca ao longo de um determinado material [57]. (a) Representação inicial da direção de propagação da trinca com $2 L$ osciladores intactos constituindo um par de segmentos paralelos que serão identificados com o perfil da trinca durante o processo de propagação. (b) Perfil da trinca em um determinado instante do processo de propagação.

propagação. Além disso, contextualizaremos as soluções do problema com as regras de propagação apresentadas nos capítulos anteriores, de maneira a permitir o cálculo do expoente de Paris nesta nova abordagem.

\subsubsection{Soluções das equações de movimento}

Seja o sistema de equações que descreve o modelo massa-mola para a propagação de trincas,

$$
\frac{\mu}{k} \ddot{u}_{j}=u_{j+1}-2 u_{j}+u_{j-1}+\frac{1}{N}\left(\delta-u_{j}\right)-\left(u_{j,+}-u_{j,-}\right) \theta\left(2 d-\left(u_{j,+}-u_{j,-}\right)\right) .
$$

Por simplicidade, consideremos configurações simétricas de equilíbrio para o sistema, ou seja,

$$
\begin{gathered}
\ddot{u}_{j}=0, \\
u_{j,-}=-u_{j,+} .
\end{gathered}
$$

Desta forma podemos escrever o sistema de equações de uma forma mais simplificada como segue:

$$
u_{j+1}-2 u_{j}+u_{j-1}+\frac{1}{N}\left(\delta-u_{j}\right)-2 u_{j} \theta\left(d-u_{j}\right)=0
$$


É conveniente definir também $\alpha=1 / N$.

Consideraremos ainda um sistema de referências em que $j<0$ para todos os osciladores cujas "ligações centrais" já se romperam, de maneira que

$$
u_{j+1}-2 u_{j}+u_{j-1}+\alpha\left(\delta-u_{j}\right)=0 \quad(j<0) .
$$

No caso particular em que $j=-1$, obtemos como condição de contorno

$$
u_{-2}-2 u_{-1}+u_{0}+\alpha\left(\delta-u_{-1}\right)=0 .
$$

Para as outras partículas do sistema podemos escrever

$$
u_{j+1}-4 u_{j}+u_{j-1}+\alpha\left(\delta-u_{j}\right)=0 \quad(j>0) .
$$

No caso em que $j=0$, obtemos uma condição de contorno particularmente importante, a saber,

$$
u_{-1}-4 u_{0}+u_{1}+\alpha\left(\delta-u_{0}\right)=0 .
$$

Resolveremos o sistema de equações resultante a partir de uma solução-tentativa ("Ansatz") do tipo

$$
u_{j}= \begin{cases}A \exp (q j)+C, & j<0 \\ B \exp (l j)+D, & j \geq 0\end{cases}
$$

onde os coeficientes $A, B, C, D$ e os parâmetros $q$ e $l$ são constantes arbitrárias a serem determinadas pelas condições de existência das soluções e pelas condições de contorno do problema.

Considerando (4.19) obtemos

$$
A \exp (q j)[\exp (q)-2+\exp (-q)-\alpha]+\alpha(\delta-C)=0 .
$$

Portanto,

$$
\left\{\begin{array}{l}
C=\delta, \\
\cosh (q)=1+\frac{\alpha}{2} .
\end{array}\right.
$$

Se admitirmos $q$ positivo então a sequência $\left(u_{j}, j<0\right)$ converge. Sendo assim é mais conveniente reescrevermos a solução como segue:

$$
u_{-j}=A \exp (-q j)+\delta ; \quad q>0, \quad j>0 .
$$

Agora, considerando (4.21) obtemos

$$
B \exp (l j)[\exp (l)-4+\exp (-l)-\alpha]+(-2 D+\alpha \delta-\alpha D)=0 .
$$

\footnotetext{
${ }^{5}$ Estamos admitindo tacitamente o sistema no limite termodinâmico, ou seja, $L \rightarrow \infty$. É importante perceber também que, apesar do limite termodinâmico, o parâmetro $N$ (ou $\alpha$ ) é finito e não dever ser confundido com o tamanho do sistema.
} 
Portanto,

$$
\left\{\begin{array}{l}
D=\frac{\alpha \delta}{\alpha+2} \\
\cosh (l)=2+\frac{\alpha}{2}
\end{array}\right.
$$

Desta forma, se $l$ é negativo, a sequência $\left(u_{j}, j \geq 0\right)$ converge e podemos reescrever a solução como segue:

$$
u_{j}=B \exp (-p j)+\frac{\alpha \delta}{\alpha+2} ; \quad l=-p, \quad p>0, \quad j \geq 0 .
$$

Sendo assim,

$$
\begin{gathered}
\left\{\begin{array}{l}
u_{-j}=A \exp (-q j)+\delta, \quad q>0, \quad j>0, \\
u_{j}=B \exp (-p j)+\frac{\alpha \delta}{\alpha+2}, \quad p>0, \quad j \geq 0 .
\end{array}\right. \\
\left\{\begin{array}{l}
\cosh (q)=1+\frac{\alpha}{2} \Rightarrow q=\ln \left[\left(1+\frac{\alpha}{2}\right)+\sqrt{\left(1+\frac{\alpha}{2}\right)^{2}-1}\right] \\
\cosh (p)=2+\frac{\alpha}{2} \Rightarrow p=\ln \left[\left(2+\frac{\alpha}{2}\right)+\sqrt{\left(2+\frac{\alpha}{2}\right)^{2}-1}\right]
\end{array}\right.
\end{gathered}
$$

Finalmente, determinaremos $A$ e $B$ pelas condições de continuidade das soluções, como segue:

$$
\left\{\begin{array}{l}
u_{-2}=A \exp (-2 q)+\delta \\
u_{-1}=A \exp (-q)+\delta \\
u_{0}=B+\frac{\alpha \delta}{\alpha+2}, \\
u_{1}=B \exp (-p)+\frac{\alpha \delta}{\alpha+2} .
\end{array}\right.
$$

De (4.20):

$$
\begin{aligned}
& B+\frac{\alpha \delta}{\alpha+2}-2 A \exp (-q)-2 \delta+A \exp (-2 q)+\delta+\alpha \delta-\alpha A \exp (-q)-\alpha \delta=0 ; \\
& \therefore \quad\{\exp (-q)-(\alpha+2)] \exp (-q)\} A+B=\frac{2 \delta}{\alpha+2} .
\end{aligned}
$$


De (4.22):

$$
\begin{gathered}
B \exp (-p)+\frac{\alpha \delta}{\alpha+2}-4 B-4 \frac{\alpha \delta}{\alpha+2}+A \exp (-q)+\delta+\alpha \delta-\alpha B-\alpha \frac{\alpha \delta}{\alpha+2}=0 . \\
\therefore \quad \exp (-q) A+[\exp (-p)-(\alpha+4)] B=-\frac{2 \delta}{\alpha+2} .
\end{gathered}
$$

Portanto,

$$
\begin{gathered}
A=\frac{\left(\frac{2}{\alpha+2}\right) \cdot[\exp (-p)-(\alpha+3)]}{\operatorname{det}(M)} \delta ; \\
B=-\frac{\left(\frac{2}{\alpha+2}\right) \cdot\{[\exp (-q)-(\alpha+1)] \exp (-q)\}}{\operatorname{det}(M)} \delta ;
\end{gathered}
$$

onde,

$$
\operatorname{det}(M)=\exp (-q)\{[\exp (-q)-(\alpha+2)][\exp (-p)-(\alpha+3)]-[\exp (-q)-(\alpha+1)]\} .
$$

Na figura 4.5 apresentamos o comportamento típico da solução para um meio material hipotético cujos parâmetros característicos sejam dados por $N=100$ e $\delta=100 a$, onde $a$ é o parâmetro de rede. É importante destacar que, no equilíbrio, o perfil da trinca não depende de parâmetros associados à interação entre as partículas como a massa $\mu$ ou a constante elástica $k$ e depende apenas dos parâmetros geométricos do modelo $(\delta$ e $N)$.

Do ponto de vista numérico a solução das equações de movimento é determinada por um sistema de equações algébricas de ordem $L \times L$ representado por uma matriz tridiagonal, onde $L$ é o número de partículas que compõem cada segmento da trinca. Além disso, podemos representar as condições de contorno como segue:

$$
\left\{\begin{array}{l}
0 \leq j<n \quad \longrightarrow \quad \theta\left(d-u_{j}\right)=0 \\
n \leq j \leq L-1 \quad \longrightarrow \quad \theta\left(d-u_{j}\right)=1
\end{array}\right.
$$

ou seja, partículas cujos índices são menores do que $n$ já se encontram com suas ligações centrais quebradas.

Perceba também que partículas situadas nas extremidades do segmento $\left(u_{0}\right.$ e $\left.u_{L-1}\right)$ devem obedecer a equações ligeiramente diferentes relacionadas ao tamanho finito do sistema, a saber,

$$
\left\{\begin{array}{l}
-u_{0}+u_{1}+\alpha\left(\delta-u_{0}\right)=0 \\
u_{L-2}-3 u_{L-1}+\alpha\left(\delta-u_{L-1}\right)=0
\end{array}\right.
$$




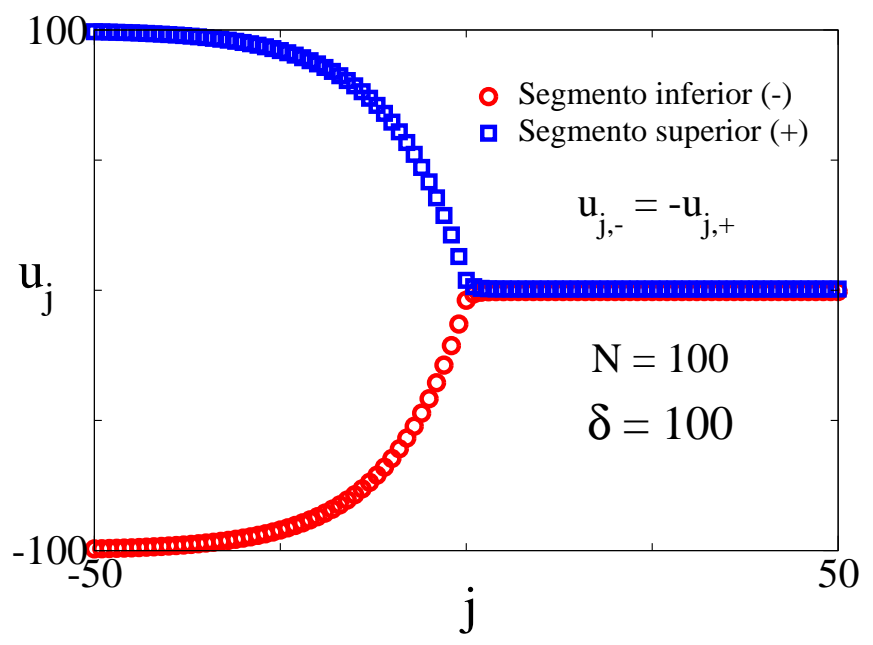

Figura 4.5: Comportamento típico da solução analítica das equações de movimento que descrevem o perfil da trinca em um determinado instante da propagação segundo o modelo massamola. O meio material hipotético está sendo representado pelos parâmetros $N=100$ e $\delta=100.0$ escolhidos arbitrariamente.

Assim, a representação matricial das equações de movimento é dada por

$$
\left[\begin{array}{ccccccccc}
-(1+\alpha) & 1 & 0 & 0 & \ldots & 0 & 0 & 0 & 0 \\
1 & -(2+\alpha) & 1 & 0 & \ldots & 0 & 0 & 0 & 0 \\
0 & 1 & -(2+\alpha) & 1 & \ldots & 0 & 0 & 0 & 0 \\
\vdots & \vdots & \vdots & \vdots & & \vdots & \vdots & \vdots & \vdots \\
0 & 0 & 0 & 0 & \ldots & 1 & -(4+\alpha) & 1 & 0 \\
0 & 0 & 0 & 0 & \ldots & 0 & 1 & -(4+\alpha) & 1 \\
0 & 0 & 0 & 0 & \ldots & 0 & 0 & 1 & -(3+\alpha)
\end{array}\right]\left[\begin{array}{c}
u_{0} \\
u_{1} \\
u_{2} \\
\vdots \\
u_{L-3} \\
u_{L-2} \\
u_{L-1}
\end{array}\right]=\left[\begin{array}{c}
-\alpha \delta \\
-\alpha \delta \\
-\alpha \delta \\
\vdots \\
-\alpha \delta \\
-\alpha \delta \\
-\alpha \delta
\end{array}\right]
$$

Uma ampla variedade de métodos numéricos com rotinas muito bem estabelecidas estão disponíveis para resolver este tipo de sistema de equações [60]. Na figura 4.6 apresentamos o confronto entre a solução analítica (ainda que no limite termodinâmico) e a solução numérica das equações de movimento obtida através de pelo menos três diferentes métodos numéricos, a saber, o método de eliminação gaussiana, o método da decomposição LU e o método iterativo de Gauss-Seidel.

O confronto entre os resultados apresenta boa concordância e representa um excelente teste para a confiabilidade do algoritmo numérico desenvolvido. Se considerarmos ainda sistemas com mais de uma trinca ao longo da linha de propagação (para os quais não dispomos de uma solução analítica em forma fechada), os resultados numéricos se sobressaem como única alternativa e justificam a importância do confronto realizado anteriormente, como mostra a figura 4.7.

\subsubsection{Cálculo do expoente de Paris}

Definiremos as regras de crescimento da trinca para o modelo massa-mola a partir de 


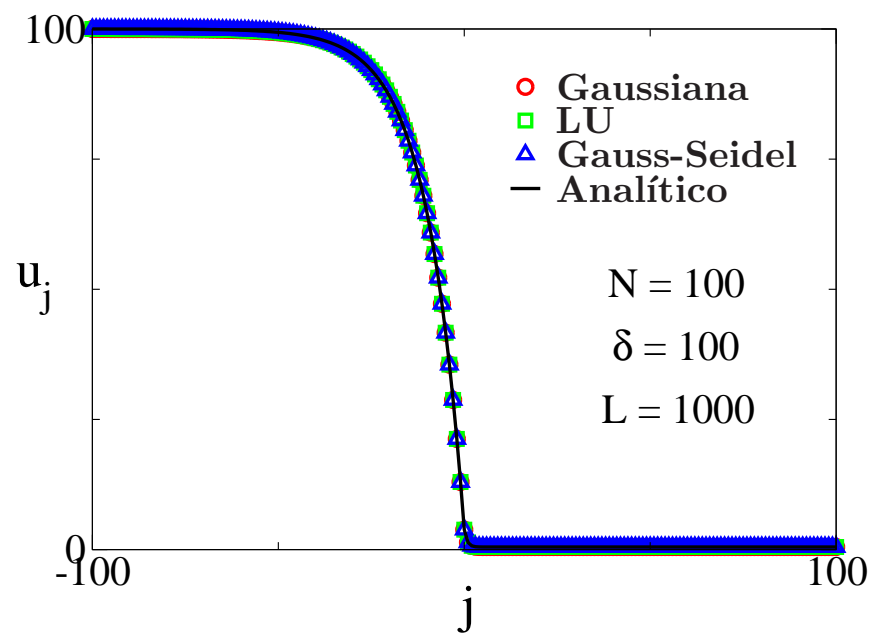

Figura 4.6: Confronto entre a solução analítica (ainda que no limite termodinâmico) e soluções numéricas obtidas através de diferentes métodos das equações de movimento que descrevem o segmento superior do perfil da trinca em um determinado instante da propagação. A amostra do material possui comprimento $L=1000$ e está sendo representada pelos parâmetros $N=100$ e $\delta=100.0$ escolhidos arbitrariamente.

algumas adaptações do modelo de Vieira e colaboradores [6], que passaremos a apresentar a seguir:

1. Primeiramente, consideraremos a propagação quase-estática de uma única trinca ao longo da direção da linha mediatriz $r$ em um meio bidimensional no limite termodinâmico.

2. A condição inicial para o perfil da trinca será definida a partir de uma configuração onde todas as ligações centrais à esquerda de uma determinada partícula $P$ escolhida arbitrariamente se encontrem previamente quebradas. Neste caso a trinca apresenta comprimento "infinito" e se propaga ao longo de uma amostra semi-infinita do material. Além disso, o ponto $P$ escolhido arbitrariamente identifica a extremidade ("ponta") da trinca.

3. Adotaremos um sistema de referências $O x y$ que contenha a linha de propagação $r$ em seu eixo das abscissas $O x$ e esteja centrado na extremidade da trinca no instante inicial da propagação.

4. A ponta da trinca sofre sucessivos incrementos em sua posição ao longo do processo de propagação tal que

$$
a_{n}=n \delta r
$$

onde $a_{n}$ é posição da ponta da trinca no instante $t$ associado a $n$-ésima iteração das regras e $\delta r$ é o incremento na posição da ponta da trinca entre duas quebras consecutivas de ligações. 


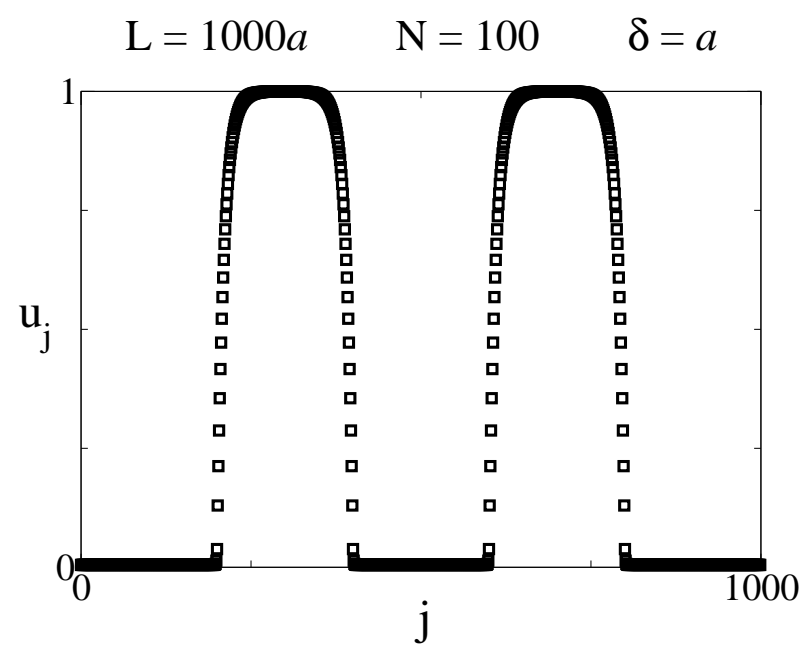

Figura 4.7: Resultados numéricos para o modelo massa-modelo na presença de duas trincas de mesmo comprimento ao longo da linha de propagação. A figura mostra o perfil superior $(+)$ do sistema que se propaga em uma amostra do material de comprimento $L=1000 a$ e está sendo representada pelos parâmetros $N=100$ e $\delta=a$, onde $a=1$ é o parâmetro de rede.

5. Relação de recorrência - lei de acumulação de danos:

$$
F_{n}(x)=F_{n-1}(x)+\delta F_{n}(x),
$$

onde $F_{n}(x)$ é o dano acumulado em uma ligação situada na posição $x$ no instante $t$ associado a $n$-ésima iteração das regras e $\delta F_{n}(x)$ é o incremento de dano sofrido pela mesma ligação neste mesmo instante.

6. Diferentemente do modelo original, em que a distribuição de tensão ao longo da linha de propagação era consequência da teoria elástica linear, assumiremos que a distribuição de forças que atuam sobre as ligações centrais do sistema massa-mola seja dada por $^{6}$

$$
\sigma_{n}(x)=2 k y_{n}(x)
$$

onde $k$ é a constante elástica associada às interações entre as partículas do sistema e $y_{n}(x)$ localiza uma componente situada no segmento superior do perfil da trinca em um instante associado a $n$-ésima iteração das regras, conforme resultados da seção anterior ${ }^{7}$.

7. Relação constitutiva - lei de incremento de dano:

$$
\delta F_{n}(x)=c \delta t\left(a_{n}\right)\left[\sigma_{n}(x)-\sigma_{n}(\infty)\right]^{\gamma},
$$

onde $\delta t\left(a_{n}\right)$ é o intervalo de tempo durante o qual a trinca permanece em uma determinada configuração do sistema, associada à n-ésima iteração das regras, $\sigma_{n}(x)$

\footnotetext{
${ }^{6}$ Representando simplesmente uma adaptação da lei de Hooke ao contexto do novo modelo proposto.

${ }^{7}$ Por conveniências associadas à notação, estamos considerando a seguinte correspondência: $u_{j}(t) \rightarrow y_{n}(x)$.
} 
é a força que atua sobre um oscilador situado na posição $x$ durante este intervalo de tempo, $c$ é uma constante associada à escala de tempo do processo e $\gamma$ é o expoente de incremento de dano.

8. Condição de avanço da trinca ${ }^{8}$ :

$$
F_{n-1}\left(a_{n}\right)+c \delta t\left(a_{n}\right)\left[\sigma_{n}\left(a_{n}\right)-\sigma_{n}(\infty)\right]^{\gamma}=F_{l i m},
$$

onde $F_{\text {lim }}$ é o limiar de força associado às ligações do sistema.

Portanto, o intervalo de tempo $\delta t\left(a_{n}\right)$ pode ser calculado como segue:

$$
\delta t\left(a_{n}\right)=\frac{F_{l i m}-F_{n-1}\left(a_{n}\right)}{c\left[\sigma_{n}\left(a_{n}\right)-\sigma_{n}(\infty)\right]^{\gamma}} .
$$

9. Condição inicial do sistema:

$$
F_{-1}(x)=0,
$$

ou seja, o sistema evolui a partir de uma configuração inicial onde o dano de todas as ligações do sistema é nulo.

Semelhantemente às regras do modelo original, destacamos que a trinca mantém-se única durante todo o processo de propagação. Além disso, o cálculo do termo geral $\delta t\left(a_{n}\right)$ pode ser realizado de maneira inteiramente análoga aos cálculos do modelo original, determinando o seguinte conjunto de equações:

$$
\begin{gathered}
\delta t\left(a_{n}\right)=\frac{F_{\text {lim }}\left(1-G_{n}\right)}{c\left[\sigma_{n}\left(a_{n}\right)-\sigma_{n}(\infty)\right]^{\gamma}} ; \\
G_{0} \equiv 0, \quad G_{n}=\sum_{k=1}^{n} g_{n k}\left(1-G_{k-1}\right), \quad n>0 ; \\
g_{n k}=\left[\frac{\sigma_{k-1}\left(a_{n}\right)-\sigma_{k-1}(\infty)}{\sigma_{k-1}\left(a_{k-1}\right)-\sigma_{k-1}(\infty)}\right]^{\gamma} .
\end{gathered}
$$

O comportamento de $g_{n k}$ pode ser determinado facilmente desde que consideremos uma importante propriedade de translação do perfil da trinca $y\left(x ; a_{n}\right)^{\S}$, a saber,

$$
y_{n}(x+n \delta r)=y_{0}(x) .
$$

\footnotetext{
${ }^{8}$ Neste caso, não temos a necessidade de corrigir os cálculos para pontos pertencentes às vizinhanças da ponta da trinca pois a distribuição de força $\sigma\left(x ; a_{n}\right)$ não apresenta singularidades ao longo da linha de propagação.

${ }^{\S}$ Uma interpretação simples para esta expressão está associada ao fato de que, no limite termodinâmico, as configurações de equilíbrio para o perfil da trinca não se alteram à medida que a trinca se propaga.
} 
Sendo assim, podemos escrever $g_{n k}$ exclusivamente em termos do perfil da trinca no instante inicial do processo $\sigma_{0}(x)$, ou seja,

$$
\begin{gathered}
\left\{\begin{array}{l}
\sigma_{k-1}\left(a_{k-1}\right)=\sigma_{0}\left(a_{0}\right), \\
\sigma_{k-1}\left(a_{n}\right)=\sigma_{0}\left(a_{n-k+1}\right), \\
\sigma_{n}(\infty)=\sigma_{0}(\infty), \\
g_{n k}=\left[\frac{\sigma_{0}\left(a_{n-k+1}\right)-\sigma_{0}(\infty) \sigma_{0}\left(a_{0}\right)-\sigma_{0}(\infty)}{\gamma} .\right.
\end{array}\right. \\
\left\{\begin{array}{l}
\sigma_{0}\left(a_{n}\right)=B \exp (-p \delta r n)+\frac{\alpha \delta}{\alpha+2}, n \geq 0 ; \\
p=\ln \left[\left(2+\frac{\alpha}{2}\right)+\sqrt{\left(2+\frac{\alpha}{2}\right)^{2}-1}\right], \\
q=\ln \left[\left(1+\frac{\alpha}{2}\right)+\sqrt{\left(1+\frac{\alpha}{2}\right)^{2}-1}\right], \\
B=-\frac{\left(\frac{2}{\alpha+2}\right)\{[\exp (-q)-(\alpha+1)] \exp (-q)\}}{\exp (-q)\{[\exp (-q)-(\alpha+2)][\exp (-p)-(\alpha+3)]-[\exp (-q)-(\alpha+1)]\}} \delta .
\end{array}\right.
\end{gathered}
$$

Portanto,

$$
g_{n k}=\exp [-\gamma p \delta r(n-k+1)] .
$$

Na figura 4.8 mostramos o comportamento típico de $g_{n k}$ para alguns poucos valores do expoente de incremento de dano $\gamma$. Perceba novamente que $g_{n k}$ apresenta valores "apreciáveis" apenas quando $k \approx n$ permitindo-nos desprezar muitos termos da soma (4.50) como segue:

$$
\begin{gathered}
G_{n} \approx\left(1-G_{n}\right) \sum_{k=1}^{n} \exp \{-\gamma p \delta r[n-(k-1)]\} \quad(n \gg 1) ; \\
\quad\left\{\begin{array}{l}
n-(k-1) \equiv j \\
\gamma p \delta r \equiv s ;
\end{array}\right. \\
\alpha_{\infty}=\sum_{j=1}^{\infty} \exp (-s j)=\frac{e^{-s}}{1-e^{-s}} \\
G^{*} \approx e^{-\gamma p \delta r} .
\end{gathered}
$$




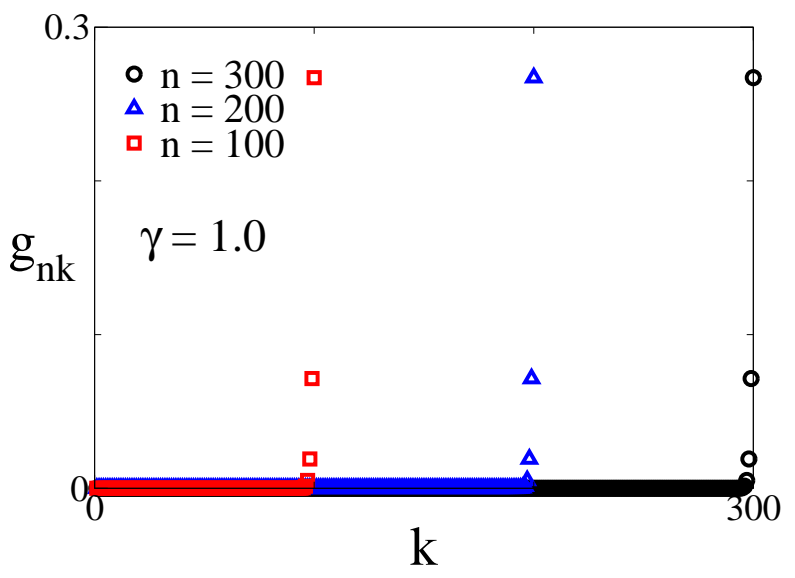

Figura 4.8: Comportamento típico de $g_{n k}$ considerando-se o modelo massa-mola com expoente de incremento de dano igual a unidade $(\gamma=1.0)$.

Agora podemos calcular a velocidade de propagação da trinca e o expoente de Paris associado como segue:

$$
\delta t\left(a_{n}\right) \approx \frac{F_{l i m}\left(1-G^{*}\right)}{c\left[\sigma_{0}\left(a_{0}\right)\right]^{\gamma}}=\text { constante } \Rightarrow m=0 .
$$

Sendo assim a lei de Paris é reproduzida de uma maneira particularmente trivial, onde o expoente de Paris resulta ser uma constante igual a zero, independentemente do expoente de incremento de dano. Acreditamos que o principal responsável por este resultado seja o fato da tensão na ponta da trinca não depender da posição da ponta da trinca em cada instante da propagação, em contraste com o modelo original, que considera os resultados obtidos pela teoria elástica linear. Este fato pode comprometer a utilização do modelo em abordagens dinâmicas da lei de Paris, onde pretendíamos utilizar a solução das equações de movimento em função do tempo ("fora do equilíbrio"), já que não a reproduz nem mesmo no regime quase-estático.

Resultados numéricos confirmam a expectativa analítica, indicando que a velocidade de propagação da trinca é, de fato, uma constante independente do valor do expoente de incremento de danos, como mostra a figura 4.9. Este resultado é intuitivo pois, de acordo com a propriedade de translação do perfil da trinca, a evolução temporal do sistema é comparável ("lembra") à propagação de uma onda progressiva em um meio não-dispersivo. 


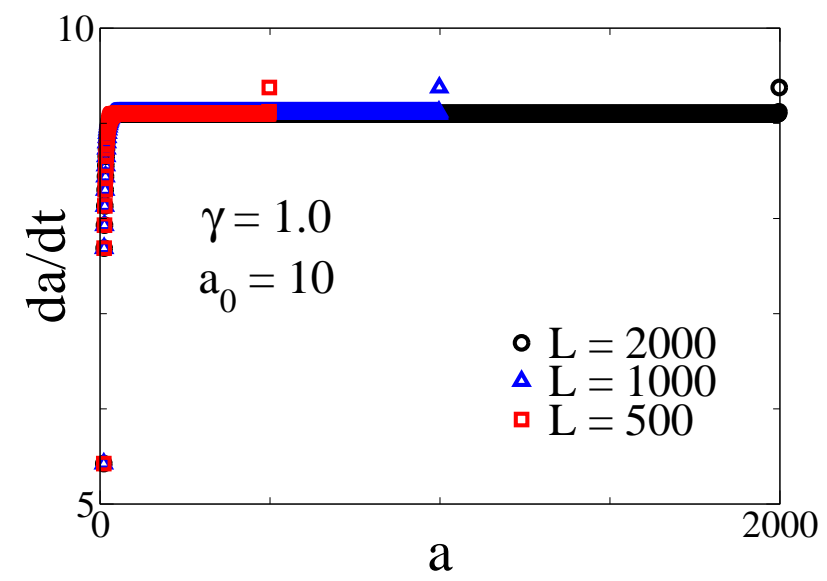

Figura 4.9: Comportamento típico da velocidade de propagação da trinca, $d a / d t$, em função do semicomprimento da trinca a para diferentes tamanhos do sistema $L$. Para sistemas de tamanho finito podemos definir o semicomprimento da trinca com sendo simplesmente o número de ligações quebradas a esquerda da ponta da trinca (naturalmente este número é "infinito" no limite termodinâmico). O meio material hipotético está sendo representado pelos parâmetros $N=100, \delta=1.0, F_{\text {lim }}=1.0 \mathrm{~N}, k=1.0 \mathrm{~N} / \mathrm{m}$ e $\gamma=1.0$ escolhidos arbitrariamente. 


\section{Capítulo 5}

\section{Conclusões}

Este trabalho corresponde aos progressos obtidos em nosso projeto de doutoramento ao longo dos últimos quatro anos de trabalho. Nossa preocupação inicial consistia em desenvolver novas metodologias capazes de descrever o processo de propagação de trincas na presença de desordem, de acordo com o modelo proposto originalmente pelo orientador deste projeto e seus colaboradores [6,32]. Apesar de nossas pretensões iniciais serem voltadas ao estudo da desordem sobre o sistema, acabamos por explorar, em um primeiro momento, as propriedades do modelo em sua versão original, fornecendo novas contribuições e generalizações a resultados previamente estabelecidos em [6].

Dentre estas contribuições, podemos citar o cálculo do expoente de Paris no limite de acumulação uniforme de dano, confirmando analiticamente a tendência do expoente de Paris em apresentar o valor $m(\gamma \rightarrow 0)=6$, conforme expectativas publicadas anteriormente. Além disso, consideramos ainda a introdução de limitações na acumulação de danos para pontos muito distantes da ponta da trinca $(x \gg a)$, onde o expoente de Paris tende a apresentar um valor constante e igual a $m=2$ no intervalo $\gamma<\gamma_{c}$, em contraste com o modelo original que apresentava um comportamento linear na forma $m(\gamma)=6-2 \gamma$.

Outras modificações nas regras do modelo levando em consideração possíveis efeitos de regeneração de trincas no processo de acumulação de danos permitem a generalização do modelo em contextos que podem se tornar de maior interesse prático. Neste caso específico, os cálculos mostram que a relação entre os expoentes de Paris e de acumulação de danos $(m \times \gamma)$ é também passível de grandes alterações quando comparada com o comportamento do modelo original a depender do tempo característico de regeneração das trincas introduzido na lei de acumulação de danos desta nova versão.

Estudamos ainda a introdução de desordem quenched nas regras do modelo, ao permitirmos limiares aleatórios de tensão associados a cada componente do sistema, segundo uma distribuição de probabilidade uniforme. A princípio, privilegiamos o estudo das propriedades relacionadas ao caso particular em que o expoente de incremento de dano é considerado nulo (acumulação uniforme de dano). A importância deste caso deve-se, principalmente, ao fato de permitir um tratamento analítico adequado em situações simplificadas do modelo.

A aplicação da aproximação de trincas independentes possibilitou um estudo razoável das propriedades do modelo para situações mais gerais de desordem. Dentro desta aproximação o modelo continua a ser capaz de reproduzir a lei de Paris independentemente do grau de desordem introduzida, embora a relação $m \times \gamma$ sofra significativas mudanças em 
seu comportamento no intervalo $\gamma<\gamma_{c}$ quando comparada com o caso original. Por exemplo, quando $\gamma \ll \gamma_{c}$, o expoente de Paris é aproximadamente constante e igual a $m=4$, em grande contraste com o valor apresentado pela versão original do modelo, dado por $m(\gamma \rightarrow 0)=6$. No intervalo $\gamma>\gamma_{c}$ o comportamento de ambas as versões é essencialmente o mesmo, independente do grau de desordem considerado.

Finalmente, maiores confrontos entre nossa abordagem e a prática experimental juntamente com outras questões associadas à dependência entre a acumulação de danos e parâmetros característicos do material em uma escala microscópica permanecem em aberto, limitando o potencial prático do modelo. 


\section{Apêndice A}

\section{Teoria elástica linear}

Neste apêndice elaboramos uma breve digressão com o objetivo de discutir temas básicos da teoria elástica linear de corpos deformados a serem utilizados nesta tese [1, $17,61]$.

\section{A.1 O tensor de deformações}

Seja um sistema de coordenadas $S$ no qual podemos localizar um ponto do sistema antes de sofrer deformações pela coordenada $\vec{r}$ e que, após a deformação, passa a ser localizado pela coordenada $\vec{r}^{\prime}$. Sendo assim, podemos definir o deslocamento sofrido em cada ponto pela diferença

$$
\vec{u}=\vec{r}^{\prime}-\vec{r}
$$

Em forma diferencial, temos que

$$
d \vec{r}^{\prime}=d \vec{r}+d \vec{u}
$$

A deformação pode ainda ser definida como segue ${ }^{1}$ :

$$
\begin{gathered}
d l^{2}=d x_{i} d x_{i}=d x_{i}^{2} ; \\
d l^{\prime 2}=d x_{i}^{\prime 2}=d x_{i}^{2}+2 d x_{i} d u_{i}+d u_{i}^{2} ; \\
d u_{i}=\frac{\partial u_{i}}{\partial x_{j}} d x_{j} ;
\end{gathered}
$$

$\therefore$

$$
d l^{\prime 2}=d l^{2}+2 \frac{\partial u_{i}}{\partial x_{j}} d x_{i} d x_{j}+\frac{\partial u_{k}}{\partial x_{i}} \frac{\partial u_{k}}{\partial x_{j}} d x_{i} d x_{j} .
$$

Vamos simetrizar a expressão manipulando o segundo membro da equação como segue:

$$
d l^{\prime 2}=d l^{2}+\left(\frac{\partial u_{i}}{\partial x_{j}}+\frac{\partial u_{j}}{\partial x_{i}}+\frac{\partial u_{k}}{\partial x_{i}} \frac{\partial u_{k}}{\partial x_{j}}\right) d x_{i} d x_{j} .
$$

\footnotetext{
${ }^{1}$ É conveniente utilizarmos a convenção de soma de Einstein.
} 
Desprezando termos de ordem superior e reescrevendo convenientemente a expressão remanescente (ajustando-a de acordo com uma forma quadrática), obtemos:

$$
d l^{\prime 2}=d l^{2}+2\left[\frac{1}{2}\left(\frac{\partial u_{i}}{\partial x_{j}}+\frac{\partial u_{j}}{\partial x_{i}}\right)\right] d x_{i} d x_{j} .
$$

Vamos definir o tensor de deformações como segue:

$$
u_{i j}=\frac{1}{2}\left(\frac{\partial u_{i}}{\partial x_{j}}+\frac{\partial u_{j}}{\partial x_{i}}\right) .
$$

Portanto,

$$
d l^{\prime 2}=d l^{2}+2 u_{i j} d x_{i} d x_{j}
$$

\section{A.2 O tensor das tensões}

A resultante das forças internas $\vec{F}$ que atuam no interior do material pode ser escrita como segue:

$$
\vec{F}=\int_{V} \vec{f} d^{3} \vec{r}
$$

onde $\vec{f}$ seria a densidade de forças trocadas no interior da amostra.

No equilíbrio, podemos identificar esta resultante com a resultante das forças externas de maneira que:

$$
\vec{F}=\oint_{S} \stackrel{\leftrightarrow}{\sigma} \cdot d \vec{A}
$$

onde $\stackrel{\leftrightarrow}{\sigma}$ define o tensor das tensões atuando na superfície da amostra.

Pelo teorema da divergência:

$$
\vec{F}=\oint_{S} \overleftrightarrow{\sigma} \cdot d \vec{A}=\int_{V} \vec{\nabla} \cdot \stackrel{\leftrightarrow}{\sigma} d^{3} \vec{r}
$$

onde a integral de superfície é revertida numa integral de volume pela divergência do tensor das tensões.

Sendo assim, podemos escrever:

$$
\vec{f}=\vec{\nabla} \cdot \stackrel{\leftrightarrow}{\sigma}
$$

Em termos das componentes do tensor:

$$
f_{j}=\frac{\partial \sigma_{i j}}{\partial x_{i}} .
$$

Podemos escrever ainda:

$$
\vec{F}=\oint_{S} \stackrel{\leftrightarrow}{\sigma} \cdot \vec{n} d A \Rightarrow \frac{d \vec{F}}{d A} \equiv \vec{p}=\stackrel{\leftrightarrow}{\sigma} \cdot \vec{n}
$$

Ou ainda em termos das componentes:

$$
p_{i}=\sigma_{i j} n_{j},
$$

representando as condições de contorno a serem satisfeitas. 


\section{A.3 Densidade de energia livre associada a um material defor- mado}

É mais fácil começar pensando na energia armazenada em um material no caso unidimensional como segue ${ }^{2}$ :

$$
\mathcal{F}(x)=\mathcal{F}_{0}+\frac{1}{2} k x^{2} .
$$

Em termos dos tensores de tensão e deformação, deveríamos reescrever a expressão como segue:

$$
\mathcal{F}(\overleftrightarrow{u})=\mathcal{F}_{0}+\frac{1}{2}\left(\frac{Y A}{L}\right) L^{2} u_{x x}^{2}
$$

onde a componente $u_{x x} \equiv x / L$ estaria associada uma deformação axial imposta ao sistema e $F_{x} / A=Y x / L$ generaliza a lei de Hooke com a correspondente definição para o módulo de Young $Y$ do material.

Sendo assim, podemos escrever ainda:

$$
\begin{gathered}
\mathcal{F}(\stackrel{\leftrightarrow}{u})-\mathcal{F}_{0}=\Delta \mathcal{F}=\frac{1}{2} Y \underbrace{(A L)}_{=\Delta V} u_{x x}^{2} \\
f(\stackrel{\leftrightarrow}{u})=\frac{1}{2} Y u_{x x}^{2}
\end{gathered}
$$

onde $f$ seria a densidade de energia livre do sistema.

Numa situação mais geral, devemos considerar uma expansão da densidade de energia livre em termos de todos os termos quadráticos possíveis, a saber:

$$
f(\overleftrightarrow{u})=\frac{1}{2} \lambda_{i j k l} u_{i j} u_{k l}
$$

onde $\lambda_{i j k l}$ são as componentes de um tensor que generaliza as constantes elásticas associadas ao material, conhecido como tensor de rigidez.

Podemos também generalizar facilmente a lei de Hooke como segue:

$$
\begin{gathered}
\sigma_{i j}=\lambda_{i j k l} u_{k l} \\
\sigma_{i j}=\lambda_{i j k l} u_{k l}=\lambda_{i j k l}\left[\frac{1}{2} \frac{\partial}{\partial u_{i j}}\left(u_{i j} u_{k l}\right)\right] ; \\
\sigma_{i j}=\frac{\partial f}{\partial u_{i j}}
\end{gathered}
$$

onde a última expressão generaliza o fato das forças consideradas serem conservativas e, portanto, derivarem de uma energia potencial.

É conveniente exercitarmos a teoria estabelecida através do caso particularmente simples de um sólido homogêneo e isotrópico. Neste caso esperamos que as simetrias do sistema permitam-nos escrever sua energia livre apenas como função dos invariantes quadráticos do tensor de deformações, a saber,

$$
\begin{aligned}
& u_{i i}^{2}=(\operatorname{tr} \overleftrightarrow{u})^{2} \\
& u_{i j}^{2}=\operatorname{tr}\left(\overleftrightarrow{u}^{2}\right)
\end{aligned}
$$

\footnotetext{
${ }^{2}$ Seria a energia livre do sistema a temperatura nula.
} 
isto é, o quadrado do traço e o traço do quadrado do tensor de deformações.

Este método é conhecido como expansão de Landau para a densidade de energia livre do sistema e resulta na seguinte expressão:

$$
f\left(u_{i j}\right)=\frac{1}{2} \lambda u_{i i}^{2}+\mu u_{i j}^{2},
$$

onde os coeficientes $\lambda$ e $\mu$ associados às constantes elásticas do material são conhecidos por constantes de Lamé.

Consequentemente, a lei de Hooke para materiais homogêneos e isotrópicos é dada por:

$$
\begin{gathered}
\sigma_{i j}=\left(\frac{\partial f}{\partial u_{i j}}\right)_{T}=\frac{\partial}{\partial u_{i j}}\left[\frac{1}{2} \lambda u_{k k}^{2}+\mu u_{i j}^{2}\right] \\
\sigma_{i j}=\frac{1}{2} \lambda \underbrace{\frac{\partial}{\partial u_{i j}}\left[\left(u_{i j} \delta_{i j}\right)^{2}\right]}_{=2 u_{k k} \delta_{i j}}+\mu \underbrace{\frac{\partial}{\partial u_{i j}}\left(u_{i j}^{2}\right)}_{=2 u_{i j}} ; \\
\sigma_{i j}=\lambda u_{k k} \delta_{i j}+2 \mu u_{i j} ;
\end{gathered}
$$

onde compatibilizamos os índices do tensor de deformações na diferenciação do primeiro termo por intermédio do símbolo delta de Kronecker $\delta_{i j}$.

É interessante desenvolvermos ainda a seguinte identidade ${ }^{3}$ :

$$
\begin{gathered}
\sigma_{i i}=\lambda \underbrace{u_{k k} \delta_{i i}}_{=3 u_{i i}}+2 \mu u_{i i} ; \\
u_{i i}=\frac{\sigma_{i i}}{3 \lambda+2 \mu} .
\end{gathered}
$$

Neste caso podemos inverter a lei de Hooke como segue:

$$
u_{i j}=-\frac{\lambda \sigma_{k k}}{2 \mu(3 \lambda+2 \mu)} \delta_{i j}+\frac{1}{2 \mu} \sigma_{i j}
$$

\section{A.4 As constantes elásticas}

Nesta seção pretendemos escrever os coeficientes da expressão que determina a densidade de energia livre do sistema em termos de grandezas físicas mais práticas do ponto de vista experimental. Dentre as grandezas mais importantes podemos destacar o módulo volumar $B$ (inverso do coeficiente de expansão volumétrica), o módulo de Young Y, o módulo de cisalhamento $\mu$ (correspondente direto a um dos coeficientes de Lamé) e a razão de Poisson $\nu$.

\footnotetext{
${ }^{3}$ É importante relembrar que estamos assumindo tacitamente a convenção de soma de Einstein, portanto, $\delta_{i i}=3$.
} 


\section{A.4.1 Cálculo do módulo volumar de um sólido isotrópico}

É instrutivo começarmos calculando a variação de volume sofrida por um corpo sob a ação de tensões capazes de deformá-lo, como segue:

$$
\Delta V=\left(\Delta x_{1}+\Delta u_{1}\right)\left(\Delta x_{2}+\Delta u_{2}\right)\left(\Delta x_{3}+\Delta u_{3}\right)-\Delta x_{1} \Delta x_{2} \Delta x_{3},
$$

onde $u_{i}$ representam as deformações associadas a cada uma das componentes $x_{i}$ do sistema.

Desprezando termos de ordem superior podemos escrever:

$$
\Delta V=\underbrace{\Delta x_{2} \Delta x_{3}}_{=\frac{V}{\Delta x_{1}}} \Delta u_{1}+\underbrace{\Delta x_{1} \Delta x_{3}}_{=\frac{V}{\Delta x_{2}}} \Delta u_{2}+\underbrace{\Delta x_{1} \Delta x_{2}}_{=\frac{V}{\Delta x_{3}}} \Delta u_{3} .
$$

Se definirmos a dilatação $\delta$ sofrida pelo material como a razão entre a variação de volume e o seu volume inicial podemos escrever:

$$
\delta \equiv \frac{\Delta V}{V}=\frac{\Delta u_{1}}{\Delta x_{1}}+\frac{\Delta u_{2}}{\Delta x_{2}}+\frac{\Delta u_{3}}{\Delta x_{3}} .
$$

No limite infinitesimal:

$$
\begin{gathered}
\delta=\frac{\partial u_{1}}{\partial x_{1}}+\frac{\partial u_{2}}{\partial x_{2}}+\frac{\partial u_{3}}{\partial x_{3}} ; \\
\delta=u_{11}+u_{22}+u_{33}=u_{i i}=\operatorname{tr} \overleftrightarrow{u} ;
\end{gathered}
$$

ou seja, a deformação do material é um dos invariantes do sistema, determinado pelo traço de seu tensor de deformações.

Uma importante equação de estado pode ser obtida ao considerarmos o caso de uma compressão hidrostática, que pode ser definido por:

$$
\sigma_{i j}=-p \delta_{i j},
$$

onde $p$ é a pressão hidrostática exercida de maneira que o agente externo não exerce forças de cisalhamento sobre a amostra.

O módulo volumar de elasticidade $B$ ("bulk modulus") é definido como segue:

$$
p=-B \delta,
$$

ou seja, é a constante de proporcionalidade entre a pressão hidrostática exercida e a deformação sofrida pelo material.

Sendo assim, podemos calculá-lo facilmente como segue:

$$
\begin{aligned}
u_{i i}=\delta & =\frac{\sigma_{i i}}{3 \lambda+2 \mu} ; \\
\sigma_{i i} & =-3 p ;
\end{aligned}
$$

$\therefore$

$$
p=-\left(\lambda+\frac{2}{3} \mu\right) \delta .
$$

Portanto,

$$
B=\lambda+\frac{2}{3} \mu \text {. }
$$




\section{A.4.2 Relação entre os módulos de elasticidade e as constantes de Lamé as- sociadas a um material isotrópico}

Pela lei de Hooke expressa em sua forma inversa, podemos escrever [Eq. (A.34)]:

$$
u_{11}=\left[-\frac{\lambda}{2 \mu(3 \lambda+2 \mu)}+\frac{1}{2 \mu}\right] \sigma_{11}-\frac{\lambda}{2 \mu(3 \lambda+2 \mu)} \sigma_{22}-\frac{\lambda}{2 \mu(3 \lambda+2 \mu)} \sigma_{33} .
$$

De acordo com as definições do módulo de Young e da razão de Poisson podemos reconhecer as seguintes identidades:

$$
\begin{gathered}
\frac{1}{Y}=-\frac{\lambda}{2 \mu(3 \lambda+2 \mu)}+\frac{1}{2 \mu} ; \\
\frac{\nu}{Y}=\frac{\lambda}{2 \mu(3 \lambda+2 \mu)} .
\end{gathered}
$$

Sendo assim:

$$
\begin{gathered}
Y=\frac{\mu(3 \lambda+2 \mu)}{\mu+\lambda} ; \\
\nu=\frac{\lambda}{2(\lambda+\mu)} .
\end{gathered}
$$

Podemos ainda inverter as relações anteriores de maneira a escrever as constantes de Lamé em termos do módulo volumar e da razão de Poisson, a saber:

$$
\begin{gathered}
\mu=\frac{3(1-2 \nu)}{2(1+\nu)} B ; \\
\lambda=\frac{3 \nu}{(1+\nu)} B .
\end{gathered}
$$

O módulo de Young também pode ser escrito em termos do módulo volumar e da razão de Poisson de acordo com a seguinte expressão:

$$
Y=3(1-2 \nu) B
$$

É tradicional escrevermos quaisquer das constantes elásticas que possam descrever um sólido isotrópico sempre em termos do módulo de Young e da razão de Poisson. Sendo assim, reescreveremos todos os resultados obtidos anteriormente como segue:

1. Coeficientes de Lamé:

$$
\begin{gathered}
\lambda=\frac{\nu Y}{(1+\nu)(1-2 \nu)} ; \\
\mu=\frac{Y}{2(1+\nu)} .
\end{gathered}
$$


2. Módulo de elasticidade:

$$
B=\frac{Y}{3(1-2 \nu)} .
$$

3. Densidade de energia livre:

$$
f=\frac{\nu Y}{2(1+\nu)(1-2 \nu)} u_{i i}^{2}+\frac{Y}{2(1+\nu)} u_{i j}^{2} .
$$

4. Lei de Hooke:

$$
\sigma_{i j}=\left[\frac{\nu Y}{(1+\nu)(1-2 \nu)} u_{k k}\right] \delta_{i j}+\frac{Y}{(1+\nu)} u_{i j} .
$$

\section{A.5 O tensor de rigidez $\lambda_{i j k l}$ associado a um material isotrópico}

Nesta seção pretendemos confirmar os resultados anteriores envolvendo as constantes elásticas que descrevem um material isotrópico ao explicitarmos as componentes do tensor de rigidez associado.

Pela lei de Hooke associada às deformações de um sólido homogêneo e isotrópico, podemos escrever:

$$
\sigma_{i j}=\lambda u_{k k} \delta_{i j}+2 \mu u_{i j}
$$

É conveniente reescrevermos as componentes do tensor de deformação como segue:

$$
\begin{gathered}
u_{k k}=\delta_{k l} u_{k l} ; \\
u_{i j}=\delta_{i k} \delta_{j l} u_{k l} ;
\end{gathered}
$$

onde compatibilizamos os índices do tensor de deformações em cada termo por intermédio do símbolo delta de Kronecker.

Assim, da comparação entre (A.59), (A.60), (A.61) e (A.23); obtemos:

$$
\sigma_{i j}=\lambda u_{k k} \delta_{i j}+2 \mu u_{i j}=\lambda\left(\delta_{k l} u_{k l}\right) \delta_{i j}+2 \mu\left(\delta_{i k} \delta_{j l} u_{k l}\right) ;
$$

$\therefore$

$$
\sigma_{i j}=\underbrace{\left(\lambda \delta_{i j} \delta_{k l}+2 \mu \delta_{i k} \delta_{j l}\right)}_{\lambda_{i j k l}} u_{k l}
$$

Portanto,

$$
\lambda_{i j k l}=\lambda \delta_{i j} \delta_{k l}+2 \mu \delta_{i k} \delta_{j l},
$$

explicitando as componentes do tensor de rigidez. 
Finalmente, reconhecemos as seguintes componentes:

$$
\begin{gathered}
\lambda_{1111}=\lambda+2 \mu=\frac{(1-\nu) Y}{(1+\nu)(1-2 \nu)} ; \\
\lambda_{1122}=\lambda_{1133}=\lambda=\frac{\nu Y}{(1+\nu)(1-2 \nu)} ; \\
\lambda_{1112}=\lambda_{1121}=\lambda_{1113}=\lambda_{1131}=\lambda_{1123}=\lambda_{1132}=0 ; \\
\lambda_{1212}=2 \mu=\frac{Y}{1+\nu} ; \\
\lambda_{1211}=\lambda_{1222}=\lambda_{1233}=0 ; \\
\lambda_{1221}=\lambda_{1213}=\lambda_{1231}=\lambda_{1223}=\lambda_{1132}=0 ;
\end{gathered}
$$

revelando que a maioria delas são nulas como se esperaria através de argumentos heurísticos simples associados à simetria do problema ${ }^{4}$.

\section{A.6 Descrição do movimento no interior de um sólido isotrópico}

Nesta seção pretendemos escrever as equações de movimento que descrevem a dinâmica no interior do material, por intermédio das leis de Newton aplicadas a cada partícula que constitui o material. Sendo assim, de acordo com a segunda lei de Newton, podemos escrever:

$$
\rho \frac{\partial^{2} \vec{u}}{\partial t^{2}}=\vec{\nabla} \cdot \stackrel{\leftrightarrow}{\sigma}+\vec{f}_{\text {ext }}
$$

onde $\vec{f}_{\text {ext }}$ são densidades de forças que atuam no interior do material ("body forces") como, por exemplo, o campo gravitacional da Terra $\left(\vec{f}_{\text {ext }}=\rho \vec{g}\right)$.

$\mathrm{Na}$ ausência destas forças, é possível simplificar ainda mais o sistema de equações como segue $^{5}$ :

$$
\rho \frac{\partial^{2} \vec{u}}{\partial t^{2}}=\vec{\nabla} \cdot \stackrel{\leftrightarrow}{\sigma}
$$

No caso de um sólido isotrópico, a divergência do tensor das tensões é dada por:

$$
\begin{gathered}
\vec{\nabla} \cdot \stackrel{\leftrightarrow}{\sigma}=\vec{e}_{i} \frac{\partial \sigma_{i j}}{\partial x_{i}}=\vec{e}_{i} \frac{\partial}{\partial x_{i}}\left[\lambda u_{k k} \delta_{i j}+2 \mu u_{i j}\right] \\
u_{i j}=\frac{1}{2}\left(\frac{\partial u_{i}}{\partial x_{j}}+\frac{\partial u_{j}}{\partial x_{i}}\right) \\
\vec{\nabla} \cdot \stackrel{\leftrightarrow}{\sigma}=\lambda \vec{e}_{i} \frac{\partial u_{k k}}{\partial x_{i}}+2 \mu \vec{e}_{i} \frac{\partial u_{i j}}{\partial x_{i}}
\end{gathered}
$$

\footnotetext{
${ }^{4}$ Simetria esta que pode ser visualizada facilmente ao permutarmos diferentes combinações de índices repetidos do tensor.

${ }^{5}$ Forças gravitacionais, apesar de sempre presente em situações práticas, podem ser desprezadas em confronto com as demais forças que tipicamente podem atuar na superfície do material, por exemplo.
} 


$$
\begin{gathered}
\vec{\nabla} \cdot \stackrel{\leftrightarrow}{\sigma}=\lambda \vec{e}_{i} \frac{\partial}{\partial x_{i}} \underbrace{\left(\frac{\partial u_{k}}{\partial x_{k}}\right)}_{=\vec{\nabla} \cdot \vec{u}}+\mu \vec{e}_{i} \frac{\partial}{\partial x_{j}}\left(\frac{\partial u_{i}}{\partial x_{j}}+\frac{\partial u_{j}}{\partial x_{i}}\right) \\
\vec{\nabla} \cdot \stackrel{\leftrightarrow}{\sigma}=\lambda \underbrace{\left(\vec{e}_{i} \frac{\partial}{\partial x_{i}}\right)}_{=\vec{\nabla}}(\vec{\nabla} \cdot \vec{u})+\mu \underbrace{\left(\frac{\partial^{2}}{\partial x_{j}^{2}}\right)}_{=\nabla^{2}} \underbrace{\left(\vec{e}_{i} u_{i}\right)}_{=\vec{u}}+\mu \underbrace{\left(\vec{e}_{i} \frac{\partial}{\partial x_{i}}\right)}_{=\vec{\nabla}} \underbrace{\left(\frac{\partial u_{j}}{\partial x_{j}}\right)}_{=\vec{\nabla} \cdot \vec{u}} \\
\vec{\nabla} \cdot \stackrel{\leftrightarrow}{\sigma}=(\lambda+\mu) \vec{\nabla}(\vec{\nabla} \cdot \vec{u})+\mu \vec{\nabla}^{2} \vec{u} .
\end{gathered}
$$

Portanto,

$$
\rho \frac{\partial^{2} \vec{u}}{\partial t^{2}}=(\lambda+\mu) \vec{\nabla}(\vec{\nabla} \cdot \vec{u})+\mu \vec{\nabla}^{2} \vec{u}
$$

\section{A.7 Equação de Laplace}

É conveniente escolhermos um sistema de referências que nos permita reduzir ainda mais as equações de movimento deduzidas anteriormente, de maneira que:

$$
\begin{gathered}
u_{x}=0 \\
u_{y}=0 \\
u_{z}=u_{z}(x, y) \equiv u
\end{gathered}
$$

onde assumimos que as deformações transversais ao eixo de aplicação da tensão externa $O z$ são desprezíveis, tal que $u_{z}$ seria a única componente de interesse para o cálculo do tensor de deformações associado ao problema.

Sendo assim,

$$
\underbrace{\frac{\partial u_{x}}{\partial x}}_{=0}+\underbrace{\frac{\partial u_{y}}{\partial y}}_{=0}+\underbrace{\frac{\partial u_{z}}{\partial z}}_{=0}=\vec{\nabla} \cdot \vec{u}=0 .
$$

No equilíbrio:

$$
\rho \frac{\partial^{2} \vec{u}}{\partial t^{2}}=\vec{f}=0 .
$$

Portanto,

$$
\nabla^{2} u=0,
$$

ou seja, as deformações sofridas pelas partículas do sistema satisfazem a equação de Laplace. 


\section{Apêndice B}

\section{O modelo da rede de fusíveis}

Neste apêndice pretendemos estabelecer uma conexão entre os resultados estabelecidos nesta tese e um modelo elétrico bastante difundido na literatura, que descreve de maneira equivalente os processos de propagação de trincas, conhecido como modelo da rede de fusíveis.

\section{B.1 Equações de Maxwell aplicadas a um condutor ôhmico}

Sejam as equações de Maxwell em um meio material linear segundo o Sistema Internacional de Unidades [1]:

$$
\begin{gathered}
\vec{\nabla} \cdot \vec{E}=\frac{\rho}{\epsilon} \\
\vec{\nabla} \cdot \vec{B}=0 ; \\
\vec{\nabla} \times \vec{E}=-\frac{\partial \vec{B}}{\partial t} ; \\
\vec{\nabla} \times \vec{B}=\mu \vec{J}+\mu \epsilon \frac{\partial \vec{E}}{\partial t}
\end{gathered}
$$

onde $(\vec{E}, \vec{B})$ representa o campo eletromagnético, $(\rho, \vec{J}=\rho \vec{v})$ representa a densidade de fontes, $\epsilon$ é a permissividade elétrica e $\mu$ é a permeabilidade magnética do material ${ }^{1}$.

A lei de Ohm completa o conjunto de equações necessárias para a descrição de um meio condutor, a saber,

$$
\vec{J}=\sigma \vec{E}
$$

ou seja, a densidade de corrente $\vec{J}$ no interior do condutor é proporcional ao campo elétrico $\vec{E}$ aplicado $^{2}$.

\footnotetext{
${ }^{1}$ Os campos eletromagnéticos são definidos de maneira a satisfazer a força de Lorentz: $\vec{f}=\rho \vec{E}+\vec{J} \times \vec{E}$, onde $\vec{f}$ é a densidade de forças eletromagnéticas.

${ }^{2} \mathrm{~A}$ lei de Ohm pode ser também enunciada na forma $\phi=R i$; onde $\phi$ é a diferença de potencial aplicada ao material, $i$ é a intensidade de corrente que atravessa o circuito e $R \equiv 1 / \sigma$ é a resistência do material.
} 
A equação da continuidade permite-nos escrever ainda:

$$
\vec{\nabla} \cdot \vec{J}=-\frac{\partial \rho}{\partial t}
$$

$\therefore$

$$
\begin{aligned}
& \vec{\nabla} \cdot(\sigma \vec{E})=\frac{\sigma}{\epsilon} \rho=-\frac{\partial \rho}{\partial t} \\
& \frac{\partial}{\partial t} \rho(\vec{r}, t)=-\frac{\sigma}{\epsilon} \rho(\vec{r}, t) .
\end{aligned}
$$

Uma solução de (B.8) capaz de satisfazer a condição inicial $\rho(\vec{r}, 0)=\rho_{0}(\vec{r})$ é dada por:

$$
\rho(\vec{r}, t)=\rho_{0}(\vec{r}) e^{-\frac{t}{\tau}} ; \quad \tau \equiv \frac{\epsilon}{\sigma}
$$

Portanto, para tempos de observação suficientemente grandes $(t \gg \tau)$ :

$$
\rho(\vec{r}, t)=0
$$

ou seja, a distribuição de cargas é nula no interior do condutor.

Sendo assim,

$$
\vec{\nabla} \cdot \vec{E}=0
$$

Podemos definir ainda os potenciais eletrodinâmicos em termos dos campos como segue:

$$
\begin{gathered}
\vec{B}=\vec{\nabla} \times \vec{A} ; \\
\vec{E}=-\vec{\nabla} \phi+\frac{\partial \vec{A}}{\partial t} .
\end{gathered}
$$

Tomando a divergência de ambos os membros da equação (B.13):

$$
\vec{\nabla} \cdot \vec{E}=-\nabla^{2} \phi+\frac{\partial}{\partial t}(\vec{\nabla} \cdot \vec{A})
$$

A escolha do calibre de Coulomb $(\vec{\nabla} \cdot \vec{A}=0)$ determina que o potencial escalar satisfaz a equação de Laplace, a saber,

$$
\nabla^{2} \phi=0
$$

Finalmente,

$$
\begin{gathered}
\phi=R i \\
\nabla^{2} i=0
\end{gathered}
$$

ou seja, equivalentemente aos processos de propagação de trincas em meios homogêneos, as correntes que percorrem um condutor ôhmico devem satisfazer a equação de Laplace. 


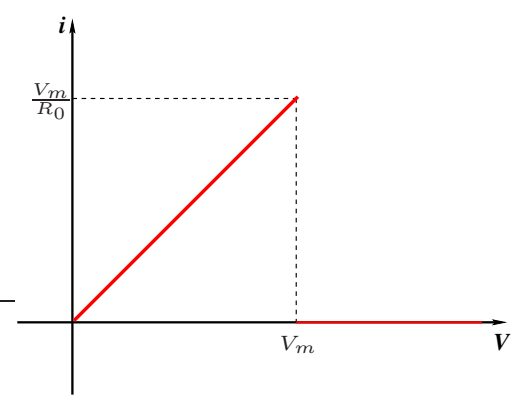

Figura B.1: Curva característica $i \times V$ associada a um fusível de resistência $R_{0}$ e tensão máxima permitida $V_{m}$.

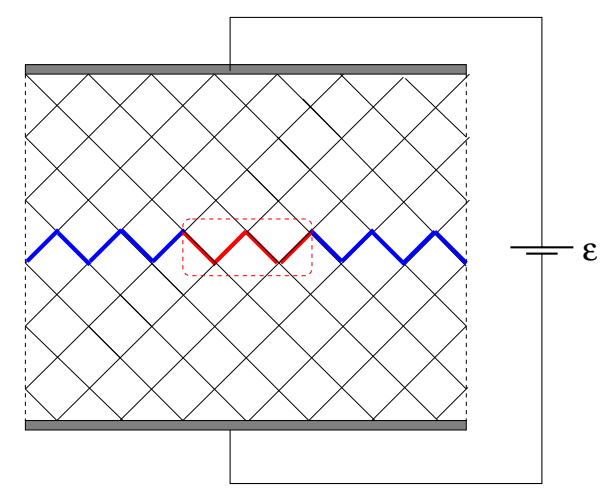

Figura B.2: Rede de fusíveis aleatórios: a linha de propagação corresponde ao conjunto de fusíveis representados em azul ao longo da linha mediatriz do sistema enquanto que os fusíveis representados em vermelho correspondem àqueles inicialmente danificados.

\section{B.2 Analogia elétrico-mecânica para o modelo de propagação de trincas}

Nesta seção apresentaremos um breve resumo dos principais aspectos relacionados ao modelo conhecido por modelo da rede de fusíveis. Definiremos um fusível como um condutor cuja resistência $R$ é uma constante $R_{0}$ para voltagens abaixo de certo valor de corte $V_{m}$ (comportando-se como um resistor ôhmico) mas que, para voltagens acima deste valor, sofre uma ruptura irreversível $(R \rightarrow \infty)$, como mostra a figura B.1.

A proposta do modelo consiste em substituir o problema do cálculo da distribuição de tensões na presença de múltiplas trincas por um problema equivalente no qual se calculam as correntes que percorrem uma associação em paralelo de fusíveis idênticos com resistência $R_{0}$ [56]. Em geral, considera-se uma associação de fusíveis dispostos em uma rede quadrada de tamanho $\mathrm{L} \times \mathrm{L}$, que recebe uma rotação de $45^{\circ}$ em torno de um eixo perpendicular ao plano que contém a rede e que passa pelo seu centro geométrico (ver figura B.2). Uma trinca corresponderia, eventualmente, a um conjunto de fusíveis vizinhos que já se encontram danificados ("cluster" de fusíveis danificados) [32, 56].

Estamos particularmente interessados em estudar a propagação unidimensional de trincas e, portanto, permitiremos apenas que os L fusíveis pertencentes a linha mediatriz do sistema se danifiquem. A introdução de desordem é considerada quando permitimos 
também que a voltagem (corrente) máxima associada a cada fusível seja distribuída aleatoriamente ao longo do sistema, semelhantemente à distribuição de limiares de ruptura $\rho\left(F_{\text {lim }}\right)[32,56]$.

Inicialmente o sistema apresenta uma única trinca de semicomprimento $a_{0}$ ao longo da linha de propagação, de maneira que seu ponto médio coincide com o centro geométrico da rede. Uma corrente transversal é aplicada a todo o sistema sendo que as correntes locais são calculadas numericamente aplicando-se as leis de Kirchhoff a cada nó da rede. A corrente é interrompida quando a linha mediatriz colapsar completamente ("percolar") à medida que a voltagem externa aplicada aumenta. 


\section{Referências Bibliográficas}

[1] M. Sands, R. Feynman, R. Leighton. The Feynman lectures on Physics, volume 2. Pearson/Addison-Wesley, 1963.

[2] T. A. Witten. Insights from soft condensed matter. Review of modern physics, 71: 367$373,1999$.

[3] S. R. White, N. R. Sottos, J. Moore, P. Geubelle, M. Kessler, E. Brown, S. Suresh, S. Viswanathan. Autonomic healing of polymer composites. Nature, 409: 794-797, 2001.

[4] S. Suresh. Fatigue of materials. Cambridge University Press, 1998.

[5] F. Kun, M. H. Costa, R. N. Costa Filho, J. S. Andrade Jr., J. B. Soares, S. Zapperi, H. J. Herrmann. Fatigue failure of disordered materials. J. Stat. Mech., 07:02003, 2007.

[6] A. P. Vieira, J. S. Andrade Jr., H. J. Herrmann. Subcritical crack growth: the microscopic origin of Paris' law. Phys. Rev. Lett., 100: 195503, 2008.

[7] A. J. Wood. Witten's lectures on crumpling. Physica A, 313: 83-109, 2002.

[8] E. E. Gdoutos. Fracture mechanics - An introduction. Springer, 2005.

[9] Donald L. Turcotte. Fractal and chaos in geology and geophysics. Cambridge University Press, 1997.

[10] M. J. Alava, Phani K. V. V. Nukala,. Statistical models of fracture. Advances in Physics, 55: 349-476, 2006.

[11] L. da Vinci. I libri di Meccanica. Hoepli, 1940.

[12] G. Galilei. Discorsi e dimostrazioni matematiche intorno a due nuove scienze. Boringhieri, 1958.

[13] G. Tokaty. A history and philosophy of fluid mechanics. Dover, 1971.

[14] J. S. Gomes, M. S. Lima, M. N. Fontes, V. Roveri, R. T. Zauberas. Acidentes de trabalho típicos na construção civil. Revista Eletrônica de Divulgação Científica da Faculdade Don Domênico, 2013.

[15] N. E. Dowling. Mechanical behaviour of materials. Prentice Hall, New Jersey, 1993.

[16] V. Bolotin. Mechanics of fatigue. CRC Press, 1998. 
[17] M. Marder. Condensed matter physics. Wiley-Interscience publication, 2000.

[18] A. A. Griffith. The phenomena of rupture and flow in solids. Philos. Trans. R. Soc. London Ser. A, 221: 163, 1921.

[19] P. G. De Gennes. Scaling concepts in polymer physics. Cornell University Press, 1979.

[20] D. Roylance. Mechanics of materials. John Wiley \& Sons, 1996.

[21] P. C. Paris, F. Erdogan. A critical analysis of crack propagation laws. J. Basic Eng., 85: 528, 1963.

[22] O. Lengliné, R. Toussaint, J. Schmittbuhl, J. Elkhoury, J. Ampuero, K. Tallakstad, S. Santucci, K. Maloy. Average crack-front velocity during subcritical fracture propagation in a heterogeneous medium. Phys. Rev. E, 84: 036104, 2011.

[23] N. A. Fleck, K. J. Kang, M. F. Ashby. The cyclic properties of engineering materials. Acta Metall. Mater., 2: 365-381, 1994.

[24] S. Li, L. Sun, W. Jia, Z. Wang. The Paris law in metals and ceramics. Journal of Materials Science Letters, 14: 1493-1495, 1995.

[25] D. Taylor, J. Hazenberg, T. Lee. Living with cracks: damage and repair in human bone. Nature Materials, 6: 263-268, 2007.

[26] P. Zhang, L. Ma, F. Fan, Z. Zeng, C. Peng, P. Loya, Z. Liu, Y. Gong, J. Zhang, X. Zhang, P. Ajayan, T. Zhu, J. Lou. Fracture toughness of graphene. Nature Communications, 5: 3782, 2014.

[27] Y. Hwangbo, C. Lee, S. Kim, J. Kim, K. Kim, B. Jang, H. Lee, S. Lee, S. Kim, J. Ahn, S. Lee. Fracture characteristics of monolayer CVD-Graphene. Scientific Reports, 4: 4439, 2014.

[28] F. Ellyin. Fatigue damage crack growth and life predction. Chapman and Hall, 1997.

[29] J. Schijve. Four lectures on fatigue crack growth. Eng. Fract. Mech., 11: 196, 1979.

[30] Cassius O. F. T. Ruchert. Estudo da inferência de carregamento em histórias de vôos simulados na liga de Al Aeronáutico SAE-AMS 7475 T7351. Universidade de São Paulo, 2007.

[31] A. M. P. de Jesus, J. M. C. Maeiro, A. L. L. da Silva, A. S. Ribeiro. Crack propagation behaviour of a puddle iron under constant and variable amplitude loading. Revista da Associação Portuguesa de Análise Experimental de Tensões, 20: 25-33, 2012.

[32] C. L. N. Oliveira, A. P. Vieira, J. S. Andrade Jr., H. J. Herrmann. Subcritical fatigue in fuse networks. Europhys. Lett., 100: 36006, 2012.

[33] M. Buehler, Z. Xu. Mind the helical crack. Nature, 464: 42, 2010.

[34] G. I. Barenblatt. Similarity, self-similarity and intermediate asymptotics. Consultant Bureau, 1979. 
[35] H. J. Herrmann e L. de Arcangelis. Scaling in fracture. Plenum Press, 1990.

[36] R. C. Hidalgo, F. Kun, H. J. Herrmann. Bursts in a fiber bundle model with continuous damage. Phys. Rev. E, 64:066122, 2001.

[37] H. J. Herrmann. Damage spreading. Physica A, 168: 516-528, 1990.

[38] V. K. Horváth, H. J. Herrmann. The fractal dimension of stress corrosion cracks. Chaos, Solitons and Fractals, 1(5):395-440, 1991.

[39] H. J. Herrmann. Some new results on fracture. Physica A, 221: 125-133, 1995.

[40] F. Raischel, F. Kun, H. J. Herrmann. Failure process of a bundle of plastic fibers. arXiv:cond-mat/0601290v2, 2006.

[41] H. J. Herrmann. Fractal deterministic cracks. Physica D, 38: 192-197, 1989.

[42] H. J. Herrmann, J. Kertész, L. de Arcangelis. Fractal shapes of deterministic cracks. Europhys. Lett., 10(2): 147-152, 1989.

[43] A. T. Skjeltorp, P. Meakin. Fracture in microsphere monolayers studied by experiment and computer simulation. Nature, 335: 424, 1988.

[44] H. J. Herrmann. Fracture patterns and scaling laws. Physica A, 163: 359-372, 1990.

[45] H. J. Herrmann. Fractals and Disordered Systems. Springer, 1996.

[46] A. Coniglio, L. de Arcangelis, H. J. Herrmann. Fractals and multifractals: applications in physics. Physica A, 157:21-30, 1989.

[47] H. J. Herrmann. Patterns and scaling in fracture. Physica Scripta, T38: 13-21, 1991.

[48] F. Kun, H. A. Carmona, J. S. Andrade Jr., H. J. Herrmann. Universality behind Basquin's law of fatigue. arXiv:cond-mat/0801.3664v1, 2008.

[49] Y. Termonia, P. Meakin. Formation of fractal cracks in a kinetic fracture model. Nature, 320: 429, 1986.

[50] R. O. Ritchie. Incomplete self-similarity and fatigue-crack growth. International Journal of Fracture, 132: 197-203, 2005.

[51] L. R. Botvina, G. I. Barenblatt. Self-similarity of damage accumulation. Strength of Materials, 17: 1653, 1986.

[52] A. Carpinteri, M. Paggi. Are the Paris' law parameters dependent on each other? Frattura ed Integrità Strutturale, 2: 10-16, 2007.

[53] F. Kun, M. H. A. S. Costa, R. N. Costa Filho, J. S. Andrade Jr, J. B. Soares, S. Zapperi, H. J. Herrmann. Damage and healing in fatigue fracture. arXiv:condmat/060r606, 2006. 
[54] J. Zhou, X. Yang, Z. Yang, H. Li, H. Zhou. Effect of random defects on the critical behaviour of Ising models. International Journal of Computational Methods, 10: 1350034, 2013.

[55] A. Gilabert, C. Vanneste, D. Sornette, E. Guyon. The random fuse network as a model of rupture in a disordered medium. J. Physique, 48: 763-770, 1987.

[56] L. de Arcangelis, S. Redner, H. J. Herrmann. A random fuse model for breaking processes. J. Physique Lett., 46: L-585, 1985.

[57] M. Marder. Statistical mechanics of cracks. Phys. Rev. E, 54(4):3442, 1996.

[58] K. V. Tittelboom, N. De Belie. Self-healing in cementitious materials - A review. Materials, 6: 2182-2217, 2013.

[59] H. A. Carmona, F. Kun, J. S. Andrade Jr., H. J. Herrmann. Computer simulation of fatigue under diametrical compression. arXiv:cond-mat/0610080v2, 2007.

[60] W. H. Press, S. A. Teukolsky, W. T. Vetterling, B. P. Flannery. Numerical recipies in C: the art of scientific computing. Cambridge University Press, 1997.

[61] L. D. Landau, E. M. Lifschitz. Theory of elasticity. Pergamon Press, 1970. 
"Combati o bom combate, completei minha carreira, guardei a fé". Paulo de Tarso. $2 \operatorname{Tm} 4: 7$. 